\title{
INCORPORATION AND TESTING OF REVISED ALGORITHMS FOR THE AQUATIC PLANT GROWTH MODEL, ECOL
}

\author{
A Thesis \\ Presented to \\ The Faculty of Graduate Studies \\ of \\ The University of Guelph
}

by

ALISON G. HUMPHRIES

In partial fulfilment of requirements

for the degree of

Master of Science

December, 1998

(C) Alison G. Humphries, 1998 
National Library of Canada

Acquisitions and Bibliographic Services

395 Wellington Street Ottawa ON K1A ON4 Canada

\section{Bibliothèque nationale} du Canada

Acquisitions et services bibliographiques

395. ne Wellington Ottawa ON K1A ON4

Canada
The author has granted a nonexclusive licence allowing the National Library of Canada to reproduce, loan, distribute or sell copies of this thesis in microform, paper or electronic formats.

The author retains ownership of the copyright in this thesis. Neither the thesis nor substantial extracts from it may be printed or otherwise reproduced without the author's permission.
L'auteur a accordé une licence non exclusive permettant à la Bibliothèque nationale du Canada de reproduire, prêter, distribuer ou vendre des copies de cette thèse sous la forme de microfiche/film, de reproduction sur papier ou sur format électronique.

L'auteur conserve la propriété du droit d'auteur qui protège cette thèse. Ni la thèse ni des extraits substantiels de celle-ci ne doivent être imprimés ou autrement reproduits sans son autorisation. 


\section{Abstract \\ INCORPORATION AND TESTING OF REVISED ALGORITHMS FOR THE AQUATIC PLANT MOD $\Xi L, E C O L$}

Alison G. Humphries
University of Guelph
Advisors:

Professor Isobel Heathcote

Professor William James

Aquatic plant growth in river systems provides a link between phosphorus enrichment and fluctuations in dissolved oxygen. Most aquatic plant models simulate the growth of a single generalized species and therefore cannot account for the wide variability in growth patterns shown by differing species. ECOL, an aquatic plant growth model developed in the late 1970s, was incorporated into the Grand River Simulation Model (GRSM) to model the growth of the three main plant species found in the Grand River watershed: Cladophora glomerata, Potamogeton pectinatus and Myriophyllum spicatum. ECOL calculates plant uptake of phosphorus, biomass production and loss, and the resulting production and consumption of dissolved oxygen (DO), using a 2-hour time step.

New algorithms to improve the sub-models in ECOL for light, temperature and phosphorus are developed and tested in this study. The present work evaluates and corrects sources of error in GRSM96, recalibrates the improved model and identifies and quantifies remaining weaknesses. The resulting model, GRSM98AH, has an average error between computed and observed DO of $19.6 \%$, which is regarded as satisfactory. 


\section{ACKNOWLEDGEMENTS}

I want to extend my most sincere thanks to all those who have helped me on this long but rewarding trek in the pursuit of new knowledge. Thanks to both of my supervisors, Drs. Isobel Heathcote and William James, who challenged me when I became complacent and provided guidance and support when I was lost. Thanks to Dr. Isobel Heathcote for her unwavering ability to see the forest from the trees. I am indebted to her for helping me to preserve my sanity for the majority of the development and writing of this thesis. To Dr. William James, I am grateful for his commitment, in both his time and rigorous attention to detail, towards helping me write a straightforward and honest thesis. I also wish to extend my appreciation to the members of my Examining Committee, Drs. Hugh Whiteley and Gord Hayward.

I express many thanks to the administrative staff at the School of Engineering, University of Guelph for their help and support. I wish to thank Mr. Mark Hartley at the Grand River Conservation Authority for his perspective of and insight into the model investigated in this thesis and for the opportunity to get my feet wet working on the Grand and Speed Rivers. I thank Mr. Don Weatherbe for providing me with some of the computer tools used in this thesis and for his valuable insight into the model. Thanks go to my supervisor, Ms. Hazel Breton, and colleagues at the Credit Valley Conservation for their support and patience through the last stretch of finishing the thesis. 
A sincere thanks goes to Danielle Marchant, whose humour, realistic perspective and sympathetic ear saved me many times from the troublesome people and obstacles I have encountered on the way. Special thanks to Donna Hartman, for reminding me what is really important, and to Jim Gillies, for making me a believer.

Thanks to my parents for their love and support, and for standing by me through all this time. Their understanding and patience have been the basis of my ability to prevail through many life experiences, including a Master's thesis. Lastly but certainly not least, I want to thank my partner in crime, Terry Scott, for sticking this one out with me, especially through the tougher times. His love and commitment are truly appreciated. 


\section{GLOSSARY OF TERMS}

CWA-Clean Water Agency

ECOL-generic version of the aquatic plant model found in the GRSM code (not date specific)

ECOLAH-stand-aione version of the aquatic plant model coded by the author to be used for model functionality testing

ECOL96-version of the aquatic plant model found in the GRSM96 code

ECOL98AH-version of the aquatic plant model found in the GRSM98AH code

GAWSER-Guelph All-Weather Sequential Event Runoff model used for simulating the hydrologic behaviour of forested, agricultural, and suburban watersheds

GRCA-Grand River Conservation Authority

GRSM-generic term for the Grand River Simulation Model (not date specific)

GRSM96-version of the Grand River Simulation Model, as of May 1996, which contains ECOL96

GRSM98AH-version of the Grand River Simulation Model, as of November 1998, which contains ECOL98AH

HEC-2: computer program which computes water surface profiles for one dimensional, gradually varied flow in rivers of any cross section.

LDI-local diffuse inflows

MOE-Ministry of the Environment (Ontario)

PWQMN-Provincial Water Quality Monitoring Network

SRP-soluble reactive phosphorus

SS-suspended solids

STP-sewage treatment plant

TP-total phosphorus 


\section{LIST OF COMMONLY USED NOTATION}

$\gamma_{1}$ : specific rate coefficient for GRSM98AH lower temperature curve $\left({ }^{\circ} \mathrm{C}^{-1}\right)$

$\gamma_{2}$ : specific rate coefficient for GRSM98AH upper temperature curve $\left({ }^{\circ} \mathrm{C}^{-1}\right)$

$\Delta \mathrm{T}:$ time step $(\mathrm{hr})$

B : aquatic plant density (g biomass $/ \mathrm{m}^{2}$ )

CLADP : GRSM98AH phosphorus limitation factor for Cladophora glomerata (dimensionless)

DEPTH : depth of stream flow (m)

$\mathrm{DO}:$ dissolved oxygen $(\mathrm{mg} / \mathrm{L})$

$\mathrm{k} 1, \mathrm{k} 2, \mathrm{k} 3, \mathrm{k} 4$ : temperature reaction rates used in GRSM98AH (dimensionless)

$\mathrm{K}_{\mathrm{A}}$ : declining limb of GRSM98AH temperature curve (dimensionless)

$\mathrm{K}_{\mathrm{B}}$ : rising limb of GRSM98AH temperature curve (dimensionless)

$\mathrm{KE}$ : light attenuation factor due to $\mathrm{SS}\left(\mathrm{m}^{-1}\right)$

$\mathrm{Km}$ : half-saturation constant for water column phosphorus used in GRSM98AH phosphorus algorithms $(\mu \mathrm{g} / \mathrm{L})$

$\mathrm{Kq}$ : half-saturation constant for internal plant phosphorus used in GRSM98AH phosphorus algorithms $(\% \mathrm{P})$

$\mathrm{Kw}$ : light attenuation factor due to plant biomass density used in GRSM98AH light algorithms ( $\mathrm{m}^{2} / \mathrm{g}$ biomass)

$\mathrm{L}_{\mathrm{L}}$ : light limitation factor (dimensionless)

$\mathrm{L}_{\mathrm{N}}$ : nitrogen limitation factor (dimensionless)

$\mathrm{L}_{\mathrm{PHOS}}$ : phosphorus limitation factor (dimensionless)

LPLANT : plant inhibition factor (dimensionless) 
$\mathrm{L}_{\mathrm{T}}$ : temperature limitation factor (dimensionless)

O2ASSIM : $\mathrm{DO}$ assimilation ratio ( $\mathrm{g} \mathrm{DO} / \mathrm{g}$ biomass)

$\mathrm{O} 2 \mathrm{P}$ : DO produced from photosynthesis $\left(\mathrm{g} \mathrm{DO} / \mathrm{m}^{2}\right)$

O2UP : DO taken up by respiration ( $\mathrm{g} \mathrm{DO} / \mathrm{m}^{2}$ )

PARD $_{\text {ss }}$ : photosynthetically available solar radiation at plant depth due to SS (Langleys/min)

PARD Tor : photosynthetically available solar radiation at plant depth due to SS and plant biomass (Langleys/min)

PASS : phosphorus assimilation ratio (g TP/g biomass)

PDEMAND : total phosphorus demand by aquatic plants (g TP)

PFAC : GRSM96 phosphorus limitation factor (dimensionless)

PHOTOmax : maximum photosynthetic rate (g biomass/g biomass-hr)

PLANT_DEPTH : depth of plant growth $(\mathrm{m})$

PROD : biomass gained through photosynthesis (gross productivity) ( $\mathrm{g}$ biomass $/ \mathrm{m}^{2}$ )

PSUPPLY : total phosphorus in water column ( $\mathrm{g}$ TP)

$\mathrm{P}_{\mathrm{up}}$ : phosphorus uptake rate by aquatic plants used in GRSM98AH phosphorus algorithms (\% P/hr)

$\mathrm{P}_{\text {upmax }}$ : maximum phosphorus uptake rate by aquatic plants used in GRSM98AH phosphorus algorithms $(\% \mathrm{P} / \mathrm{hr})$

$\mathrm{Q}$ : plant tissue phosphorus used in GRSM98AH phosphorus algorithms (\%P)

Qo : minimum phosphorus concentration in plant tissue used in GRSM98AH phosphorus algorithms (\%)

$\mathrm{R} 20$ : unit respiration rate at $20^{\circ} \mathrm{C}$ (g biomass/g biomass-hr)

REQFAC : nutrient utilization efficiency factor (dimensionless)

RESP : biomass lost through respiration ( $\mathrm{g}$ biomass $/ \mathrm{m}^{2}$ ) 
SAREA : surface area of sub-reach $\left(\mathrm{m}^{2}\right)$

SHADE : shading multiplier used in GRSM96 light algorithms (dimensionless)

SHADE_FACT : biomass-density-dependent shading factor used in GRSM96 light algorithms ( $\mathrm{g}$ biomass $/ \mathrm{m}^{2}$ )

ShaFac : shape factor for GRSM96 temperature algorithms (dimensionless)

SRP : soluble reactive phosphorus $(\mu \mathrm{g} / \mathrm{L})$

SS : suspended solids $(\mathrm{mg} / \mathrm{L})$

STFAC : GRSM96 fraction of water column phosphorus taken up by plant tissue (dimensionless)

$\mathrm{T}$ : observed water temperature $\left({ }^{\circ} \mathrm{C}\right)$

TC : temperature coefficient factor for respiration (dimensionless)

Tmax : maximum temperature for growth used in GRSM98AH and GRSM96 $\left({ }^{\circ} \mathrm{C}\right)$

Tmin : minimum temperature for growth used in GRSM98AH $\left({ }^{\circ} \mathrm{C}\right)$

Topt : optimal water temperature for growth used in GRSM96 $\left({ }^{\circ} \mathrm{C}\right)$

Topt2 : lower optimum temperature for growth used in GRSM98AH $\left({ }^{\circ} \mathrm{C}\right)$

Topt3 : upper optimum temperature for growth used in GRSM98AH $\left({ }^{\circ} \mathrm{C}\right)$

TP : total phosphorus $(\mathrm{mg} / \mathrm{L})$

TPROD: production of total biomass ( $\mathrm{g}$ biomass $/ \mathrm{m}^{2}$ )

TRES : respiration of total biomass ( $\mathrm{g}$ biomass $/ \mathrm{m}^{2}$ )

UniFac : calibration factor for GRSM96 temperature algorithms $\left({ }^{\circ} \mathrm{C}^{-1}\right)$

W : biomass washout fraction (dimensionless)

WASH : biomass lost through washout ( $\mathrm{g}$ biomass $/ \mathrm{m}^{2}$ )

WATI : solar radiation just underneath the water surface (Langleys/min) 


\section{TABLe OF CONTENTS}

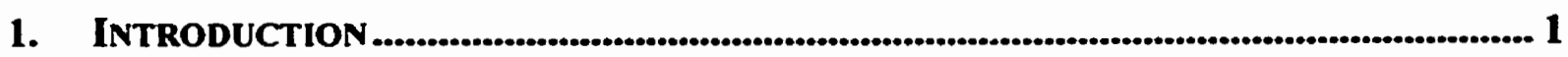

2. GRSM MODEL DESCRIPTION_................................................................................. 4

$2.1 \quad$ Structure of GRSM .......................................................................................... 4

2.2 Inputs

2.2.1 Climate Data........................................................................................................... 6

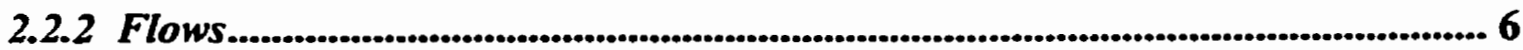

2.2.3 Water Quality Parameters.................................................................................... 7

2.2.4 Reaction Rates and Temperature Coefficients.................................................. 9

2.2.5 Biological Parameters............................................................................................... 9

2.3 ECOL Subroutine

2.3.1 Biomass Production, Respiration and Washout .............................................. 13

2.4 Assumptions in GRSM and ECOL .................................................................... 16

2.4.1 Long Reach Lengths and Spatial Averaging ................................................. 16

2.4.2 Aquatic Plant Density........................................................................................... 17

2.4.3 Phosphorus Dynamics......................................................................................... 18

2.4.4 Assumptions for Aquatic Plant Growth........................................................... 19

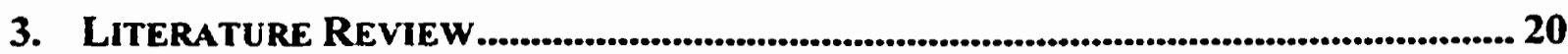

3.1 Factors Not Modelled in ECOL ........................................................................ 20 
3.1.I Herbivore-Plant Interactions

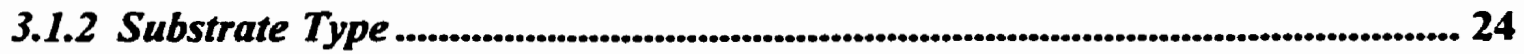

3.1.3 Riparian Shading ............................................................................... 27

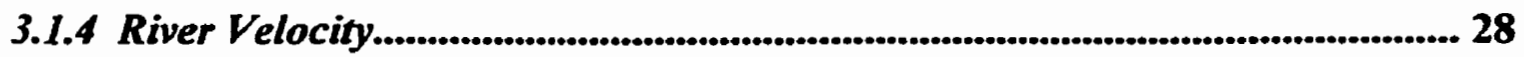

3.1.5 Phosphorus Uptake by Sediment or Roots ................................................. 30

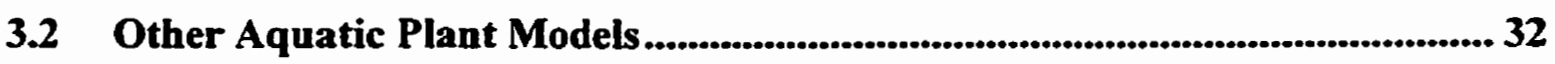

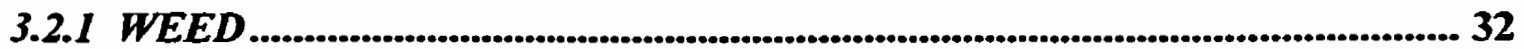

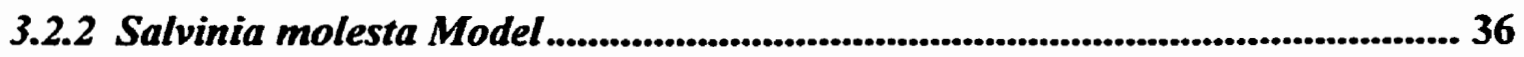

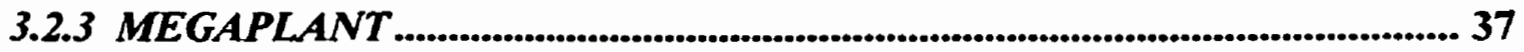

3.2.4 Lake Huron Cladophora Model ............................................................ 38

3.2.5 Estuary Cladophora Model................................................................. 39

3.2.6 Rooted Macrophyte Growth Model............................................................. 40

3.2.7 CE-QUAL-RI Macrophyte Sub-model.............................................. 41

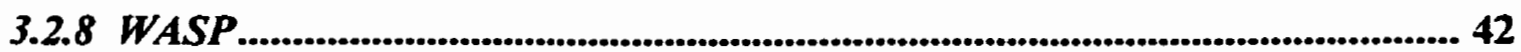

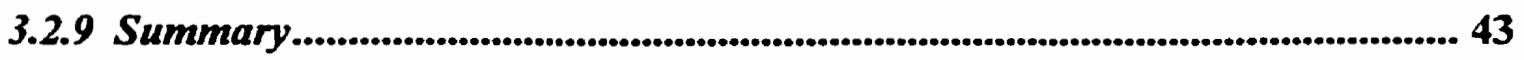

3.3 Model Functionality Testing................................................................. 44

4. Plant Growth AlgorithMS.................................................................................... 46

4.1 GRSM96 Phosphorus Limitation Equations .......................................... 46

4.2 Proposed Changes to Phosphorus Limitation Equations .............................. 47

4.3 GRSM96 Temperature Limitation Equations ............................................ 52 
4.4 Proposed Temperature Limitation Equations ................................................... 53

4.5 GRSM96 Light Limitation Equations ..................................................... 56

4.6 Proposed Light Limitation Equations .......................................................... 57

4.7 Proposed Dissolved Inorganic Carbon Equation ........................................... 59

4.8 Reviewing the Literature Survey ............................................................59

4.9 Incorporating the New Algorithms ...........................................................60

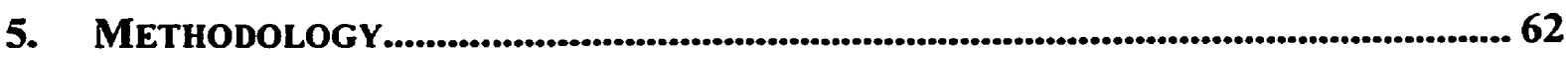

5.1 Model Preparation .......................................................................................... 62

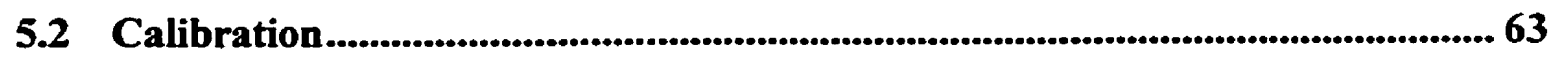

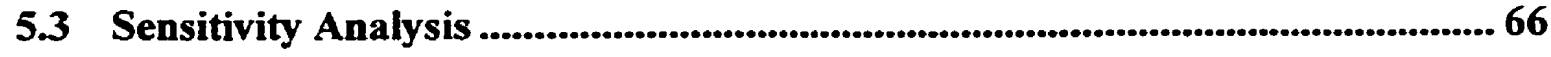

5.4 Model Functionality Testing ....................................................................6. 67

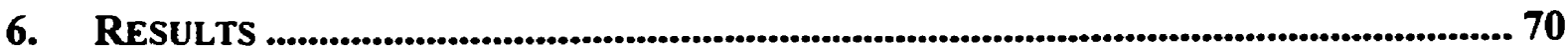

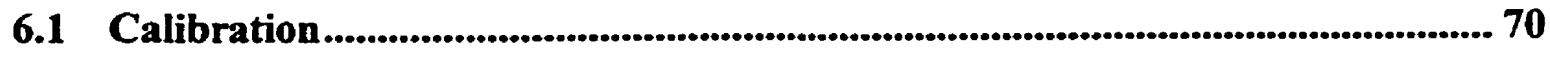

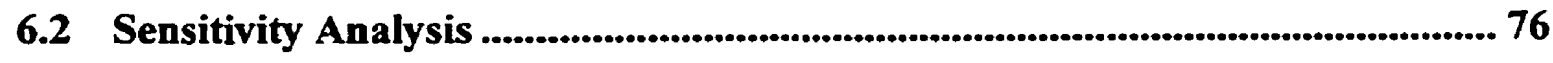

6.2.1 Most Sensitive Parameters........................................................................... 78

6.2.2 Less Sensitive Parameters...................................................................... 80

6.2.3 Insensitive Parameters............................................................................. 81

6.2.4 General Comments................................................................................... 81 
6.3 Comparing ECOLAH to GRSM98AH .......................................................... 85

6.4 Model Functionality Testing ...................................................................................... 87

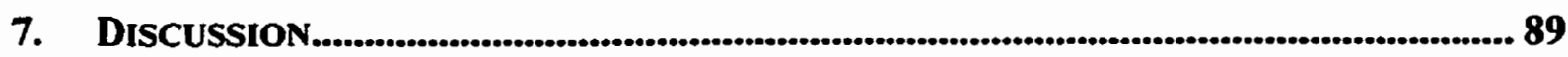

7.1 Calibration................................................................................................................. 89

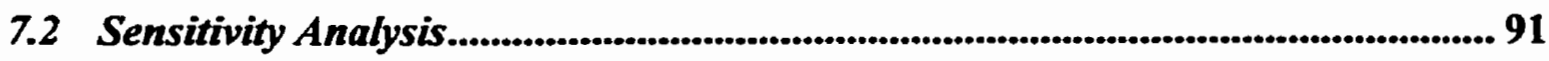

7.3 Comparing ECOLAH to GRSM98AH ............................................................ 93

7.4 Model Functionality Testing .................................................................. 94

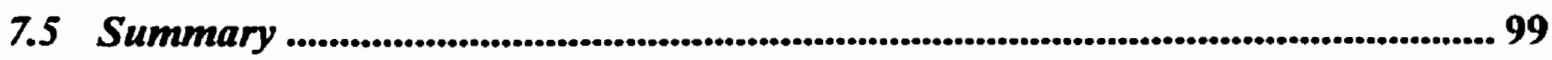

8. CONCLUSIONS AND RECOMMENDATIONS .............................................................. 100

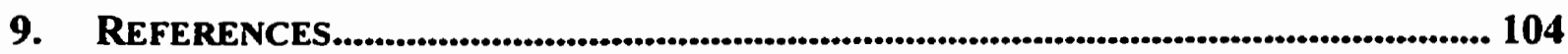

APPENDIX A: ECOL98AH CODE AS SEEN IN GRSM98AH CODE .............................. 112

APPENDIX B: STAND ALONE ECOLAH CODE......................................................... 127 


\section{LIST OF FIGURES}

Figure 2.1: Modelled reaches of the Grand River watershed ........................................ 5

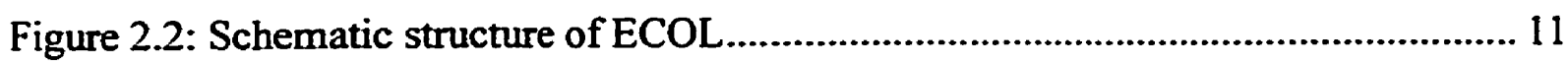

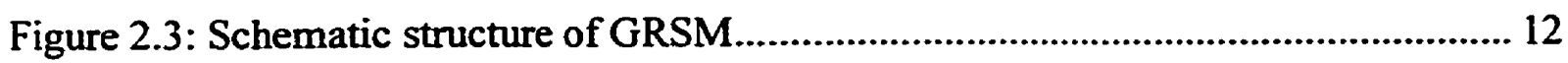

Figure 4.1: External $P$ increased from 0 to $800 \mu g /$ (Internal $P=0.12 \%$ ) ................. 49

Figure 4.2: Internal $P$ increased from 0 to $0.1 \%$ (External $P=400 \mu \mathrm{g} / \mathrm{L})$................ 49

Figure 4.3: GRSM96 temperature limitation factors for the three species modelled...... 53

Figure 4.4: Proposed temperature limitation factors for the three species modelled........ 55

Figure 6.1: Computed versus observed DO for sub-reach 10 (Speed River at Wellington

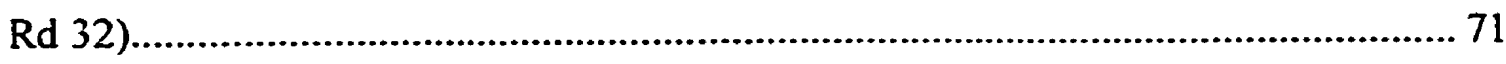

Figure 6.2: Computed biomass for sub-reach 10 (Speed River at Wellington Rd 32) .... 71

Figure 6.3: Computed versus observed DO for sub-reach 2 (Grand River at Bridgeport) 72

Figure 6.4: Computed biomass for sub-reach 2 (Grand River at Bridgeport) ................. 72

Figure 6.5: Computed versus observed DO for sub-reach 6 (Grand River at Blair) ........ 73

Figure 6.6: Computed biomass for sub-reach 6 (Grand River at Blair)........................ 73

Figure 6.7: Sensitivity ratios of more sensitive species-specific parameters ................. 79

Figure 6.8: Sensitivity ratios of less sensitive species-specific parameters ................... 80

Figure 6.9: Sensitivity ratios for less sensitive non-species-specific parameters ............ 81

Figure 6.10: Increasing and decreasing sensitivity ratios of more sensitive parameters .. 82

Figure 6.11: Sensitivity ratios of temperature parameters and frequency of observed

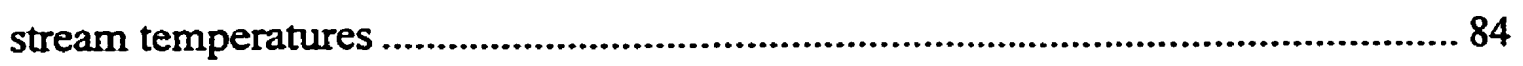


Figure 6.12: Sensitivity ratios of $k$ (temperature) parameters and frequency of observed stream temperature 85

Figure 6.13: Comparison of ECOLAH and GRSM98AH peak biomass values ............... 86

Figure 6.14: Modified comparison of ECOLAH and GRSM98AH peak biomass values 86

Figure 7.1: Phosphorus limitation curves for the three species modelled ......................... 95

Figure 7.2: Computed water temperature from $100 \%$ and $75 \%$ solar radiation input ...... 96 


\section{LIST OF TABLES}

Table 4.1: Phosphorus-related constants reported in the literature.

Table 4.2: Temperature ranges in the literature 53

Table 4.3: Light extinction coefficients within weedbeds. 58

Table 5.1: Changes to input parameters in model functionality testing 69

Table 6.1: Plant inhibition factors for Cladophora 74

Table 6.2: Plant inhibition factors for P. pectinatus 74

Table 6.3: Plant inhibition factors for M. spicatum 74

Table 6.4: GRSM98AH input parameters used in final calibration run 75

Table 6.5: Sensitivity ranking of all ECOL98AH non-temperature parameters 77

Table 6.6: Expected and computed results in model functionality for ECOLAH 87

Table 7.1: Maximum computed biomass densities (in $\mathrm{g} / \mathrm{m}^{2}$ ) under varying suspended solids concentrations and depths in ECOLAH 97 


\section{INTRODUCTION}

Ontario has many lakes and rivers and protection of their water quality is a high priority. Good water quality is critical not only for a healthy aquatic ecosystem for fisheries and macroinvertebrates but also for human consumption and recreational purposes. Maintaining good water quality in southern Ontario is particularly challenging because of the multiple anthropogenic influences of agriculture and urbanization.

Government agencies dedicated to the protection of the environment are responsible for the oversight of public lands and waters. Similarly, the Grand River Conservation Authority (GRCA), located in southwestern Ontario, is responsible for many management decisions affecting the water quality of the Grand River and its tributaries.

One of the tools used by the GRCA in assessing alternative scenarios for water quality improvement in the Grand River watershed is the Grand River Simulation Model (GRSM), developed in the 1970s by the GRCA and the Ministry of Environment (MOE).

GRSM96 is a continuous water quality model, unique because it includes a multi-species aquatic plant growth subroutine, ECOL. GRSM has been used previously (CH2M Gore and Storrie, 1996) for water management decisions. Attempts to improve the model are ongoing. 
With advances in technology and research, GRSM has undergone many modifications, moving from mainframe computers to personal computers with Windows ${ }^{\bullet}$ interfaces. A calibration, sensitivity analysis and verification procedure was carried out in 1995 and 1996 (CH2M Gore and Storrie, 1996), whereby parameters already present were calibrated against two data sets. Special attention was paid to the aquatic plant parameters in ECOL, because model performance was weaker during periods of high plant growth, such as during the late summer. Component equations were however not updated, and the credibility of GRSM was not improved.

In 1996, the GRCA proposed a more rigorous approach to the improvement and calibration of GRSM and approached researchers at the Universities of Guelph and Waterloo to undertake this task. In 1997, a literature review uncovered new equations that had been published in current studies of aquatic plant growth (Carr, 1997). Their suitability for GRSM, and more specifically for the ECOL subroutine, was examined and some were selected for incorporation into ECOL96 and GRSM96. This thesis develops new algorithms for incorporating these equations into ECOL96, tests the new model, herein called ECOL98AH and GRSM98AH, and discusses the relevance of these tests to future developments ECOL and GRSM. Table 1.1 provides an explanation of the terminology used for naming the models and sub-routines investigated in this thesis. 
Table 1.1: Explanation of model and sub-routine terminology

\begin{tabular}{|l|l|l|}
\hline Model/Sub-routine & \multicolumn{1}{|c|}{ Version } & Date \\
\hline GRSM & generic Grand River Simulation Model & None \\
\hline ECOL & generic ECOL sub-routine & None \\
\hline GRSM96 & GRSM that this thesis made changes to & May 1996 \\
\hline ECOL96 & ECOL that this thesis made changes to & May 1996 \\
\hline GRSM98AH & GRSM that this thesis produced & Nov 1998 \\
\hline ECOL98AH & ECOL that this thesis produced & Nov 1998 \\
\hline ECOLAH & intermediate ECOL model used in this thesis & Nov 1998 \\
\hline
\end{tabular}

Specific objectives of this thesis are to:

1) evaluate sources of error in the ECOL96 subroutine of GRSM96;

2) develop and incorporate new algorithms for ECOL to create GRSM98AH;

3) perform an initial calibration on GRSM98AH;

4) perform a sensitivity analysis on input parameters of ECOL98AH (in GRSM98AH);

5) evaluate how GRSM98AH responds to a normal range of alternate data sets;

6) recalibrate GRSM98AH based on insights gained through Objectives 4) and 5); and

7) identify remaining weaknesses in ECOL98AH (in GRSM98AH) and recommend further improvements to GRSM98AH. 


\section{GRSM MODEL DESCRIPTION}

\subsection{Structure of GRSM}

GRSM is a computer-based mathematical model for water flows and quality in the Grand and Speed Rivers in southwestern Ontario. The modelled reach of the Grand River extends from the confluence of the Conestoga and Grand Rivers to below the oxbow turn in the Grand River, downstream of Brantford. The modelled reach of the Speed River, a major tributary of the Grand River, extends from the confluence of the Eramosa and Speed Rivers to the confluence of the Speed and Grand Rivers. The reaches are presented in Figure 2.1. Altogether, eighteen sub-reaches on the Grand River and seven sub-reaches on the Speed River are modelled.

In GRSM, water quality and hydraulic parameters, such as temperature, flow rates, and biomass density, are held constant along the length, width and depth of the sub-reach. The average reach is $7 \mathrm{~km}$ long, but sub-reaches are generally shorter in locations where more changes in parameter values are expected. The model calculates major water quality indicators such as total phosphorus, plant tissue phosphorus, biochemicai oxygen demand (BOD) and biomass density, but the central computed water quality indicator for GRSM is dissolved oxygen (DO). All the water quality parameters, including DO, are calculated for every reach at 2-hour time intervals. Routines in GRSM include routing procedures, water flow and quality calculations resulting from the various inputs to and withdrawals from the river, and an aquatic plant growth procedure, ECOL. 


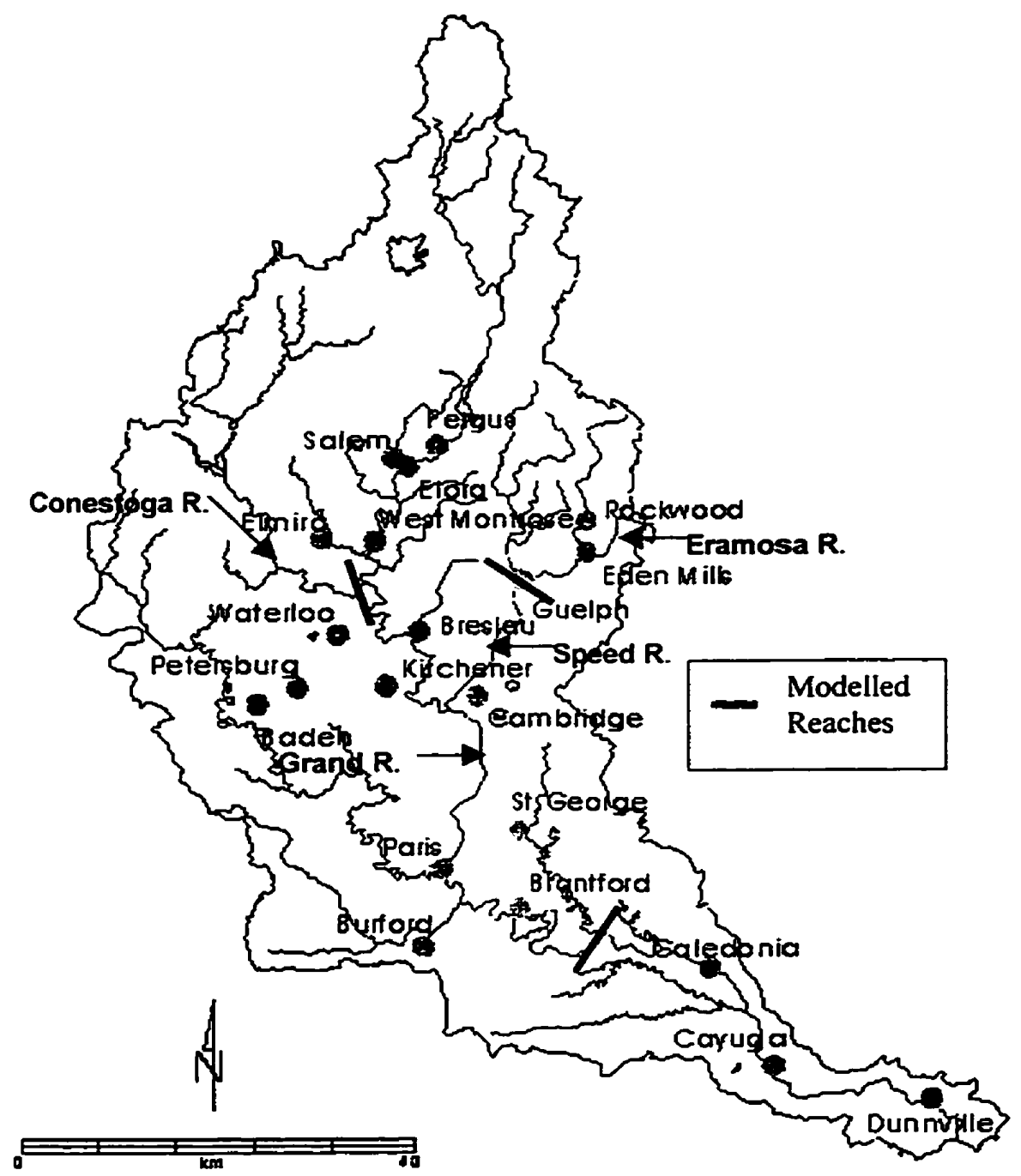

Figure 2.1: Modelled reaches of the Grand River watershed

\subsection{Inputs}

In the following sections, the inputs to GRSM are briefly described, with special emphasis on their significance to biomass production. GRSM requires a large amount of input data including climate data, inflows and outflows, water quality values of inflows, various reaction rates and initial conditions. All of these inputs affect biomass production 
either directly or indirectly. The original developers required these inputs in GRSM and they remain in the GRSM98AH model.

\subsubsection{Climate Data}

Solar radiation and air temperature values are inputted daily for the simulation period. These values are converted by GRSM to air temperatures, stream temperatures and solar radiation for the 2-hour time-step. Solar radiation directly affects growth of aquatic plants because of their requirement for photosynthetically available radiation. Stream temperatures directly affect plant growth according to the optimum temperature for growth and indirectly through temperature-dependent reaction rates.

\subsubsection{Flows}

Input flows at each sub-reach of the river include upstream channels, boundary inflows, local diffuse inflows, sewage treatment plant (STP) discharges, and urban stormwater inputs. Point-source withdrawals are also possible for each sub-reach in cases of water intakes. At the head of each reach, all of the forementioned inflows (positive values) and withdrawals (negative values) are summed to calculate the total flow for the reach. Leopold-Maddock parameters produced by HEC-2 are used to convert daily average flow rates to velocities and depths for each sub-reach. GAWSER (Guelph All Weather Storm Erosion Run-off) was used to generate daily boundary flows, urban stormwater inputs and non-point source inflows (CH2M Gore and Storrie, 1996). Non-point sources, which are identified as local diffuse inflows (LDI's) in GRSM, are mainly from smaller 
unaccounted-for tributary inputs, groundwater discharges and run-off. Flows for the STP discharges were generated by gathering data on the average daily STP outflows from the eight sewage treatment plants along the Grand and Speed Rivers.

In GRSM, flow rates indirectly affect biomass production by influencing the depth of water, which in turn affects the solar radiation reaching the aquatic plants, depending on the turbidity of the water column. In addition, higher velocities increase reaeration rates, which increase the dissolved oxygen concentration, which in turn affects the respiration of the aquatic plants.

\subsubsection{Water Quality Parameters}

GRSM requires the following input boundary water quality parameters: dissolved oxygen, carbonaceous biochemical oxygen demand ( $C B O D)$, nitrogenous oxygen demand (NOD), nitrates $\left(\mathrm{NO}_{2+3}\right)$, suspended solids (SS), total phosphorus (TP), organic nitrogen, and $\mathrm{pH}$. Although not an input, un-ionized ammonia $\left(\mathrm{NH}_{3}\right)$ is also modelled in GRSM using NOD, organic nitrogen, $\mathrm{pH}$ and water temperature. Dissolved oxygen and phosphorus and, to a lesser degree, nitrogen, are the most important parameters for plant growth computation.

Probability distribution functions were established for $\mathrm{DO}, \mathrm{CBOD}, \mathrm{NOD}, \mathrm{NO}_{2+3}$, SS and TP (CH2M Gore and Storrie, 1996) for the boundary inflows and STP effluents using historical data from the Ministry of the Environment (MOE) Provincial Water Quality 
Monitoring Network (PWQMN) and the Clean Water Agency (CWA), respectively. The only STP data not taken from the CWA were supplied by the City of Guelph for the Guelph STP. Eleven water quality probability distribution functions for the urban stormwater inputs and the LDI's were developed using GAWSER (CH2M Gore and Storrie, 1996). The distributions were derived at $10 \%$ increments, for each water quality parameter. These values represented the level exceeded at a given percentage of the time, from $0 \%$ to $100 \%$ of the time. Values for $\mathrm{pH}$ and organic nitrogen, based on more analysis of PWQMN data, were inputted on a monthly and sub-reach basis.

Although all the water quality parameters have some effect on net plant production, some parameters, such as the nutrient concentrations, have a more direct effect. Once the nutrients, nitrogen and phosphorus, are mixed into a river reach through various inputs, their concentrations will directly affect the growth rate of the aquatic plants by limiting or, under optimal conditions, promoting growth. Increasing suspended solids concentrations in the water column will indirectly affect plant growth by decreasing the amount of photosynthetically available radiation. NOD, CBOD and ambient dissolved oxygen values will influence dissolved oxygen, which again affects aquatic plant respiration. Diurnal fluctuations of dissolved oxygen from the photosynthesis and respiration processes of the aquatic plants are of the most interest because the low DO concentrations caused by respiration can be a detriment to aerobic aquatic biota. 


\subsubsection{Reaction Rates and Temperature Coefficients}

Decay rates, reaeration rates and various temperature parameters are input variables to calculate the chemical fate of the six water quality parameters modelled. Coefficients to calculate the stream temperature, from the air temperature and solar radiation for a given time-step, and correction factors, to account for temperature effects on the decay and reaeration rates, are the two main types of temperature-related parameters. Decay rates affect dissolved oxygen concentrations, which again affect the respiration of plants. The influences of reaeration rates and temperature on aquatic plant biomass were discussed in section 2.2.1.

\subsubsection{Biological Parameters}

GRSM requires input parameters related to the growth, respiration and washout of the three species of aquatic plants modelled in ECOL. The primary species-specific parameters used in ECOL are the unit respiration rates at $20^{\circ} \mathrm{C}$, maximum photosynthesis rates and washout fractions. Other required input parameters, most of which are speciesspecific, are used to calculate the limitations to the maximum macrophyte and macroalgal growth rates based on plant growth response to stream temperature, solar radiation and nutrient concentrations. The following is a brief introduction to the processes, inputs and outputs of ECOL. 


\subsection{ECOL Subroutine}

ECOL was originally developed in the 1970 s as a stand-alone continuous aquatic plant growth model. Using solar radiation, stream temperature and nutrient concentrations as the main inputs, ECOL simulates the net change in biomass densities of three species of aquatic plants for each time-step through production (photosynthesis), respiration, and washout. A schematic representation of ECOL and its role in GRSM are shown in Figures 2.2 and 2.3. The three plant species originally modelled were periphyton, Cladophora glomerata and Potamogeton pectinatus. In 1996, periphyton was replaced by Myriophyllum spicatum due to the significant increase of Milfoil in the Grand River (CH2M Gore and Storrie Ltd., 1996). M. spicatum and P. pectinatus are rooted macrophytes while $C$. glomerata is an attached algae. 


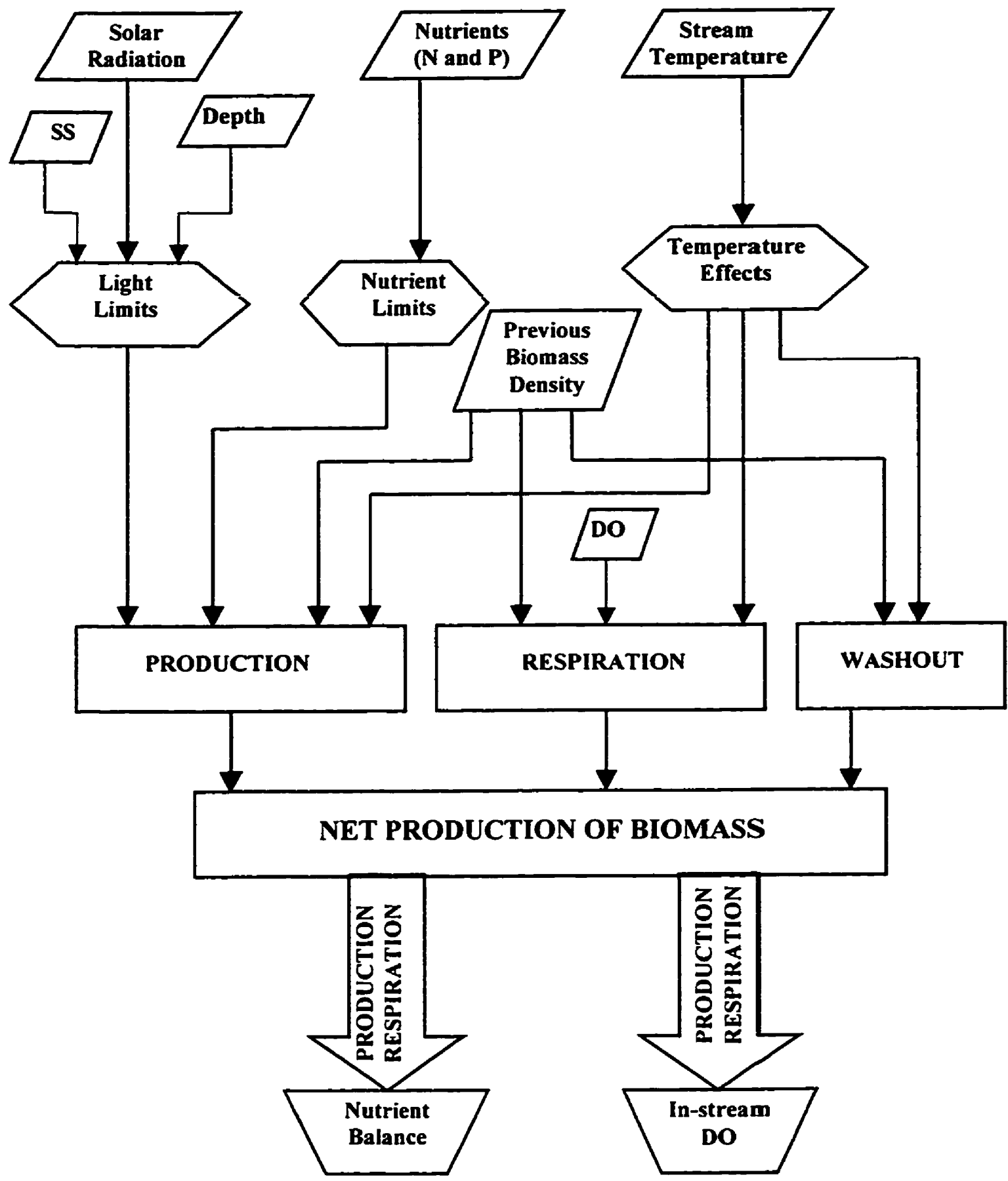

Figure 2.2: Schematic structure of ECOL 


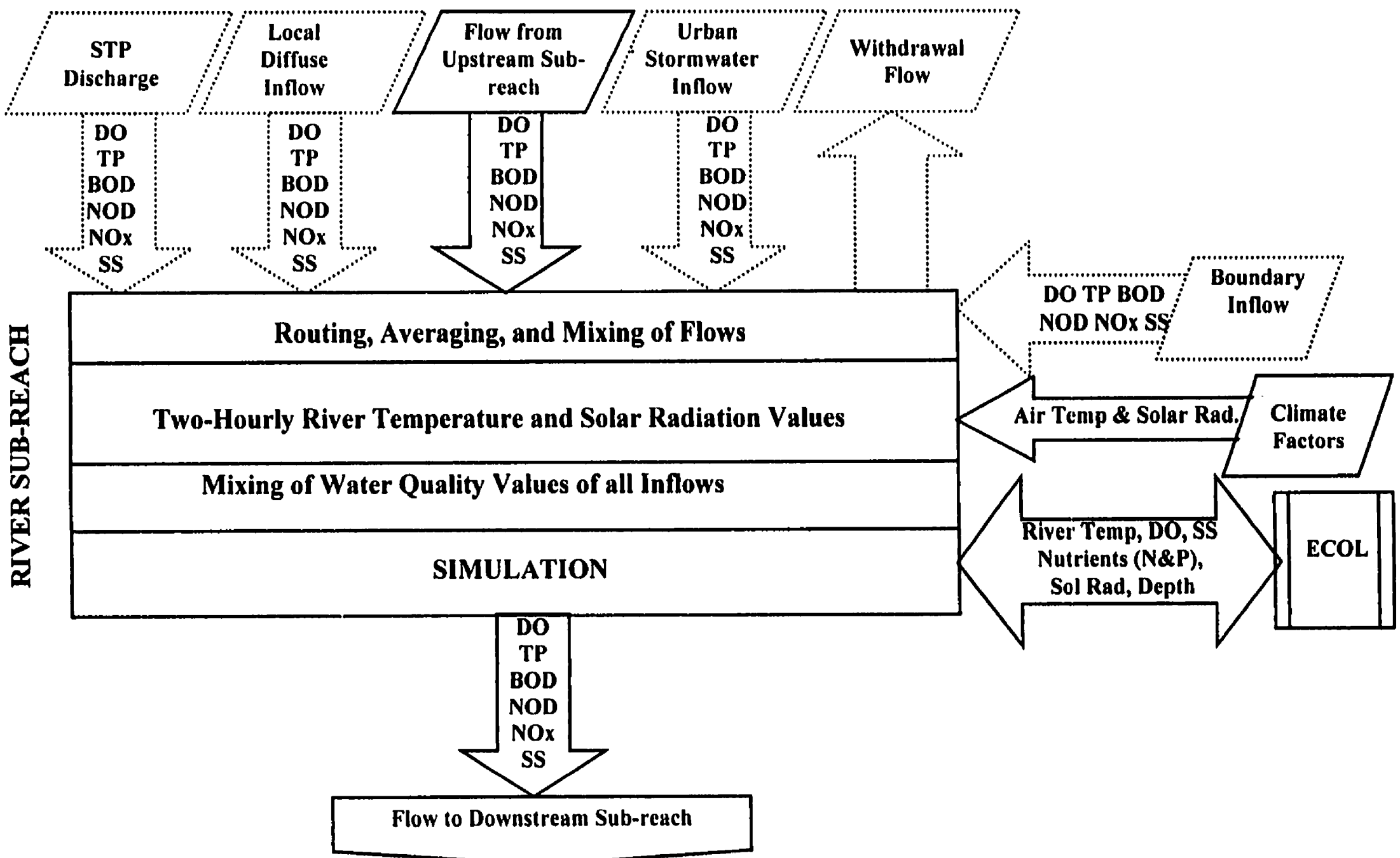

Figure 2.3: Schematic structure of GRSM (required processes are shown in bold outline, optional processes are shown in dotted outline) 


\subsubsection{Biomass Production, Respiration and Washout}

Biomass production (gain in biomass) is limited by solar radiation, stream temperature and available nutrients, while respiration and washout results in a loss of biomass. All three processes (production, respiration, and washout) are dependent on the biomass density at the previous time-step. Therefore the values calculated by each process increase as the biomass densities increase.

These species-specific limitations to production are modelled as simple proportions of the optimal photosynthesis rate:

$$
\mathrm{PROD}_{1}=\text { PHOTO }_{\max }{ }^{*} \mathrm{~B}_{i-1}{ }^{*} \mathrm{~L}_{L i} * \mathrm{~L}_{\pi i}^{*} \mathrm{~L}_{\text {PHOSi }}{ }^{*} \mathrm{~L}_{N_{i}}{ }^{*} \mathrm{~L}_{\text {PLANTi }} * \Delta \mathrm{T}
$$

where:

$$
\begin{aligned}
\mathrm{PROD}_{i} & =\text { gross productivity at time step } \mathrm{i} \text { ( } \mathrm{g} \text { biomass } / \mathrm{m}^{2} \text { ) } \\
\mathrm{PHOTO}_{\max } & =\text { maximum photosynthetic rate }(\mathrm{g} \text { biomass } / \mathrm{g} \text { biomass-hr) } \\
\mathrm{B}_{i-l} & \left.=\text { biomass density at previous time step (g biomass } / \mathrm{m}^{2}\right) \\
\mathrm{L}_{L i} & =\text { light limitation factor at time step } \mathrm{i} \text { (dimensionless) } \\
\mathrm{L}_{T_{i}} & =\text { temperature limitation factor at time step } \mathrm{i} \text { (dimensionless) } \\
\mathrm{L}_{P H O S i} & =\text { phosphorus limitation factor at time step } \mathrm{i} \text { (dimensionless) } \\
\mathrm{L}_{N i} & =\text { nitrogen limitation factor at time step i (dimensionless) } \\
\mathrm{L}_{P L A N T} & =\text { plant inhibition factor at time step } \mathrm{i} \text { (dimensionless) } \\
\Delta \mathrm{T} & =\text { time step }(\mathrm{hr})
\end{aligned}
$$


The plant inhibition factor is a generic limitation factor to account for all factors affecting plant growth factors not explicitly modelled in ECOL, as discussed in the literature review. The inhibition factors are designated by plant species, sub-reach and month.

Biomass respiration is based on the unit respiration rate of each species at $20^{\circ} \mathrm{C}$. A temperature coefficient is used to adjust the respiration rate for temperatures above and below $20^{\circ} \mathrm{C}$. Increased respiration rates caused by increased DO levels are also taken into account in the respiration equation:

$$
\mathrm{RESP}_{i}=\mathrm{R}^{2} 0^{*} \mathrm{~B}_{i-1} * \mathrm{TC}_{i} * \Delta \mathrm{T} * \frac{\mathrm{DO}_{i-1}}{\mathrm{DO}_{i-1}+1.5}
$$

where:

$$
\begin{aligned}
\mathrm{RESP}_{i} & =\text { biomass loss by respiration at time step } \mathrm{i}\left(\mathrm{g} \text { biomass } / \mathrm{m}^{2}\right) \\
\mathrm{R} 20 & =\text { unit respiration rate at } 20^{\circ} \mathrm{C} \text { ( } \mathrm{g} \text { biomass } / \mathrm{g} \text { biomass- } \mathrm{hr} \text { ) } \\
\mathrm{TC}_{i} & =\text { temperature coefficient factor for species time step } \mathrm{i}(\text { dimensionless) } \\
\mathrm{DO}_{i-1} & =\text { dissolved oxygen concentration at previous time step }(\mathrm{mg} / \mathrm{L})
\end{aligned}
$$

Biomass washed out is calculated as a fraction of the existing biomass as shown in [2.3]. The washout fraction is a function of water temperature for $C$. glomerata and $P$. pectinatus. M. spicatum has a constant washout fraction, independent of water temperature.

$$
\mathrm{WASH}_{i}=\mathrm{W}_{i}^{*} \mathrm{~B}_{i-1}^{*} \Delta \mathrm{T}
$$


where:

$$
\begin{aligned}
\text { WASH }_{i} & =\text { biomass washed out at time step } \mathrm{i}\left(\mathrm{g} \text { biomass } / \mathrm{m}^{2}\right) \\
\mathrm{W}_{i} & =\text { biomass washout fraction at time step } \mathrm{i}\left(\mathrm{hr}^{-1}\right)
\end{aligned}
$$

For each time step, a new biomass density for each species is calculated by summing the gains in biomass, through production, and the losses in biomass, through washout and respiration:

$$
\mathrm{B}_{i}=\mathrm{PROD}_{i}-\mathrm{RESP}_{i}-\mathrm{WASH}_{i}
$$

where:

$$
\mathrm{B}_{i}=\text { the total biomass of the species calculated for the time step } \mathrm{i} \text { ( } \mathrm{g} \text { biomass } / \mathrm{m}^{2} \text { ) }
$$

From the production and respiration rates of the plants and the resulting net biomass, the consumption and release of dissolved oxygen (DO) is computed. When periods of high aquatic plant biomass occur, DO may fluctuate widely over a 24 -hour period since the biomass will produce oxygen from net photosynthesis (photosynthesis - respiration) in the daylight hours and consume oxygen from respiration at night. The oxygen produced and consumed by the net biomass production and respiration, respectively is calculated in $[2.5]$ and $[2.6]$.

$$
\begin{aligned}
\mathrm{O}_{i} \mathrm{P}_{i} & =\mathrm{TPROD}_{i}^{*} \mathrm{O}^{\text {ASSIM }} \\
\mathrm{O}^{2} \mathrm{UP}_{i} & =\mathrm{TRES}_{i}^{*} \mathrm{O}^{\text {OASSIM }}
\end{aligned}
$$


where:

$$
\begin{aligned}
\text { TPROD }_{i} & =\text { production of total biomass at time step i }\left(\mathrm{g} \text { biomass } / \mathrm{m}^{2}\right) \\
\text { TRES }_{i} & =\text { respiration of total biomass at time step i }\left(\mathrm{g} \text { biomass } / \mathrm{m}^{2}\right) \\
\text { O2ASSIM } & =\mathrm{O}_{2} \text { assimilation ratio for all plants }\left(\mathrm{g} \mathrm{O}_{2} / \mathrm{g}\right. \text { biomass) } \\
\mathrm{O}_{2} \mathrm{P}_{i} & =\mathrm{O}_{2} \text { produced by photosynthesis at time step i }\left(\mathrm{g} \mathrm{O}_{2} / \mathrm{m}^{2}\right) \\
\text { O2UP }_{i} & =\mathrm{O}_{2} \text { taken up by respiration at time step i }\left(\mathrm{g} \mathrm{O}_{2} / \mathrm{m}^{2}\right)
\end{aligned}
$$

\subsection{Assumptions in GRSM and ECOL}

As with all models, GRSM and ECOL contain numerous simplifying assumptions to reduce required input data, decrease computation and represent unknown, complex processes. Of the numerous simplifications that may produce significant error in the model, four factors have been identified as most likely to affect the accuracy of modelling plant growth in ECOL: 1) long reach lengths, 2) no cross-section variability, 3) inability to separate total phosphorus into organic and inorganic phosphorus, and 4) inability to have zero aquatic plant biomass density within a reach. Other simplifying assumptions such as grazing pressure on aquatic plants, substrate type, and riparian shading are accounted for in more general terms such as plant inhibition factors or sediment oxygen demand rates.

\subsection{Long Reach Lengths and Spatial Averaging}

The average reach length is approximately $7 \mathrm{~km}$, and within this distance, a!l the parameters and values calculated for a given time-step in the model, are averaged. These 
include flows, aquatic plant biomass density, dissolved oxygen levels, and both in-stream and plant phosphorus. The literature indicates a high spatial variability in aquatic plant biomass density (French and Chambers, 1996). In the growing seasons of 1995 (Mangile, 1997), 1996 (Mangile, 1997) and 1997 (Mangile, 1997) on the Grand and Speed Rivers, field observations indicated there were no $7 \mathrm{~km}$ stretches of the river that had a constant biomass density unless the density was zero. Furthermore, the lengths of the reaches in GRSM were defined mainly by the position of convenient locations for sampling, such as bridges or other accessible areas. An improvement to the existing division of reaches would be to define the reaches based on similar river characteristics, such as sediment type, width and riparian shading.

Averaging over the entire cross-section of the river is also unrealistic. Due to river bends and other natural variations, the characteristics of the cross-sections of both the Grand and the Speed Rivers vary. During periods of lower flow and in wider stretches of the river, the outsides of the bends tend to be deeper. Other zones are more subject to sediment accumulation, because of slower velocities. These differing velocity and substrate conditions significantly impact aquatic plant growth.

\subsubsection{Aquatic Plant Density}

The assumption of non-zero biomass densities for any of the aquatic plant species modelled is an obvious inaccurate assumption in GRSM. Field observations in 1997 in the Grand River (Mangile, 1997, and from personal observation) revealed many sub- 
reaches with zero macrophyte densities for all three species. Although there is most likely some minimum photosynthetic activity from ubiquitous algae, their effect on the dissolved oxygen would be less than the minimum densities used in the model. Currently, the model does not allow $C$. glomerata, $P$. pectinatus and $M$. spicatum to go below 10,10 and $5 \mathrm{~g} / \mathrm{m}^{2}$ of dry biomass, respectively. These minimum densities apply for all reaches of the Speed and Grand Rivers, including those that have been observed by the writer to have zero macrophyte densities.

\subsubsection{Phosphorus Dynamics}

Two major simplifying assumptions are made with respect to phosphorus dynamics in ECOL and GRSM. First, only total phosphorus is used in the simulation. The phosphorus water quality distributions for all the inputs are in terms of total phosphorus and all the plant production factors are calculated using total phosphorus values. In order for aquatic plants to use phosphorus as a nutrient source, the phosphorus must be in a bioavailable form, which is typically soluble and inorganic (Robinson et al., 1994). Using undifferentiated phosphorus in calculating plant growth will lead to computing erroneously high biomass densities if some or most of ambient total phosphorus is in fact sediment-bound and/or organic, and thereby not available to the aquatic plants.

Secondly, there is no accounting for uptake of phosphorus by the sediment or by the roots of the rooted macrophytes, $P$. pectinatus and $M$. spicatum. A high degree of interaction between sediments and phosphorus is expected due to the ability of phosphorus to adsorb 
to soil particle surfaces and chemically bind to mineral complexes already on the soil particles (Novotny and Olem, 1994; Olila and Reddy, 1995; Reddy et al., 1996). Rooted aquatic plants are known to take up a significant proportion of phosphorus from the interstitial water of the sediment (Reddy et al., 1996; Howard-Williams, 1985). Again, modelled aquatic plant biomass may be higher than the actual biomass if plant uptake from the water column is the only mechanism in the model responsible for phosphorus removal.

\subsubsection{Assumptions for Aquatic Plant Growth}

The first two assumptions of spatial averaging and biomass minima (Section 2.4.1 and 2.4.2) are considered to be beyond the scope of this thesis. The assumptions of phosphorus dynamics, grazing pressure, substrate type, velocities, and riparian shading are considered in the following literature survey. 


\section{LITERATURE REVIEW}

In this chapter, literature covering factors not directly modelled in ECOL is reviewed from the perspective of how ECOL may indirectly account for these factors. An overview of existing aquatic plant models is presented with comparisons to ECOL. The role of basic model functionality testing in determining model validity is also briefly discussed.

\subsection{Factors Not Modelled in ECOL}

Ecological simulation models can not be expected to capture all natural processes because of the infinite number of interactions that may occur within an ecological system and because the system remains open to the biosphere. Modelling the growth of aquatic macrophytes is no exception as there are many phenomena that must be taken into account, and the body of water, in which the vegetation grows, may be subject to numerous unanticipated inputs and outputs. Examples of phenomena not directly modelled by ECOL are: the effects of herbivorous grazers, river current, riparian shading, substrate type, sediment and root uptake of phosphorus, and phosphorus speciation.

Factors such as exotic aquatic plant species, pest infestation and disease can also drastically affect aquatic plant growth. Because these factors are innately random and are not representative of a typical growth season, their usefulness in a management water quality model is minimal and therefore they will not be discussed further. 


\subsubsection{Herbivore-Plant Interactions}

In any body of water that supports aquatic plant life, there are many organisms that will use these plants for food or shelter, or both. In the case of herbivorous organisms, this translates to an increase or decrease in the biomass density of the plants according to the population and growth rates of the organisms. Mammals, waterfowl, fish, crustaceans, and insect larvae are some of the main herbivores affecting aquatic plants. The impact of herbivory on biomass can be significant. A review of grazer impact by Lodge (1991), for instance, demonstrated that herbivorous activities can cause dramatic changes in macrophyte biomass, productivity and relative species abundance.

The fish, Scardinius erythrophthalmus, and the coot (Fulica atra), a waterbird, were found to be the main cause of the decrease in abundance of total macrophytes and shift in species composition in a lake in the Netherlands (van Donk and Otte, 1996). In another study in the Netherlands, waterfowl grazing reduced the density of $P$. pectinatus to $17 \%$ of its non-grazed biomass density (van Wijk, 1988). In a series of experiments to determine the main limiting factors to $P$. pectinatus, it was determined that $20 \%$ or greater of the difference in biomass density in their experiments was due to waterfowl grazing (Jupp and Spence, 1977). It can be generally stated that $P$. pectinatus is more sensitive to waterfowl grazing than $M$. spicatum (Weisner et al., 1997). Cyprinus carpio was found to cause damage to macrophytes through both herbivory and physical disturbance (Crivelli, 1983). 
In Augusta Creek in Michigan, the density of C. glomerata (Creed, 1994) was increased 10-fold by the removal of grazing pressure caused by crayfish. Hart (1992) attributed the spatial changes in biomass density of Cladophora in Augusta Creek to the crayfishs' inability to forage effectively in velocities greater than $0.5 \mathrm{~m} / \mathrm{s}$. Lodge et al. (1994) used the term "clear-cutting" to describe the effect of the omnivorous crayfish, Orconectes rusticus, on the macrophytes in Plum Lake, Wisconsin. A non-native craytish in northern Wisconsin lakes has greatly reduced macrophyte densities in this region (Lorman and Magnusan, 1978). Macrophyte density can also be affected by the clipping activity of the crayfish as they can clip single stems near the bottom (Lodge and Lorman, 1987). The clipping activity can have both a negative and positive impact of macrophyte density, depending whether the clipped fragment regenerates into a new plant or dies off. For $M$. spicatum, the clipping could lead to greater propagation since this species is known for spreading rapidly by fragmentation propagation (Owttrim and Colman, 1989). The biomass density of $P$. pectinatus would more likely be reduced by clipping activity since cutting of this species in the River Susa was severely effected by cutting the plant $10 \mathrm{~cm}$ above the sediment (Sand-Jensen et al., 1989). This is due to growth mechanism of $P$. pectinatus, which is from the apical meristem, the upper portion of the plant (SandJensen et al., 1989). To further complicate the herbivore-macrophyte interactions, the increased grazing activity of a crayfish (Pacifastacus leniusculus) was correlated with increasing temperature under laboratory conditions (Nystrom and Strand, 1996). 
Macroinvertebrate larva can also hinder the growth of aquatic algae and plants through herbivory. The invertebrate grazers, dominantly caddisfly, reduced the Cladophora in a Californian stream by $80 \%$ (Dudley and D'Antonio, 1991). In a second Californian stream, two larval instars of the caterpillar, Petrophila confusalis, were observed to have significantly reduced the biomass density of Cladophora (Bergey, 1995). The authors of a study on a third Caiifornian stream noted that there was a succession from attached algae $C$. glomerata in early spring to diatoms and blue-green algae later in the summer from non-grazing factors such as light, temperature and nutrients and not from grazing activity (Feminella and Resh, 1991). However, a species of caddisfly, Gumaga nigricula, was determined to have accelerated the reduction of $C$. glomerata by 4 to 6 weeks (Feminella and Resh, 1991). In constrast, communities of $C$. glomerata in the Madison River were found not to be grazed upon by normal densities of herbivorous invertebrates associated with the community (Dodds, 1991a, Dodds, 1991b). Instead, the invertebrates preferred the epiphytes that lived within the stand (Dodds, 1991b). The North American weevil, Euhrychiopsis lecontei, was found to have a significant negative impact on M. spicatum in a pond in Vermont (Creed and Sheldon, 1993). At every stage of its life, from first instar larvae to full grown adult, this weevil used $M$. spicatum as its food source.

The effect herbivory has on the densities of macrophytes and attached algae in the Grand and Speed Rivers is unknown. During field studies in (Mangile, 1997, and from personal observations) crayfish were routinely found in areas of high aquatic plant density. In one 
study it was predicted that the success of crayfish foraging was limited to waters with lower velocities than $0.5 \mathrm{~cm} / \mathrm{s}$ (Hart, 1992), which could apply to some reaches on the Grand and Speed Rivers, especially in late summer during low flow periods. Macroinvertebrate larva (species unknown) were found in high densities on $P$. pectinatus for a period in the later summer, during the 1997 field program (Mangile, 1997, and from personal observations) at the Blair station and further downstream. Mallards and Canadian geese were also observed in areas where river velocities were suitably slow. The sub-routine ECOL assumes, however, that the decrease in plant biomass density due to herbivore-plant interactions is insignificant compared to the three main factors modelled: temperature, light and nutrients. ECOL takes account for herbivory through a plant inhibition factor, which is specific for each species, sub-reach and month, and can be calibrated to account for herbivorous activity. Spatial variations in grazer impacts can also be represented by the inhibition factor since it is defined by sub-reach. Lastly, temperature and flow effects on grazers could be represented by the inhibition factor on a monthly basis. Modelling effects of herbivory may be difficult because growth patterns and/or migration of these organisms can be influenced by subtle environmental clues.

\subsubsection{Substrate Type}

Six main classifications in substrate type for rivers can be used: bedrock, boulders, cobble, gravel, sand, and silts and clays, given in decreasing particle size. The only effect of the substrate that is modelled in GRSM is the sediment oxygen demand (SOD) by 
giving a rate of SOD for each sub-reach for each month. Since SOD affects the dissolved oxygen level, which in turn affects the respiration rates of the plants, the net plant growth in the ECOL subroutine is affected. However, there are other aspects of the substrate type that may influence plant growth.

In a study on macrophyte production in a marsh in southern France, it was shown that $M$. spicatum had a lower biomass density than $P$. pectinatus when grown on sediments with low organic matter (2-4\%) concentration (van Wijck et al., 1994). Conversely, on higher organic (9-13\%) sediments, $M$. spicatum outperformed $P$. pectinatus in biomass density (van Wijck et al., 1994). In addition, in a lake along the Quebec-Vermont border, $75 \%$ of the shoot biomass density of $M$. spicatum was attributed to sediment composition (Chambers and Kalff, 1985). That is, with increasing organic concentration there was a corresponding increase in the shoot biomass density. In two other studies on macrophytes from this lake, the highest macrophyte biomass densities were observed in the most fertile sediments, while the lowest biomass densities were found in the least fertile sediments (Chambers and Kalff, 1987; Chambers, 1987). The M. spicatum stands in the Tern River in the U.K. were dominant with one other macrophyte (Ranunculus fluitans) in gravel substrates, which have the capacity to collect sediments (French and Chambers, 1996). Increased densities of C. glomerata in Badfish Creek were positively correlated with increasing organic concentration and decreasing particle size (Madsen and Adams, 1989a). The P. pectinatus in Badfish Creek was found to grow better on silt and gravel than on sand (Madsen and Adams, 1989a). These findings are also indicative 
of higher organic concentrations causing increases in biomass production, since silt has a higher organic content than sand, and gravel has the capacity to hold deposits of finer, organic particles. Sand, which generally has a very low organic content, was shown to depress plant growth in the Badfish Creek study (Madsen and Adams, 1989a). In Nechako River, $P$. pectinatus was also found to be most abundant at sites with silty substrates rather than those within bare rock or sand (French and Chambers, 1996).

In Report \#14 of the Grand River Basin Water Management Study (Walker et al., 1982) the Grand River was defined as having a stony (gravel to cobble) substrate while the Speed River was defined as bedrock and stony. From field reports there is great variation in substrate type in both rivers. There are large areas in both the Speed and Grand with complete silt or bedrock substrates, and in the Grand River there are large areas of boulders and sand (Mangile, 1997, and from personal observations). Field observations revealed that areas primarily comprising of silt, sand or smooth bedrock substrate typically did not support aquatic vegetation (Mangile, 1997, and from personal observations). The absence of plants on sand and smooth bedrock was likely to be due, in part, to the very low organic content found in or on these substrates. Since the silt regions also were correlated with slower flow and increased depth, it is also possible that grazing or increased depth suppressed the growth of the macrophytes in these locations. 


\subsubsection{Riparian Shading}

Riparian shading can include trees, brush, or any other living or inanimate phenomenon that leads to the reduction of light reaching the water surface of the river or lake. The calculations in ECOL do not consider land-based shading, thus hindering GRSM's ability to assess the management option of riparian shading. Light availability due to riparian shading was found to be a major factor affecting macrophyte communities in a stream in North Carolina (Everitt and Burkholder, 1991) According to this study, riparian shading influenced the presence or absence of a plant species depending on its shade tolerance. Another study in Wisonsin, on Badfish Creek, found that one of the most significant environmental factors that was correlated to biomass distribution was light intensity, as affected by canopy and riparian vegetation (Madsen and Adams, 1989a). In a study on the irrigation and drainage canals of the Nile Delta, shading by riparian vegetation was found to be an effective management technique for submerged macrophytes compared to emergent aquatic vegetation (Khedr et al., 1997).

Although both the Grand and Speed Rivers have natural riparian shading, the extent that shading reduces light may be insignificant overall since both rivers have an average width at low flow of over $35 \mathrm{~m}$ (Walker et al., 1982). Normally, riparian vegetation is considered an option for reducing aquatic vegetation for streams where the width of flow is smaller than the widths of the Speed and Grand Rivers (Dawson, 1978). According to Khedr et al. (1997), the effect of shading is inversely proportional to the width of the 
canal, leading the authors to suggest shading as a management alternative for the control of macrophytes only in narrower canals.

\subsubsection{River Velocity}

The ECOL subroutine does not explicitly account for the influence of flow variation on plant biomass. The amount of plant biomass washed out is calculated as a fraction of the existing biomass density for each species. The fraction of biomass washed out either accounts for the increased death and detachment at some 'washout' temperature or is set at a minimum washout fraction of $0.1 \%$. Scouring or sloughing effects of high velocities are neglected in the model.

In the Badfish creek in Wisconsin, $P$. pectinatus was found to have a strong negative correlation with current velocity (Madsen and Adams, 1989a). However, in this case, the authors theorized that it was the high biomass density that was causing the lower velocities in the stream. This effect has been noted in other studies (Gregg and Rose, 1982, Madsen and Warncke, 1983) and apparently improves the current environment for P. pectinatus, thereby improving its net growth rate. During in situ experiments using plants from the Nechako River, macrophyte stands that included $P$. pectinatus were found to shelter other macrophytes from scouring currents (French and Chambers, 1996).

P. pectinatus in the Nechako River was found to be most abundant at sites with slower current velocities $(<0.2 \mathrm{~m} / \mathrm{s}$ ) (French and Chambers, 1996). The dormant period of $P$. 
pectinatus in the River Susa in Denmark was correlated with periods of high discharge (Sand-Jensen et al., 1989). Furthermore, high discharges in the spring and early summer in the River Susa were thought to be responsible for delaying macrophyte development for up to three weeks (Sand-Jensen et al., 1989). In the Madison River in Montana, it was suggested that periods of high current velocities could remove $C$. glomerata through scouring and sloughing processes (Dodds, 1991b). In the River Suldalslagen, in southwestern Norwary, the decrease in macrophyte density from scouring exhibited a strong log-linear relationship to higher flows (Rørslett and Johansen, 1996). Ice runs and sharply peaking flows resulted in significant to heavy loss of macrophytes in this Norwegian river (Rørslett and Johansen, 1996). By contrast, C. glomerata density was positively correlated with velocity due to the inability of crayfish to forage on the species under higher velocity conditions $(50 \mathrm{~cm} / \mathrm{s})(\mathrm{Hart}, 1992)$. Since flows from the Madison River study were not converted to velocities it is difficult to compare these two results. Possibly, as current velocity increases, the aquatic plant biomass increases due to reduced foraging, until some threshold velocity is reached where the $C$. glomerata is no longer strong enough to remain attached.

During the spring melt and associated runoff, the Grand and Speed Rivers experience increased flows, which may lead to scouring of the previous year's aquatic plants. Field observations revealed the presence of more large floating plant debris in the Grand River after periods of high rainfall (Mangile, 1997, and from personal observations). However, whether the velocities of the Speed and Grand Rivers significantly influence the biomass 
densities of the three plant species modelled is unknown since the percentage of observed debris to total biomass present was not determined.

\subsubsection{Phosphorus Uptake by Sediment or Roots}

As discussed in Section 2.4.3, phosphorus has a high potential to interact with sediment, but none of those interactions are modelled in ECOL. As a result, the availability of this nutrient to plants may be overestimated in ECOL. In fact, some studies have demonstrated that sediment has more control over long-term phosphorus than aquatic vegetation or periphyton (Reddy et al., 1996; Hill, 1982; McCallister and Logan, 1978). Reddy et al. (1996) estimated that 56 to 77 percent of the phosphorus taken up by above ground aquatic vegetation during periods of active growth is released within six months of senesence. Gumbricht (1993a) found only $20 \%$ of the removed phosphorus to be in the aquatic plants harvested in a wastewater treatment pond and therefore dismissed direct uptake and subsequent harvest as the most important removal process of phosphorus.

Sediment uptake of phosphorus through adsorption and precipitation includes interactions with aluminum, calcium and clay minerals (Khalid et al., 1977; Holford and Patrick, 1979) and can be affected by chemical conditions such as $\mathrm{pH}$ and Eh (redox) and physical conditions such as temperature and flow rates (Gumbricht. 1993b). Decreases in sediment $\mathrm{pH}$ lead to an increase in phosphate-binding capacity since the protonation of 
aluminum and iron surfaces has increased ( $\mathrm{Ku}$ et al., 1978). Lowering of the sediment redox-potential has been observed to increase the sediment solution phosphorus content, which is thought to be connected to the reduction of Fe(III) to Fe(II) (Holford and Patrick, 1979) and to increase the phosphorus sorption capacity (Khalid et al., 1977; Holford and Patrick, 1979).

In ECOL, the growth of the two rooted macrophytes, $M$. spicatum and $P$. pectinatus, in response to phosphorus is based on the water column phosphorus. Smith and Adams (1986) demonstrated that the majority of phosphorus uptake by $M$. spicatum was through the roots while the majority of phosphorus release was through the shoots. Other studies have also indicated that root uptake of phosphorus exceeds that of shoot uptake (Barko and Smart, 1980; Carignan and Kalff, 1980) due to the higher concentration of phosphorus in sediment pore water (Carignan, 1982). One hypothesis is that the missing algorithms for calculating root uptake of phosphorus may be implicitly modelled through existing algorithms of water column phosphorus uptake if water column and interstitial phosphorus are related. Where sediments are saturated with phosphorus, the diffusion of phosphorus from the sediments to the water column may maintain phosphorus at 'saturated' levels in the water column. The aquatic plant growth would reflect the saturated conditions of both the sediments and the water column. 


\subsection{Other Aquatic Plant Models}

Most water quality models incorporate some limited effects of aquatic plants, normally to account for diurnal fluctuations in dissolved oxygen, but there is wide range in the degree of detail in the models. Some water quality models, such as QUAL2E as applied in the River Sava, Slovenia, implicitly assume inclusion of biomass production and respiration through SOD rates (Drolc and Koncan, 1996). The Segment Travel River Ecosystem Autograph Model (STREAM) uses fixed photosynthetic and respiration rates and does not relate the nutrients, such as soluble phosphorus, to the potential for aquatic plant growth (Park and Lee, 1996). Other models, such as WEED go into great detail, such as calculating different production rates for separate parts of the plant (Titus et al., 1975). Some of the models, which were derived to model plant growth only, do not make the connection between the simulated plant growth and the resulting water quality.

The following sections discuss some of the most prominent aquatic plant models currently available.

\subsubsection{WEED}

WEED was specifically developed to study the growth of $M$. spicatum in Lake Wingra, Michigan (Titus et al., 1975). Leaves, stems, roots and carbohydrates are the four biomass compartments employed by this model. The carbohydrate pool is considered to 
be all available (in terms of energy and substrate sources) non-structural carbohydrates. Similar to ECOL, WEED uses a maximum net photosynthesis value and then computes various fraction multipliers to reduce this value.

Light and temperature are the main factors used to model net photosynthesis in aquatic plant leaves in WEED. Stems and root growth are a function of the leaf production and the pool of carbohydrates. As in ECOL, suspended solids and weedbed density are used to attenuate the light reaching the photosynthetic leaf; however, unlike ECOL, the light attenuation calculations are partitioned in to $10-\mathrm{cm}$ intervals. This allows WEED to calculate biomass densities at $10-\mathrm{cm}$ intervals to take into account the effect of weedbed shading as the depth increases. This can be essential in a lake environment where depth can play a crucial role in the location of photosynthetic activity within a macrophyte (Titus et al, 1975). Nutrient responses are not modeled in WEED since the researchers found no evidence that there were nutrient limitations in Lake Wingra (Titus et al, 1975). Furthermore, rooted macrophytes are at an advantage in terms of obtaining nutrients since they have the ability to incorporate nutrients from both the sediment, through roots, and the water column, through the shoots (Titus et al, 1975, Barko et al., 1991).

Photosynthetic response to temperature was calculated based on the following temperature function [3.1] developed by Schugart et al. (1974).

$$
f(T)=V^{x} e^{x(1-\nu)}
$$


where:

$$
\begin{gathered}
V=\frac{\left(T_{\max }-T\right)}{\left(T_{\max }-T_{\text {opt }}\right)} \\
X=\frac{W^{2}\left[1+\left(1+\frac{40}{W}\right)^{\frac{1}{2}}\right]^{2}}{400} \\
W=(S-1)\left(T_{\max }-T_{\text {opt }}\right) \\
\mathrm{T}_{\max }=\text { maximum water temperature for growth }\left({ }^{\circ} \mathrm{C}\right) \\
\mathrm{T}=\text { observed water temperature }\left({ }^{\circ} \mathrm{C}\right) \\
\mathrm{T}_{\text {opt }}=\text { optimal water temperature for growth }\left({ }^{\circ} \mathrm{C}\right)
\end{gathered}
$$

Empirically derived, the slope $S$ is equivalent to the $\mathrm{Q}_{10}$ value at intermediate temperatures.

$$
Q_{10}=\left(\frac{k_{2}}{k_{1}}\right)^{\frac{10}{T_{2}-T_{1}}}
$$

where:

$$
\begin{aligned}
& Q_{10}=\text { temperature factor (no units) } \\
& k_{1}=\text { reaction rates at temperature } 1\left(\mathrm{hr}^{-1}\right) \\
& k_{2}=\text { reaction rates at temperature } 2\left(\mathrm{hr}^{-1}\right) \\
& T_{1}=\text { water temperature } 1\left({ }^{\circ} \mathrm{C}\right) \\
& T_{2}=\text { water temperature } 2\left({ }^{\circ} \mathrm{C}\right)
\end{aligned}
$$

WEED also allows for temperature acclimation by adjusting values of $T_{\max }$ and $T_{\mathrm{opt}}$ using another empirically-derived function developed by Schugart et al. (1974). Maximum and 
optimum temperatures for $M$. spicatum were used to determine the temperature effects on photosynthesis in WEED. ECOL includes these two parameters, but also takes into account an optimum range of temperatures for plant growth and the effects of temperature on respiration.

The light limitation factors are modelled by an empirical hyperbolic function that takes into account light attenuation due to water particles and weedbed density. Titus and al. (1975) modelled light attenuation using a hyperbolic relationship based on other studies using this empirical relationship by Rabinowitch (1951), Monteith (1965), deWit (1965), and Duncan et al. (1967). However, this function does not necessarily maintain the light limitation values below 1.0. Therefore, as the light increases, the function allows the photosynthetic rate to increase above its maximum, an unrealistic situation.

Lastly, washout of $M$. spicatum is modelled in WEED by the incorporation of three constant sloughing-off terms, which reduce leaf and stem biomass. One term is applied on a continuous basis to the leaves and is dependent on leaf biomass, while the other two terms represent observed periods of washout in Lake Winga and are applied to both leaf and stem biomass. Using observed periods of sloughing instead of modelling the causes of sloughing, such as currents and temperature, restricts the flexibility of the model to respond accurately to changes in the normal season. WEED uses a very detailed approach, in terms of compartmentalizing the plant, to model plant growth. However 
other factors such as light, nutrients and washout that affect plant growth do not reflect the same detail of modelling.

\subsubsection{Salvinia molesta Model}

Developed by Toerien et al. (1983) this model calculates the growth of Salvinia molesta from nitrogen, phosphorus and temperature. Nutrient modelling was achieved through Michaelis-Menten algorithms [3.3] and an Arrhenius function [3.4] was used to model temperature effects. Light limitations were assumed to be minimal, perhaps because Salvinia is a tropical weed and the modelling was for wastewater treatment lagoons or lakes where light may have not been a limiting factor. The nutrient limitation factor is given in [3.3].

$$
\mathrm{L}_{\text {NUT }}=\frac{\mathrm{NUT}}{\mathrm{K}_{\text {NUT }}+\mathrm{NUT}}
$$

where:

$$
\begin{aligned}
& \mathrm{L}_{N U T}=\text { limitation factor for nutrients (dimensionless) } \\
& \mathrm{NUT}=\text { concentration of nutrients (either } \mathrm{N} \text { or } \mathrm{P})(\mathrm{mg} / \mathrm{l}) \\
& \left.\mathrm{K}_{N U T}=\text { half-saturation constant for nutrients (either } \mathrm{N} \text { or } \mathrm{P}\right)(\mathrm{mg} / \mathrm{l}) \\
& \mathrm{RGR}=1.42 * 10^{12} * e^{\frac{-8763}{r}}
\end{aligned}
$$

where:

$$
\begin{aligned}
\mathrm{RGR} & =\text { relative growth rate }\left(\mathrm{day}^{-1}\right) \\
T & =\text { water temperature }(\mathrm{K})
\end{aligned}
$$




\subsubsection{MEGAPLANT}

MEGAPLANT (Scheffer et al., 1993) models generic aquatic plant growth from light and temperature, as well as major seasonal changes in aquatic plant growth including grazing, overwintering strategies, wave action and seed dispersal. The maximum growth rates are limited by a Michaelis-Menten light function and a Hill function empirically derived from various data sources (Barko et al., 1982; Spencer, 1986; Madsen and Adams, 1989b). The Hill function is given by:

$$
f(T)=\frac{1.35 T^{3}}{\left(T^{3}+14^{3}\right)}
$$

where:

$$
T=\text { water temperature }(\mathrm{K})
$$

As with the Arrhenius equation, the Hill function does not allow for decreased photosynthetic activity under temperatures above the optimal growth temperatures. Similar to the attempts of WEED, MEGAPLANT uses a Michaelis-Menten equation to account for varying growth rates within an individual plant. Photosynthetic activity is assumed to decrease with distance of the tissue from the shoot tip based on aging effects. A half-saturation distance is used for these calculations. 
Three mortality factors are modelled in MEGAPLANT. First, a thinning law (Westoby, 1984) similar to a washout process is activated when the biomass density increases over a certain maximum. Second, wave damage, which decreases with increases in lake depth, is modelled using a Michaelis-Menten function. Third, loss of biomass due to grazing is calculated based on the predatory community present and biomass density of the macrophytes. Techniques for overwintering strategies can use a combination of the first and third factor.

Although MEGAPLANT covers a wide range of environmental factors affecting aquatic plant growth, it relies heavily on Michaelis-Menten functions and lacks an explicit growth response to nutrients.

\subsubsection{Lake Huron Cladophora Model}

A model for the net photosynthetic and respiration rates of $C$. glomerata based on light and temperature was developed through an intense series of laboratory experiments (Graham et al, 1982). Rates of photosynthesis and respiration were measured for 64 different scenarios in triplicate using oxygen electrode techniques. These points were graphed three-dimensionally and fitted to a $4^{\text {th }}$ order polynomial surface. Nutrients, washout and grazing are obvious factors missing in this model. However these experiments were designed to investigate light and temperature effects under laboratory conditions and not to be used as a stand-alone model for plant growth. The external and internal phosphorus algorithms related to plant growth proposed for incorporation into 
ECOL98AH were also derived from Cladophora from Lake Huron data (Auer and Canale, 1982a, 1982b). Painter and Jackson (1989) combined the light and temperature polynomial from Graham et al. (1982) and the internal and external phosphorus from Auer and Canale (1982a, 1982b) to model the growth of Cladophora in Lake Huron. Although sloughing off and self-shading were not accounted for in this model, the observed versus simulated biomass values were relatively similar. Locations of expected wide variability, such as the mouths of rivers, produced the worst results. Since the polynomial for light and temperature is so specific for Cladophora growing in Lake Huron, transfer of this function to the Grand and Speed Rivers was not considered to be scientifically sound. However, the more general phosphorus algorithms were considered for incorporation into the ECOL model

\subsubsection{Estuary Cladophora Model}

The massive amounts of Cladophora montagneana growing in the shallow, eutrophic Peel-Harvey estuary in Australia prompted the development of a model that simulates the growth of the algal species as a function of light, temperature and inorganic nutrients (Gordon and McComb, 1989). Nutrients and light were modelled through MichaelisMenten kinetics similar to those in ECOL, but temperature and growth were described using a linear relationship. It should be recognized that the model only functions within a limited range of temperatures, and assumes that all increases in water temperature cause an increase in growth. The limitation for each factor is calculated separately, and then 
the limitation factor, which caused the slowest growth rate, is chosen. Therefore, the model does not account for the combined effects of more than one growth factor.

\subsubsection{Rooted Macrophyte Growth Model}

Wright and McDonnell (1986a, 1986b) developed a model to simulate rooted macrophyte growth in Spring Creek, Pennsylvania. Photosynthetically available light is calculated using an exponential attenuation function which includes the effects of the water column and plant density, as in ECOL. The model also includes a riparian shading function, since Spring Creek is small enough to be affected by riparian vegetation shading.

Temperature effects on photosynthesis were treated like the adjusted respiration rates and therefore cannot account for the decrease in photosynthetic rates when the optimum temperature is surpassed. Washout, defined in this model as advective loss, was logarithmically related to the existing biomass density and not associated with temperature changes, as in ECOL. Similar to ECOL's function in GRSM, the model calculates oxygen mass balances in the modelled stream segments using the resulting photosynthetic and respiration rates, in addition to reaeration rates. The ultimate function

of the model was to provide a direct linkage between allocatable phosphorus loading and dissolved oxygen as a water quality criterion. 


\subsubsection{CE-QUAL-RI Macrophyte Sub-model}

The macrophyte model in CE-QUAL-RI calculates plant growth using photosynthesis, respiration, washout and excretion and incorporates the results into the computations of various water quality parameters (Collins and Wlosinski, 1989). CE-QUAL-R1 is used for reservoir modelling and uses only one generalized aquatic plant species. Net gain or loss of aquatic plant biomass by respiration, photosynthesis, washout and excretion are included in this model. Photosynthetic rates are calculated from Michaelis-Menten equations for nutrients. Steele's (1962) equation and a shade factor model light response. Thorton and Lessem (1978) algorithms are used to model water temperature response. Steele's equation for the light limitation factor is shown in [3.6] (Steele, 1962):

$$
\mathrm{L}=\frac{\mathrm{I}}{\mathrm{L}_{\text {sat }}} * e^{\left[\mathrm{L}-\left(\frac{\mathrm{I}}{\mathrm{L}_{\text {ser }}}\right)\right]}
$$

where:

$$
\begin{aligned}
\mathrm{L} & =\text { light limitation factor }(<\mathrm{l}) \\
\mathrm{I} & =\text { irradiance (Langleys/min) } \\
\mathrm{L}_{\text {sat }} & =\text { irradiance at maximum production (Langleys/min) }
\end{aligned}
$$

Equation in [3.6] calculates a decrease in photosynthetic activity past irradiance at the maximum production, which was observed in a study of light effects on Cladophora (Graham et al., 1982). Photoinhibition was not, however, observed in $M$. spicatum (Collins and Wlosinski, 1989). However, growth response to light in the current literature 
is more often compared to the rectangular shape curve from a Michaelis-Menten relationship, and the associated half-saturation constant is determined from this curve (Scheffer et al., 1993; Madsen et al.; 1991; Madsen and Adams, 1989b; Van et al., 1976). Other studies present a positive-only trend towards increasing photosynthetic activity with realistic increases in exposure to irradiance (Barko et al., 1982; Madsen and Adams, 1989b).

Similar to ECOL, the macrophyte submodel calculates a respiration rate dependent on water temperature using the $Q_{10}$ relationship and computes an accelerated washout function based on an upper or lower temperature limit. Excretion of nutrients is based on the light limitation factor in the QUAL macrophyte submodel, in contrast to ECOL, where nutrient release is based on the light, temperature and nutrient limitation effects.

\subsubsection{WASP}

The Water Quality Analysis Simulation Program (WASP5) is one of the better-known models used for continuous water quality modelling (Ambrose et al., 1993). WASP5 models the growth of a single species, phytoplankton, and includes Michaelis-Menten nutrient response, light saturation algorithms similar to CE-QUAL-R1, and a temperature coefficient to adjust photosynthetic and respiration rates (Ambrose et al., 1993). Similar to ECOL, WASP5 has a non-predatory washout function but also decreases biomass through a grazing rate based on the calculated zooplankton population. Two 
phytoplankton respiration rates are inputted into WASP5 to represent both the endogenous respiration (at $20^{\circ} \mathrm{C}$ ) and the decompostion rates of the phytoplankton in the sediment (at $20^{\circ} \mathrm{C}$ ), both of which are adjusted for temperature. The main drawback to this model is that only one plant species is modelled, thus limiting the model's ability to represent circumstances where multiple species, with differing growth patterns, are affecting the consumption and production of dissolved oxygen.

\subsubsection{Summary}

A wide variety of aquatic plant models, using different algorithms and developed for different purposes, can be found in the literature. Michaelis-Menten kinetics is the most commonly used approach for modelling nutrient response for aquatic plant growth. There is more debate over the choice of temperature and light algorithms for adjusting photosynthetic and respiration rates. Many of the algorithms developed for photosynthesis have the problematic response of an unbounded exponential, where temperatures over the maximum or below the minimum do not result in a decrease in the photosynthetic rate. Washout is generally derived from empirical formulas. Of all the models investigated in the literature, the Spring Creek rooted macrophyte model in Pennsylvannia (Wright and McDonnell, 1986a, 1986b), and the QUAL model (Collins and Wlosinski, 1989), most closely resemble ECOL in terms of both the algorithms used and the link to dissolved oxygen as a water quality criterion. Even before changes are 
made to ECOL96, the ability to model multiple plant species is the main obvious advantage which ECOL has over other aquatic plant models.

\subsection{Model Functionality Testing}

Model functionality testing is defined in this thesis as altering model input data sets within realistic ranges to test whether the computed response is reasonable. Not considered as a rigorous examination of the validity of the model, such as verification, model functionality testing is to be used either as a first examination of the reasonableness of new algorithms or as further confirmation that the model is behaving realistically. For example, if the input value of suspended solids concentration was increased, one would expect a decrease in plant biomass production because of the attenuation of photosynthetically available light. If this is not observed in the results, further examination of the results is required to determine the cause (such as the water body too shallow for effective light attenuation, or the suspended solids concentration already above a level affecting maximum light attenuation). Sensitivity analysis is a form of model functionality testing as one often anticipates the direction of change when decreasing or increasing certain parameters. In a study of $3 \mathrm{D}$ regional biogeochemical models, model functionality testing was used to build the model in a step-wise manner (Robinson and McKay, 1990). The approach taken in their model design was first to construct simplified models with a minimal number of biogeochemical components, and then, step-by-step, to introduce further components and detailed intercomponent 
interactions based on reasonable results at each incremental phase. In Painter and Jackson's (1989) model of Cladophora growth, the output of the model was checked against the current understanding of Cladophora physiology. That is, at optimal nutrient and light levels, the maximum growth rate was expected to occur at the optimal temperature. Model functionality testing provides a simple model testing methodology that has the ability to detect gross inaccuracies or unexpected model results. 


\section{Plant Growth Algorithms}

In this chapter, the main algorithms of ECOL are reviewed, and special emphasis is given to the algorithms recommended from an earlier literature survey (Carr, 1997). Comparisons are made between existing (in ECOL96) and proposed (for ECOL98AH) algorithms. The model prior to algorithm alterations is termed GRSM96 and the proposed algorithms are described for incorporation into GRSM98AH.

\subsection{GRSM96 Phosphorus Limitation Equations}

Originally, the limiting factor for phosphorus, PFAC, was the ratio of the total phosphorus in the water column of a sub-reach to the phosphorus required by the plants in that same sub-reach. The phosphorus limiting factor (PFAC) did not vary with internal phosphorus concentration already present in the plants so a phosphorus storage factor (STFAC) was an used to account for changes in internal plant phosphorus concentrations.

$$
\text { PFAC }=\frac{\text { PSUPPLY }}{\text { PDEMAND }}+\text { STFAC }
$$

where:

$$
\begin{aligned}
\text { PFAC }= & \text { phosphorus limitation factor (dimensionless) } \\
\text { PSUPPLY }= & \text { water column phosphorus }(\mathrm{g} T \mathrm{TP}) \\
\text { PDEMAND }= & \text { total phosphorus demand by plants }(\mathrm{g} \text { TP) } \\
\text { STFAC }= & \text { fraction of water column phosphorus taken up by plant tissue } \\
& \text { (dimensionless) }
\end{aligned}
$$


Total phosphorus demand by plants is calculated in GRSM96 by summing the required total phosphorus for each species as calculated in [4.2]:

$$
\mathrm{PDEMAND}=\mathrm{PHOTO}_{\max }{ }^{*} \mathrm{~L}_{\mathrm{T}}{ }^{*} \mathrm{~B} * \mathrm{REQFAC}^{*} \mathrm{SAREA} * \Delta \mathrm{T}
$$

where:

$$
\begin{aligned}
\text { PHOTO }_{\max } & \left.=\text { maximum photosynthetic rate ( } \mathrm{g} \text { biomass } / \mathrm{g} \text { biomass }-\mathrm{hr}^{-1}\right) \\
\mathrm{L}_{\mathrm{T}} & =\text { temperature limitation factor (dimensionless) } \\
\mathrm{B} & =\text { biomass density }\left(\mathrm{g} \text { biomass } / \mathrm{m}^{2}\right) \\
\text { PASS } & =\text { phosphorus assimilation ratio }(\mathrm{g} \mathrm{P} / \mathrm{g} \text { biomass) } \\
\mathrm{REQFAC} & =\text { nutrient utilization efficiency factor (dimensionless) } \\
\text { SAREA } & =\text { surface area of sub-reach }\left(\mathrm{m}^{2}\right)
\end{aligned}
$$

The GRSM96 phosphorus limitation factor, PFAC, is linearly related to the total phosphorus in the water column. When total phosphorus levels are high, a frequent occurrence on the Grand and Speed Rivers (PWQMN, MOEE), ECOL96 calculates unreasonably high PFAC values, which are then constrained to a maximum of 1.2.

\subsection{Proposed Changes to Phosphorus Limitation Equations}

The literature suggests that aquatic plant growth does not respond linearly to water column total phosphorus (Auer and Canale, 1982a; Tilman and Kilham, 1976; Rosemarin, 1982) but rather hyperbolically, as derived from Michaelis-Menten kinetics. Most of the aquatic plant models reviewed in the literature used Michaelis-Menten related equations to model plant growth response to nutrients. These included the 
Salvinia molesta model (Toerien et al. 1983), MEGAPLANT (Scheffer et al., 1993), the Australian estuary Cladophora model (Gordon and McComb, 1989), the rooted macrophyte growth model (Wright and McDonnell, 1986a, 1986b), and CE-QUAL-R1 (Collins and Wlosinski, 1989). The following Michaelis-Menten based equation was developed by Auer and Canale (1982a) to model phosphorus uptake by Cladophora in Lake Huron from both external water column phosphorus and internal plant phosphorus (Auer and Canale, 1982a):

$$
\mathrm{P}_{\mathrm{up}}=\mathrm{P}_{\mathrm{upmax}} * \frac{\mathrm{SRP}}{\mathrm{Km}+\mathrm{SRP}} * \frac{\mathrm{Kq}}{\mathrm{Kq}+(\mathrm{Q} 1-\mathrm{Qo})}
$$

where:

$$
\begin{aligned}
\mathrm{P}_{\mathrm{up}}= & \text { phosphorus uptake rate by plant }(\% \mathrm{P} / \mathrm{hr}) \\
\mathrm{P}_{\mathrm{upmax}}= & \text { maximum phosphorus uptake rate by plant }(\% \mathrm{P} / \mathrm{hr}) \\
\mathrm{Km}= & \text { half-saturation constant for uptake as a function of external } \\
& \text { water column phosphorus concentration }(\mu \mathrm{g} / \mathrm{L}) \\
\mathrm{Kq}= & \text { half-saturation constant for uptake as a function of internal } \\
& \text { plant phosphorus concentration }(\% \mathrm{P}) \\
\mathrm{Qo}= & \text { minimum phosphorus concentration for plant }(\% \mathrm{P}) \\
\mathrm{SRP}= & \text { phosphorus concentration in water column, if known use } \\
& \text { Soluble Reactive Phosphorus (SRP), which is plant available }(\mu \mathrm{g} / \mathrm{L}) \\
\mathrm{Q} 1= & \text { phosphorus concentration in plants }(\% \mathrm{P})
\end{aligned}
$$

The half-saturation constants are defined as the amount of phosphorus (internal or external) at which the phosphorus uptake rate is half of the maximum uptake rate. They 
are empirically derived and species-specific. Using this approach, the uptake of phosphorus increases as $\mathrm{P}$ concentrations in the water increase and as $\mathrm{P}$ concentrations in the plant decrease, as illustrated in Figure 4.1 and Figure 4.2.

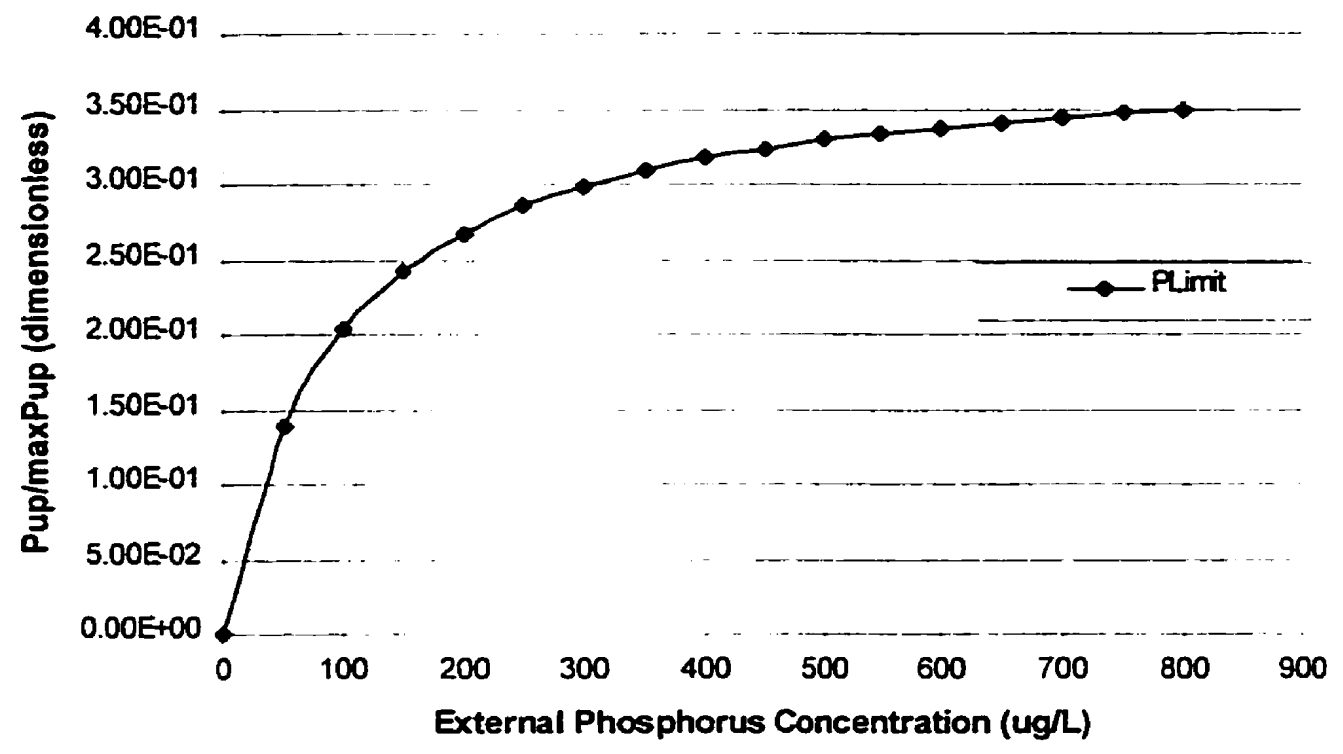

Figure 4.1: External $P$ increased from 0 to $800 \mu \mathrm{g} / \mathrm{L}$ (Internal $P=0.12 \%$ )

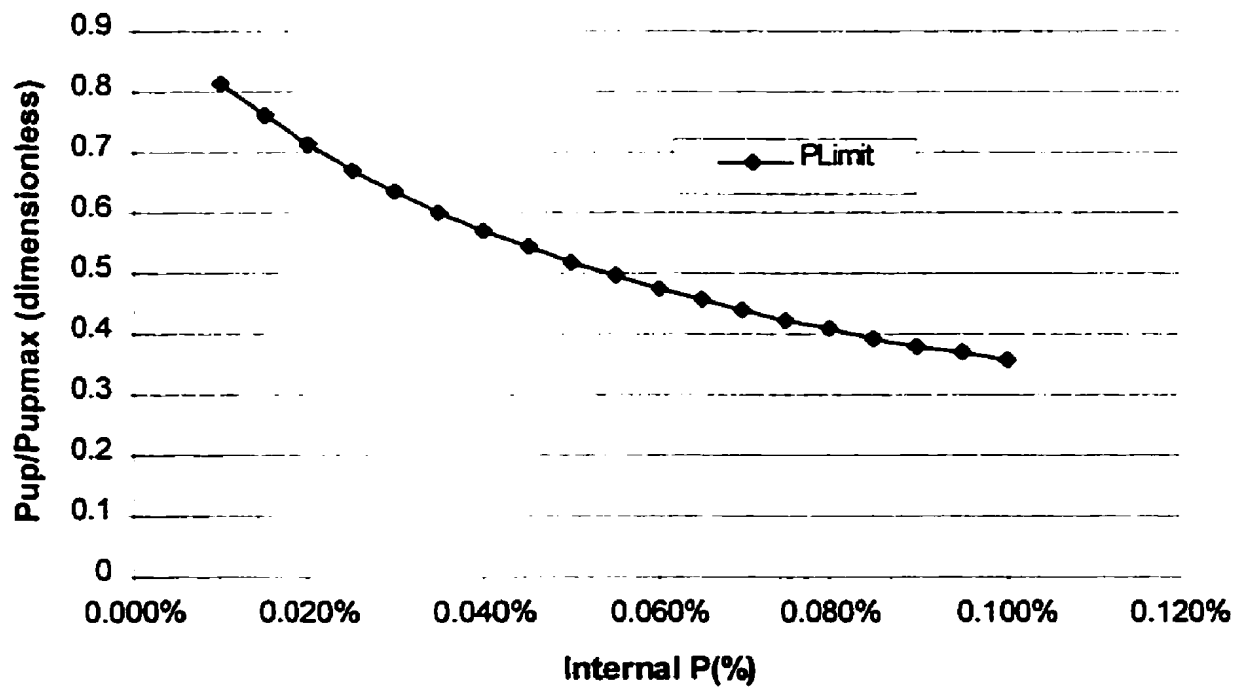

Figure 4.2: Internal $P$ increased from 0 to $0.1 \%$ (External $P=400 \mu \mathrm{g} / \mathrm{L})$ 
The next step was to apply this equation to the model. There was sufficient information in the literature, as seen in Table 4.1, to develop an equation that described the effects of both internal and external phosphorus for the species $C$. glomerata. The equations for calculating the phosphorus limitation factors for this species are (Auer and Canale, 1982a):

$$
\begin{aligned}
\mathrm{Q} 2 & =\mathrm{Q} 1+\left(\mathrm{P}_{\mathrm{up}}-\mathrm{PHOTO}_{\max }^{*} \mathrm{Q} 1\right)^{*} \Delta \mathrm{T} \\
\mathrm{CLADP} & =1-\frac{\mathrm{Q} 0}{\mathrm{Q} 2}
\end{aligned}
$$

where:

$$
\begin{aligned}
\mathrm{Q} 2 & =\text { the new plant phosphorus concentration }(\% \mathrm{P}) \\
\mathrm{Q} 1 & =\text { the last plant phosphorus concentration }(\% \mathrm{P}) \\
\mathrm{P}_{\mathrm{up}} & =\text { plant phosphorus uptake rate }(\% \mathrm{P} / \mathrm{hr}) \\
\text { PHOTO }_{\max } & =\text { maximum photosynthesis/growth rate }\left(\mathrm{hr}^{-1}\right) \\
\mathrm{Qo} & =\text { minimum phosphorus concentration }(\% \mathrm{P}) \\
\text { CLADP } & =\text { phosphorus limiting growth for } C . \text { glomerata (dimensionless) }
\end{aligned}
$$

The other two species did not have sufficient information in the literature to take into account the internal phosphorus concentration and could not be derived from Cladophora data. Plant physiology differences between attached algae like Cladophora and rooted macrophytes, like M. spicatum and P. pectinatus, do not allow for legitimate comparison. Some tentative values for half-saturation constants for external phosphorus were found in the literature as shown in Table 4.1. 
Table 4.1: Phosphorus-related constants reported in the literature

\begin{tabular}{|c|c|c|c|c|c|}
\hline Species & $\begin{array}{l}\text { Km(SRP) } \\
\mu \mathrm{g} / \mathrm{L}\end{array}$ & $\begin{array}{l}\mathbf{K q} \\
\% \mathbf{P P}\end{array}$ & $\begin{array}{l}\text { Qo } \\
\% P\end{array}$ & $\begin{array}{l}\mathbf{P}_{\text {upmax }} \\
\% \mathbf{P} / \mathbf{h r}\end{array}$ & Reference \\
\hline $\begin{array}{l}\text { C. } \\
\text { glomerata }\end{array}$ & 125 & .07 & .05 & 0.188 & $\begin{array}{l}\text { Auer and Canale, } \\
\text { 1982a,1982b }\end{array}$ \\
\hline $\begin{array}{l}\text { C. } \\
\text { glomerata }\end{array}$ & & & & $0.03-0.30$ & Planas et al., 1996 \\
\hline $\begin{array}{l}\text { C. } \\
\text { glomerata }\end{array}$ & $15-86$ & & & $\begin{array}{l}0.006- \\
0.017\end{array}$ & $\begin{array}{l}\text { Lohman and } \\
\text { Priscu, } 1992\end{array}$ \\
\hline $\begin{array}{l}\text { Macrophyte- } \\
\text { periphyton } \\
\text { community }\end{array}$ & 4.7 & & & & $\begin{array}{l}\text { Wright and } \\
\text { McDonnell, 1986b }\end{array}$ \\
\hline $\begin{array}{l}\text { Macrophyte } \\
\text { community }\end{array}$ & 5 & & & & $\begin{array}{l}\text { Collins and } \\
\text { Wlosinski, } 1989\end{array}$ \\
\hline
\end{tabular}

It is recommended, at least until more internal phosphorus response research is conducted, that Michaelis-Menten kinetics, as used in the above aquatic plant models, be used to represent external phosphorus response of $P$. pectinatus and $M$. spicatum:

$$
L_{p}=\frac{S R P}{S R P+K m}
$$

where:

$$
\begin{aligned}
\mathrm{SRP}= & \text { phosphorus concentration in water column: if known, use } \\
& \text { Soluble Reactive Phosphorus (SRP), which is plant-available }(\mu \mathrm{g} / \mathrm{L}) \\
\mathrm{Km}= & \text { half-saturation constant for external } \mathrm{P} \text { concentration, } \mathrm{SRP}(\mu \mathrm{g} / \mathrm{L}) \\
\mathrm{L}_{\mathrm{P}}= & \text { limiting growth factor for phosphorus (dimensionless) }
\end{aligned}
$$

The equations for all three species are given under the block " $U$ of $G$ biomass production equations based on Michaelis-Menten kinetics" in the code of the ECOL98AH subroutine (Appendix A). 


\subsection{GRSM96 Temperature Limitation Equations}

The original equations for the temperature limitation on the optimal growth rates of the three species took into account the maximum and optimal temperatures, and a calibration factor, termed the shape factor. The shape factor and its corresponding unity factor maintain the temperature limit $\left(\mathrm{L}_{T}\right)$ below 1 . The following form of the equation was used for each species and is illustrated in Figure 4.3.

$$
\left.\mathrm{L}_{\mathrm{T}}=e^{[(\mathrm{UniFa} \bullet}(\mathrm{T}-\mathrm{Top})\right] *\left(\left|\frac{\mathrm{Tmax}-\mathrm{T}}{\operatorname{Tmax}-\mathrm{Topt}}\right|\right)^{\text {ShaFac }}
$$

where:

$$
\begin{aligned}
\mathrm{L}_{\mathrm{T}} & =\text { temperature limiting factor }(\text { dimensionless) } \\
\mathrm{T} & =\text { observed stream temperature }\left({ }^{\circ} \mathrm{C}\right) \\
\mathrm{Topt} & =\text { optimum temperature for species growth }\left({ }^{\circ} \mathrm{C}\right) \\
\mathrm{Tmax} & =\text { maximum temperature for species growth }\left({ }^{\circ} \mathrm{C}\right) \\
\text { ShaFac } & =\text { shape factor (dimensionless) } \\
\text { UniFac } & =\text { ShaFac/(Tmax-Topt })\left({ }^{\circ} \mathrm{C}^{-1}\right)
\end{aligned}
$$

The GRSM96 temperature equation accounts for neither a minimum temperature for plant growth, nor a range of optimum temperatures for growth. Because of differing ages of plant tissue and differing tissue type, it is improbable that a plant species in the natural world would have one single temperature that would give a maximum growth rate. Maximum growth is more likely to occur over a range of optimum temperatures. Lastly, qualitatively speaking, the curves in Figure 4.3 appear to be unnaturally symmetrical. 


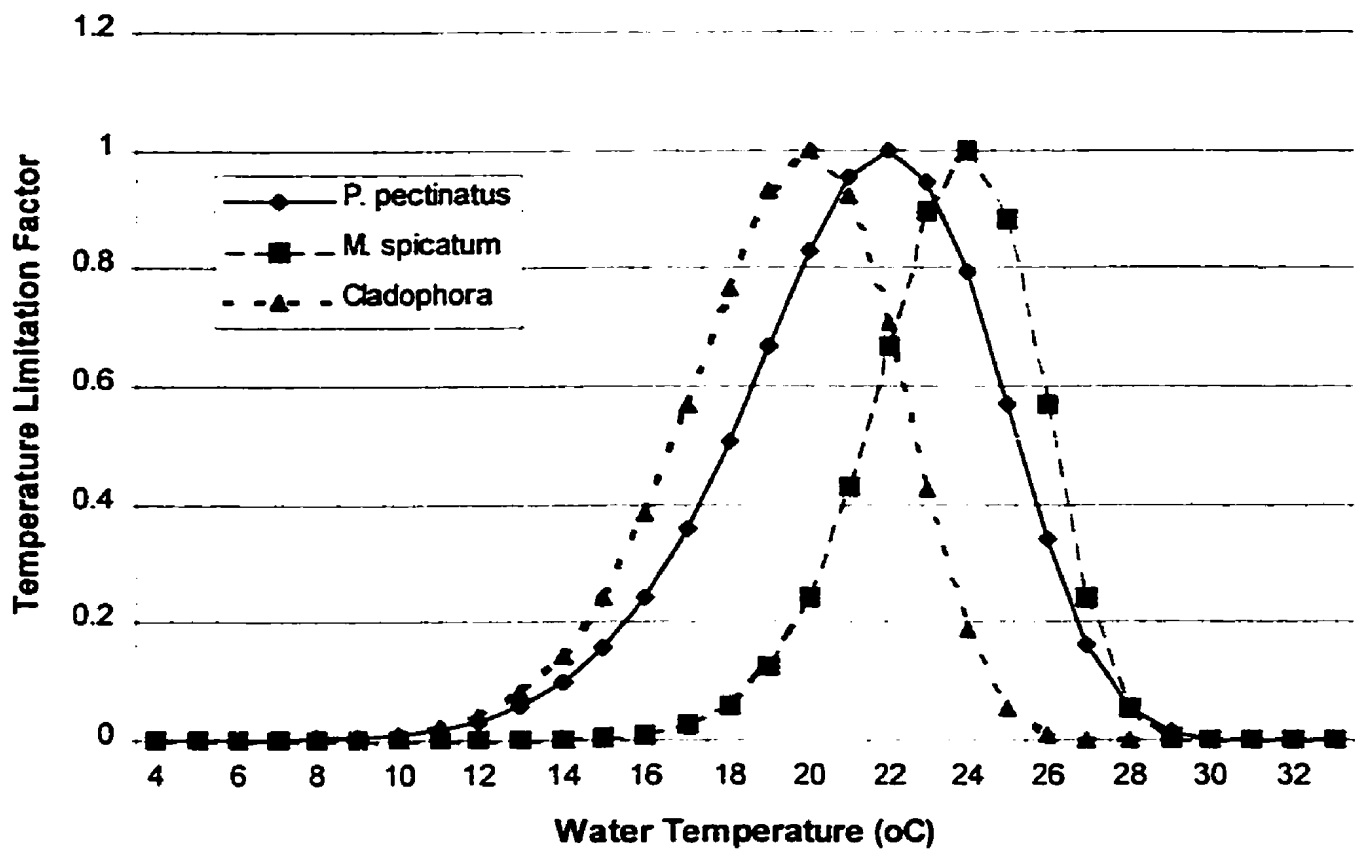

Figure 4.3: GRSM96 temperature limitation factors for the three species modelled

\subsection{Proposed Temperature Limitation Equations}

A newer approach to modelling the temperature limitation factor (Thornton and Lessem, 1978) makes use of both maximum and minimum temperatures, as well as a range of optimum temperatures. The range of optimum temperatures is warranted by the wide range of optimum temperatures in the literature as seen in Table 4.2.

Table 4.2: Temperature ranges in the literature

\begin{tabular}{|l|l|l|l|l|}
\hline Species & $\begin{array}{l}\text { TempMin } \\
\left({ }^{\circ} \mathrm{C}\right)\end{array}$ & $\begin{array}{l}\text { TempOpt } \\
\left({ }^{\circ} \mathrm{C}\right)\end{array}$ & $\begin{array}{l}\text { TempMax } \\
\left({ }^{\circ} \mathrm{C}\right)\end{array}$ & Reference \\
\hline M. spicatum & 5 & 33.6 & 54.7 & Titus and Adams, 1979 \\
\hline M. spicatum & & 30 & & Owttrim and Colman, 1989 \\
\hline M. spicatum & $<10$ & 35 & $>44$ & Madsen and Adams, 1989b \\
\hline P. pectinatus & $<10$ & $25-30$ & -35 & Lester et al., 1988 \\
\hline C. glomerata & & $28-31$ & & Graham et al., 1982 \\
\hline
\end{tabular}




\begin{tabular}{|l|l|l|l|l|}
\hline C. glomerata & 5 & $13-17$ & 30 & Wong et al., 1978 \\
\hline C. glomerata & & 18 & 23.5 & Simpson and Eaton, 1986 \\
\hline C. glomerata & & 20 & & Van et al., 1976 \\
\hline
\end{tabular}

The new form of the temperature limitation factors consists of two curves, one for the temperatures from the minimum to the lower optimum and one for the temperatures for the upper optimum to the maximum. The product of these two curves is the limitation factor for any given temperature (Thornton and Lessem, 1978):

$$
\mathrm{L}_{T}=\mathrm{K}_{\mathrm{A}}(\mathrm{T}) * \mathrm{~K}_{\mathrm{B}}(\mathrm{T})
$$

where:

$$
\begin{aligned}
& \mathrm{K}_{\mathrm{A}}(\mathrm{T})=\frac{\mathrm{k}_{1}{ }^{*} e^{\left[\gamma_{1} \cdot(\mathrm{T}-\mathrm{T} \min )\right]}}{1+\mathrm{k}_{1} *\left\{e^{\left[\gamma_{1}\left(\mathrm{~T}-\mathrm{T}_{\mathrm{min}}\right) \mid\right.}-1\right\}} \\
& \gamma_{1}=\frac{1}{\text { Topt2 }-T \min } * \ln \left(\frac{\mathrm{k}_{2}^{*}\left(1-\mathrm{k}_{1}\right)}{\mathrm{k}_{1}^{*}\left(1-\mathrm{k}_{2}\right)}\right) \\
& \mathrm{K}_{\mathrm{B}}(\mathrm{T})=\frac{\mathrm{k}_{4}{ }^{*} e^{\left[\gamma_{2} \cdot\left(T_{\max }-T\right)\right]}}{1+\mathrm{k}_{4} *\left\{e^{\left[\gamma_{2} \cdot\left(\mathrm{T}_{\max }-T\right)\right]}-1\right\}} \\
& \gamma_{2}=\frac{1}{\operatorname{Tmax}-\operatorname{Topt}^{3}} * \ln \left(\frac{\mathrm{k}_{3}^{*}\left(1-\mathrm{k}_{4}\right)}{\mathrm{k}_{4}^{*}\left(1-\mathrm{k}_{3}\right)}\right) \\
& \mathbf{k}_{1}, \mathbf{k}_{2}, \mathbf{k}_{3}, \mathbf{k}_{\mathbf{4}}=\min \text {, lower opt, upper opt, and max reaction rates (dimensionless) } \\
& (0.1,0.98,0.98,0.1)
\end{aligned}
$$




$$
\begin{aligned}
\mathrm{T} & =\text { observed stream temperature }\left({ }^{\circ} \mathrm{C}\right) \\
\text { Tmin } & =\min \text { temperature }\left({ }^{\circ} \mathrm{C}\right) \\
\text { Topt2 } & =\text { lower optimum temperature }\left({ }^{\circ} \mathrm{C}\right) \\
\text { Topt } 3 & =\text { upper optimum temperature }\left({ }^{\circ} \mathrm{C}\right) \\
\text { Tmax } & =\max \text { temperature }\left({ }^{\circ} \mathrm{C}\right)
\end{aligned}
$$

The temperature limitation factors iilustrated in Figure 4.4 are based on [4.8] to [4.12] and show a broader range of optimum growth temperatures. This may be caused by tissue of varying ages or composition, which would have different associated optimum temperatures.

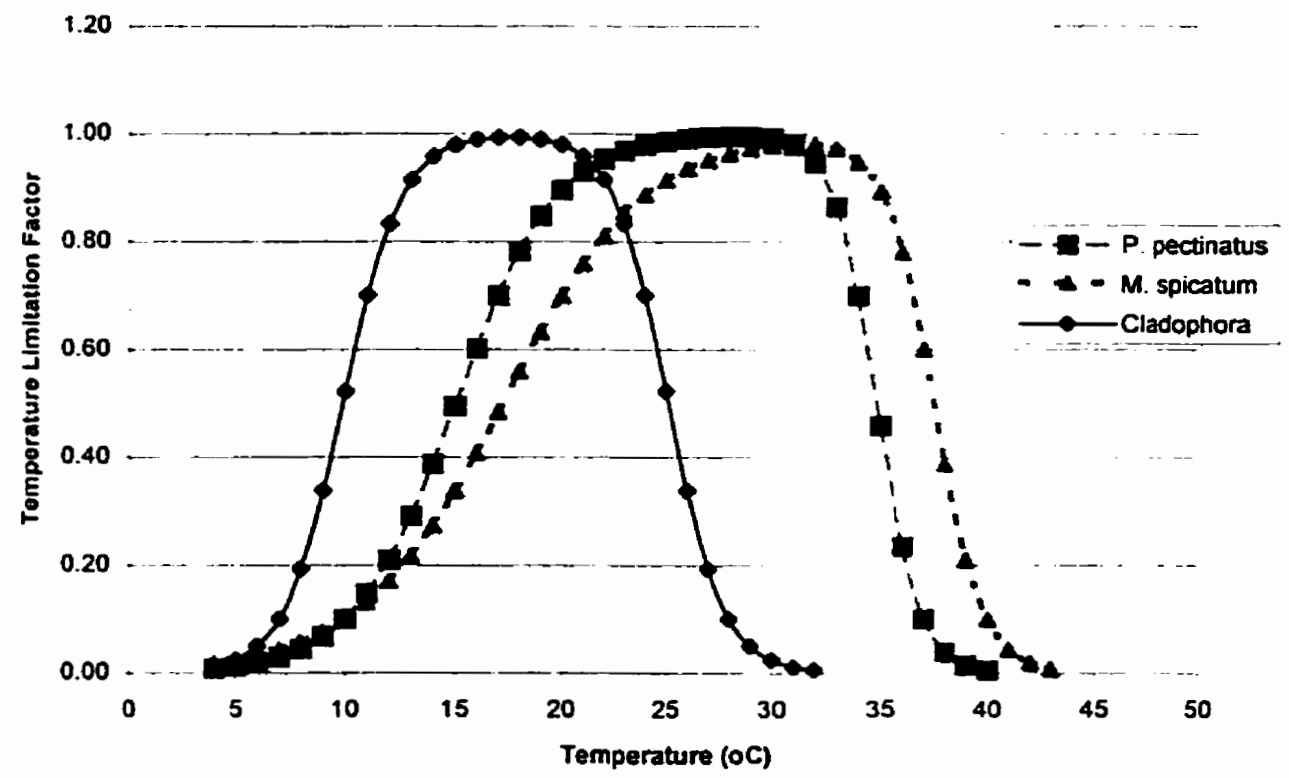

Figure 4.4: Proposed temperature limitation factors for the three species modelled

The new equations for the three species are under the block " $U$ of $G$ Temperature Correction Factors for CLAD, POT, and MILFOIL" in the code of the ECOLAH98 subroutine (Appendix A). 


\subsection{GRSM96 Light Limitation Equations}

A Michaelis-Menten-based algorithm is used to calculate the light limitation factor in both ECOL96 and ECOL98AH. The photosynthetically available light was calculated by the Lambert exponential attenuation formula based on the concentration of suspended solids in the water column and a multiplier, called a self-shading factor. The self-shading multiplier was constant upon reaching a significant biomass density and represents the decrease in light due to in-stream biomass shading. The following is an example of the algorithm to calculate the photosynthetically available light in ECOL96.

$$
\text { PARD }_{\mathrm{SS}}=\mathrm{WATI}^{*} e^{[\text {-KE*(DEPTH-PLANT_DEPTH) }}
$$

where:

$$
\begin{aligned}
\text { PARD }_{\text {SS }}= & \text { photosynthetically available radiation at plant depth due } \\
& \text { to SS (Langleys/min) } \\
\text { WATI = } & \text { amount of light just underneath water surface } \\
& \text { (Langleys/min) } \\
\text { KE }= & \text { light attenuation factor due to suspended solids }\left(\mathrm{m}^{-1}\right) \\
\text { PLANT_DEPTH }= & \text { depth of plant growth }(\text { set at } .9 \mathrm{~m}) \\
\text { DEPTH }= & \text { depth of stream flow }(\mathrm{m})
\end{aligned}
$$

The shading caused by existing plant biomass was accounted for by the application of a shading factor to the photosynthetically available light (after the attenuation by SS) to calculate a total value of photosynthetically available light shown in [4.14] and [4.15]. 
PARD $_{\text {TOT }}=$ PARD $_{S S} *$ SHADE

SHADE $=\cos ($ B/SHADE_FACT $)$

where:

$$
\begin{aligned}
\text { PARDTOT }= & \text { photosynthetically available radiation at plant depth due to } \\
& \text { SS and plant biomass }(\text { Langleys } / \mathrm{min}) \\
\text { SHADE }= & \text { shading multiplier for species (dimensionless) } \\
\text { SHADE_FACT }= & \text { shade factor for species }\left(\mathrm{g} \text { biomass } / \mathrm{m}^{2}\right) \\
\mathrm{B}= & \text { plant biomass density }\left(\mathrm{g} \text { biomass } / \mathrm{m}^{2}\right)
\end{aligned}
$$

At high biomass densities, SHADE becomes an unrealistic negative value. The trigonometric relationship is not documented in any of the models found in the literature and the scientific reasoning behind the algorithm is unclear.

\subsection{Proposed Light Limitation Equations}

The proposed method for ECOL98AH of calculating light limitation factors maintains the Michaelis-Menten relationship for the limitation factor. However, the ability of plant biomass density to attenuate light is modelled in the same manner as the suspended solids. A weedbed light attenuation coefficient and plant density are introduced to the Lambert attenuation equation [4.16]: 
PARD $_{\text {TOT }}=$ WATI $^{*} e^{-[\text {KE*(DEPTH-PLANT_DEPTH }+ \text { KW*B] }}$

where:

$$
\mathrm{Kw}=\text { weedbed light attenuation coefficient }\left(\mathrm{g} \text { biomass } / \mathrm{m}^{2}\right)
$$

The proposed equation calculates photosynthetically available light at the top of the plant growth, where most photosynthetic activity would occur. The value for the weedbed light attenuation coefficient is obtained from the literature and represents the dominant species in that particular reach. Species-specific $\mathrm{Kw}$ values reported in the literature are presented in Table 4.3.

Table 4.3: Light extinction coefficients within weedbeds.

\begin{tabular}{|l|l|l|}
\hline Species & $\mathbf{K w}\left(\mathbf{m}^{2} / \mathbf{g}\right.$ biomass $)$ & Source \\
\hline P. pectinatus & 0.024 & Van der Bijl et al., 1989 \\
\hline P. pectinatus & 0.008 & Westlake, 1964 \\
\hline M. spicatum & 0.0083 & Owens et al., 1967 \\
\hline M. spicatum & 0.006 & Titus and Adams, 1979 \\
\hline Cladophora sp. & 0.024 & $\begin{array}{l}\text { Bruskin, 1984 (cited in Sand- } \\
\text { Jensen et al., 1989) }\end{array}$ \\
\hline
\end{tabular}

Aquatic models by Wright and McDonnell (1986b) and van der Bijl et al. (1989) used this type of algorithm in their model of macrophyte growth to calculate light attenuation from both suspended solids and weedbed density. 


\subsection{Proposed Dissolved Inorganic Carbon Equation}

ECOL96 does not model plant growth response to dissolved inorganic carbon (DIC). Carr's literature review recommended an addition of a limitation factor based on DIC in the water column. Dissolved inorganic carbon was identified as a limiting factor for photosynthesis for submerged aquatic plants (Sand Jensen, 1983; Barko et al., 1986). Low values of DIC in the water column are attributed to the slow rates of diffusion of gases into water compared to air and the low equilibrium concentration of $\mathrm{CO}_{2}$ in water. A Michaelis-Menten type rectangular hyperbola is used to describe plant growth response to DIC in M. spicatum growing in Italian lakes (Adams et al., 1978) and macrophytes growing in shallow stagnant water (Ondok and Pokorny, 1987). Stevenson (1988) suggested that the DIC limitation is not a significant factor for macrophyte production in rivers because of turbulence. Compared to other waterbodies such as lakes, rivers typically have better mixing of DIC and higher reaeration rates (to introduce $\mathrm{CO}_{2}$ to the water column) to provide sufficient DIC to aquatic plants.

\subsection{Reviewing the Literature Survey}

An examination of the proposed algorithms was undertaken to decide which algorithms were suitable for incorporation into ECOL96. Michaelis-Menten kinetics are chosen to model plant growth limitation to phosphorus because the equation is more biologically sound, as it is based on observed enzymatic functions. Furthermore, Michaelis-Menten 
kinetics is the standard algorithm type used to calculate phosphorus limitations in the aquatic plant models reviewed. Thorton and Lessem (1978) temperature aigorithms are chosen to model temperature effects on photosynthesis because of the flexibility of the algorithms. Using Thortom and Lessem equations allow incorporation of ranges for optimum temperatures, values for both maximum and minimum temperatures, and selection of rates for each marker temperature. Furthermore, this algorithm is based on the $Q_{10}$ equation, a well-recognized biological temperature response equation. The proposed light attenuation equations are selected to standardize the methodology used by ECOL98AH to attenuate light in the water column by any material. Proposed DIC equations are not selected because there is a lack of DIC data. Furthermore, some studies have demonstrated that DIC is not limiting in rivers, where there is more mixing and air exchange.

\subsection{Incorporating the New Algorithms}

All the proposed algorithm changes, except those for DIC, are incorporated in to the FORTRAN code of ECOL96. The parameter values cited in Carr's review (1997) are used to determine general ranges for parameters during calibration of the model.

As requested by the GRCA, all the changes made in ECOL are clearly documented in the code. That is, all new code is preceded by a comment indicating a 'University of Guelph, 1998' change and all code that was removed was simply commented out as 'PreUniversity of Guelph 1998' code. In addition, every new parameter and algorithm incorporated into ECOL96 is labelled and identified by a preceding comment. For 
further clarification, all other commented-out code in ECOL96 is labelled to mark it as not relating to any changes carried out through the University of Guelph in 1998. 


\section{Methodology}

\subsection{Model Preparation}

Model preparation involved two main activities: understanding the model and overcoming the numerous obstacles in using the input data. Set in a Windows environment, GRSM96 was relatively easy to run and to view results. However, various minor issues and several major obstacles were identified in the model preparation for this thesis. The format and content of some of the input files were difficult to interpret, even with the manual. Meticulous input was necessary to accommodate the Fortran file structure. As a result, the input files contained many small errors that required identification and correction before GRSM96 ran successfully. In addition, some of the menu items displayed by GRSM are not currently functioning, including 'exceedences' analysis, minimising of graphical plots, and the removal of an individual plot from the graph.

The limitation most relevant to this thesis work, and to any analytical efforts on GRSM, was the lack of flexibility in interpreting results. Results may be viewed or graphed in GRSM, which allowed a generalized, yet adequate, representation of model results. However, GRSM is unable move beyond this simple display of the results because the GRSM output files are of binary type and can not be exported to another application for analysis. GRSM does perform some limited analysis on the computed results but it lacks the ability to perform critical model analysis, such as a numerical comparison of observed 
data to computed results. Furthermore, the observed DO data were also in binary form. This posed a significant challenge to a numerical approach to the calibration process. The source coding of GRSM, written in FORTRAN, was another major obstacle. The organization of the code in parts of the program was poor, and documentation and explanation, both in the code and in the manuals, were often missing. Because of the difficulties in manipulating and interpreting results from GRSM, an alternative program (called ECOLAH) to further test new algorithms for ECOL98AH was written. A description of this program is given in Section 5.4 .

\subsection{Calibration}

An initial calibration was performed on ECOL98AH with the new algorithms and parameters that had been chosen from the literature survey recommendations. Simulated dissolved oxygen from a 1995 data set for GRSM98AH was used to test against observed dissolved oxygen. In 1995, there were three locations in the modelled system where DO was measured every two hours for an extended period: 1) Wellington Rd 32 on the Speed River, 2) Bridgeport on the Grand River and 3) Blair on the Grand River. These three stations provided three data sets of observed dissolved oxygen for 1995. The Speed River station demonstrated the most varied DO pattern over the growing season and was chosen for an initial calibration. It was presumed that a more variable dissolved oxygen pattern would indicate varying growth patterns for aquatic plants, which would provide more clues for correct calibration. 
There was not sufficient data to calibrate the 1995 model using aquatic plant biomass and therefore the calibration could not be species-specific, other than the given ranges in the literature, with respect to changing parameter values. It was recognized that a simulated DO time series which appeared to mimic the observed DO time series could be the result of different plant species growing at different times, but creating the same DO pattern. An inherent inaccuracy was noted in using dissolved oxygen for calibration. Since GRSM does not allow for numerical comparisons between observed data and simulated results, an initial qualitative assessment was carried out in increments of ten percent. Satisfactory computed results were designated to be between seventy to eighty percent in agreement with observed results. With the help of programming experts at the University of Guelph (Dr. Dony), the binary computed and observed DO data were converted to ASCI format to perform a numerical comparison. The standard error of estimation (SEE) (James, 1994), average error (AE) and relative error (RE) were computed on the complete data set as described below:

$$
\begin{aligned}
& \mathrm{SEE}=\left[\frac{\sum_{i=1}^{\mathrm{n}}\left(\mathrm{ODO}_{i}-\mathrm{CDO}_{i}\right)^{2}}{\mathrm{n}-2}\right]^{\frac{1}{2}} \\
& \mathrm{AE}=\frac{\mathrm{SEE}}{\overline{\mathrm{ODO}}} * 100 \%
\end{aligned}
$$




$$
\mathrm{RE}=\frac{(\overline{\mathrm{ODO}}-\overline{\mathrm{CDO}})}{\overline{\mathrm{ODO}}} * 100 \%
$$

where:

$$
\begin{aligned}
\mathrm{ODO} & =\text { observed } \mathrm{DO} \text { value } \\
\mathrm{CDO} & =\text { computed } \mathrm{DO} \text { value } \\
\mathbf{n} & =\text { number of paired values }
\end{aligned}
$$

The observed DO at the Speed River station was compared with computed DO for subreach 10 in GRSM98AH, which runs from Wellington Road to Glen Christie. After numerous major adjustments and a high degree of refinement, the values of the new parameters and the arrangement of the algorithms were tentatively set based on the observed DO data from the Speed River station. Observed DO from the Bridgeport station was compared to computed DO from sub-reach 2, which represents the sub-reach on the Grand River from Laurel Creek to the CNR Bridge. Observed DO from the Blair station was compared to computed DO from sub-reach 6 , which represents the sub-reach on the Grand River from the 401 to the Speed River. The associated computed biomass densities for each of these sub-reaches were then plotted for comparison. The DO observed data from the other two stations were used to calibrate GRSM98AH for the corresponding sub-reaches. The initial tentative input data were adjusted slightly to produce a better fit for the observed DO curve at all three stations. In particular, the plant inhibition factors were adjusted during calibration, on a monthly basis, at the Blair and Bridgeport stations, to capture potential grazing pressures in the later summer months. 


\subsection{Sensitivity Analysis}

Sensitivity tests were carried out on all changed parameters in ECOL98AH on a speciesspecific basis where possible. The methodology for all the non-temperature-related parameters was to decrease and increase their calibrated values by a certain percentage. Where meaningful, all these parameters were increased and decreased by three percentage values each. The simulated peak biomass of the species-specific parameters were recorded for the given plant species while the simulated peak biomass values for all three of the plant species were recorded for the non-species-specific parameters. Therefore the sensitivity analysis for the species-specific parameters was based on six peak biomass values while the non-species-specific parameters had eighteen peak biomass values.

A ratio, identified here as the 'sensitivity ratio', was developed for the percent change in the peak biomass compared to the percent change in the parameter. Therefore if the senstivity ratio was one, a certain percent change in the given parameter caused the same percent change in the peak biomass

Unlike mass or energy, temperature is not an absolute value and is measured on a relative scale. Temperature-related parameters were dealt with by increasing the temperature values by degrees Celsius and comparing this change to the change in peak biomass. These sensitivity ratios were only compared against other temperature-related parameters. 


\subsection{Model Functionality Testing}

Following development of a general understanding of the sensitivity of each parameter, the next step was to investigate how the model behaved under specifically altered conditions. These altered conditions included increasing and decreasing the flows, temperatures, solar radiation, nitrogen levels, and phosphorus levels. All changes were chosen to be realistic and reasonable. Initially, this model functionality testing was to be completed in GRSM98AH, however two main factors contributed to choosing an alternative, and complementary, process for testing the durability of GRSM98AH. These factors were: 1) the innate complexity of GRSM and 2) the poor quality of the documentation in the code making it difficult to predict the outcome of a change in one parameter.

For instance, one of the model functionality tests involved increasing the total phosphorus levels in the river by a certain amount. In order to achieve a known increase, mass balances on all the input flows and the phosphorus concentrations would have to be known for every time step at all locations. To add confusion to this labour-intensive task, the phosphorus concentrations are chosen randomly, as described in Section 2.2.3, and the phosphorus levels would also be influenced by uptake and release of phosphorus from the growing plants. The lack of proper documentation both in the code and in the manual, especially with respect to ECOL, led to a lack of confidence in manipulating the model for these tests. 
Therefore, a stand-alone model, based on ECOL98AH, was built to simulate simpler conditions. The code was again in FORTRAN but was organized in a more rational and comprehensive manner than the ECOL found in GRSM. This model was called ECOLAH and will be referred to as such for the remainder of this thesis. The code used in ECOLAH, and relevant input parameters are in Appendix B. The main processes in ECOL98AH were separated into subroutines, and any complicated processes within these subroutines were broken down again into more subroutines. All the subroutines in the final version of ECOLAH were less than a page long, were coded in a simple, straightforward manner, and were fully documented. ECOLAH was built to behave as ECOL does in GRSM but within only one reach, with constant inputs of flows and water quality parameters.

There was a need to provide evidence that ECOLAH and the ECOL98AH in GRSM98AH were computing equivalent results given that the input data were the same. To prove that ECOLAH was truly a simplistic version of the ECOL98AH in GRSM98AH, one simple case for GRSM98AH was chosen for comparing both models. To simplify GRSM98AH, some re-coding was required to set certain variables, such as phosphorus concentrations, nitrogen concentrations and flows to constants. Water quality parameters were chosen from the ranges already presented in GRSM96's water quality probability distribution curves. In addition, all the reaches in GRSM96 were inputted as having identical characteristics. These characteristics were then applied to the one reach in ECOLAH and the same constants set in GRSM98AH were inputted into ECOLAH. 
The results from the two models were compared by changing the inputs of the temperature and light series, changing the nutrients and suspended solids levels and changing the flows. The two sets of results were plotted on an $\mathrm{XY}$ graph to confirm a one-to-one ratio. Many corrections were made to ECOLAH before the model was satisfactorily mimicking the performance of ECOL98AH in GRSM98AH. The results of these tests were also used to test the realism of ECOL98AH. The tests in Table 5.1 were performed on ECOLAH:

Table 5.1: Changes to input parameters in model functionality testing

\begin{tabular}{|l|l|l|l|}
\hline Input Parameter & Original Value & \multicolumn{1}{|c|}{ Decrease } & \multicolumn{1}{c|}{ Increase } \\
\hline Air Temperature & 1995 time series & $\begin{array}{l}\text { all values by } 1 \text { and } \\
2^{\circ} \mathrm{C}\end{array}$ & $\begin{array}{l}\text { all values by } 1 \text { and } \\
2^{\circ} \mathrm{C}\end{array}$ \\
\hline Solar Radiation & 1995 time series & all values by $10 \%$ & all values by $10 \%$ \\
\hline Phosphorus & $0.1 \mathrm{mg} / \mathrm{L}$ & to $0.05 \mathrm{mg} / \mathrm{L}$ & to $0.5 \mathrm{mg} / \mathrm{L}$ \\
\hline Nitrates & $1.52 \mathrm{mg} / \mathrm{L}$ & to $0.9 \mathrm{mg} / \mathrm{L}$ & to $2 \mathrm{mg} / \mathrm{L}$ \\
\hline Suspended Solids & $4.57 \mathrm{mg} / \mathrm{L}$ & $20 \mathrm{mg} / \mathrm{L}$ & $0.07 \mathrm{mg} / \mathrm{L}$ \\
\hline Flow & $12 \mathrm{~m}^{3} / \mathrm{s}$ & To $6 \mathrm{~m}^{3} / \mathrm{s}$ & to $24 \mathrm{~m}^{3} / \mathrm{s}$ \\
\hline
\end{tabular}

More detailed testing was performed in areas where either the results required a more complex explanation or when the realism of the results became questionable. These included changes to temperature, solar radiation, suspended solids, and phosphorus inputs. 


\section{Results}

\subsection{Calibration}

An $80 \%$ agreement between observed and computed DO of was obtained for the initial calibration based on the Speed River station. The calibration results for the Speed River sub-reach are piotted in Figure 6.1 and the associated biomass densities for sub-reach 10 are presented in Figure 6.2. The same input data used in the initial calibration, with a slight change to the $P$. pectinatus plant inhibition value for August, were used to compare the observed and computed DO for the Bridgeport station, as shown in Figure 6.3. The associated biomass densities for sub-reach 2 are presented in Figure 6.4. The Blair station was least consistent, using the input data from the initial calibration, between observed and computed DO. The plant inhibition factors for sub-reach 6 were adjusted to produce a better fit of the DO curves. Figure 6.5 presents the DO calibration results for sub-reach 6 and the associated biomass densities are plotted in Figure 6.6. The average error between all observed and computed DO was $19.6 \%$ with a standard error of estimate for DO of $1.86 \mathrm{mg} / \mathrm{L}$. The relative error was $7.7 \%$. Therefore, the model achieved a satisfactory agreement of $80 \%$ between observed and computed DO. 

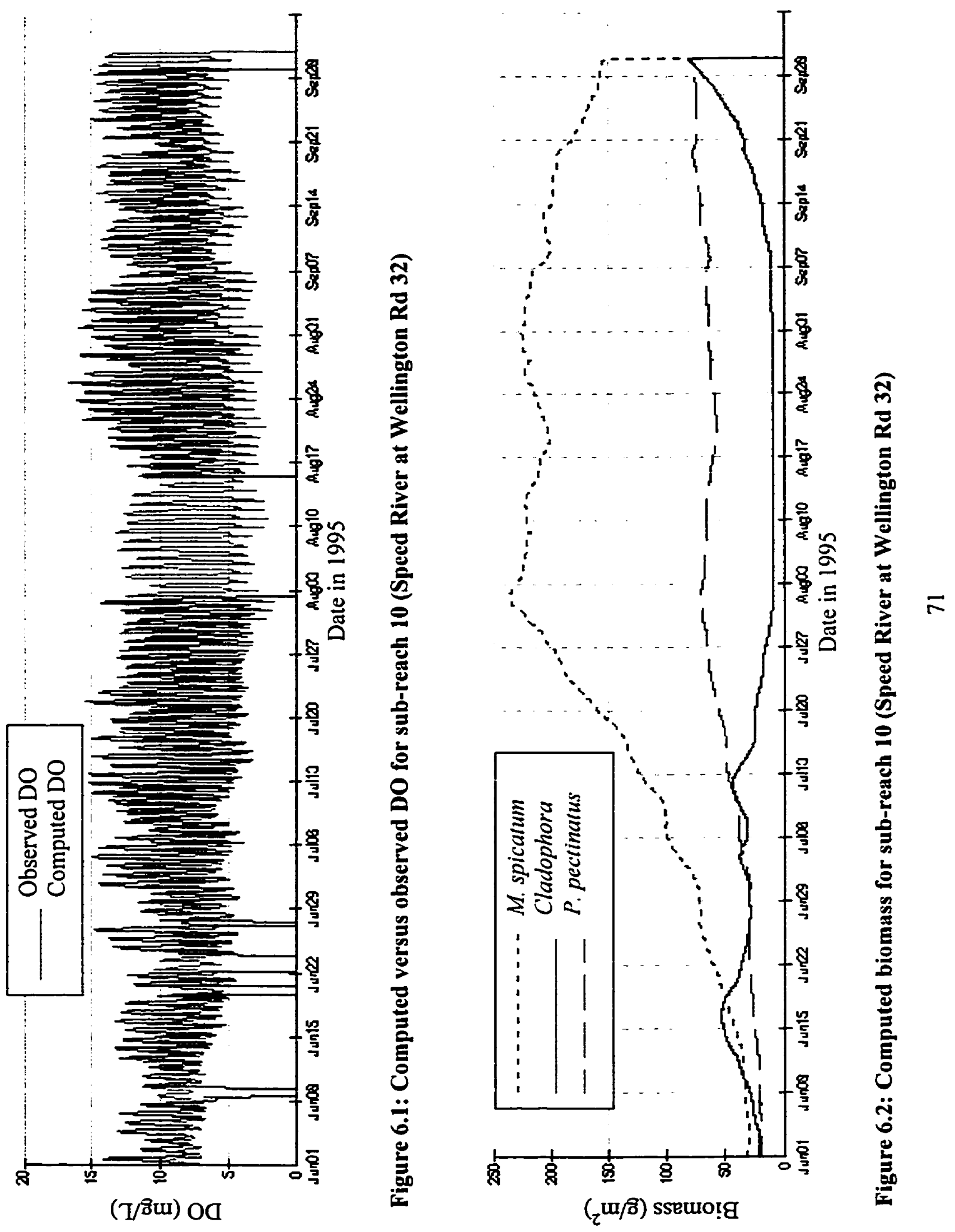

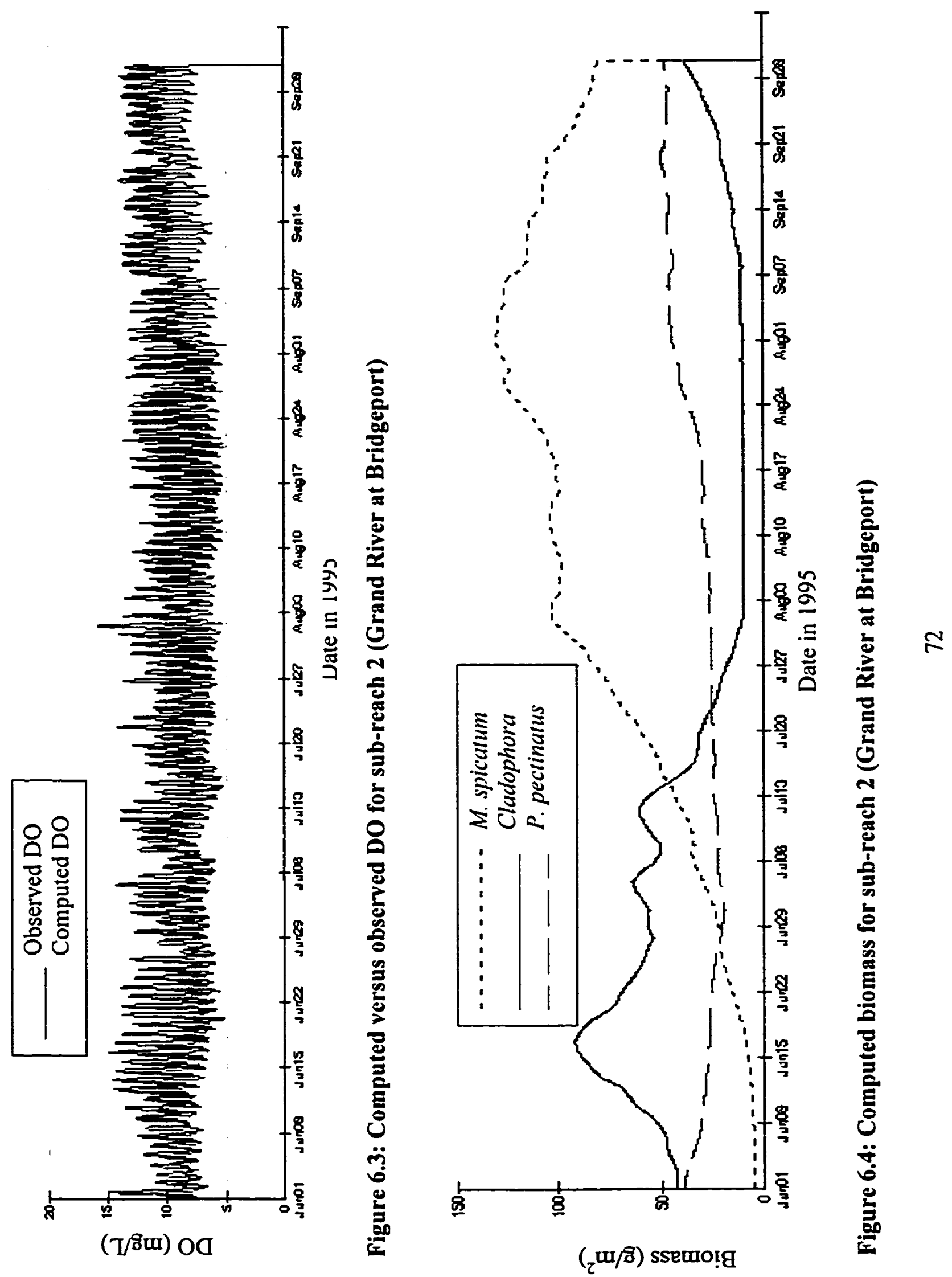

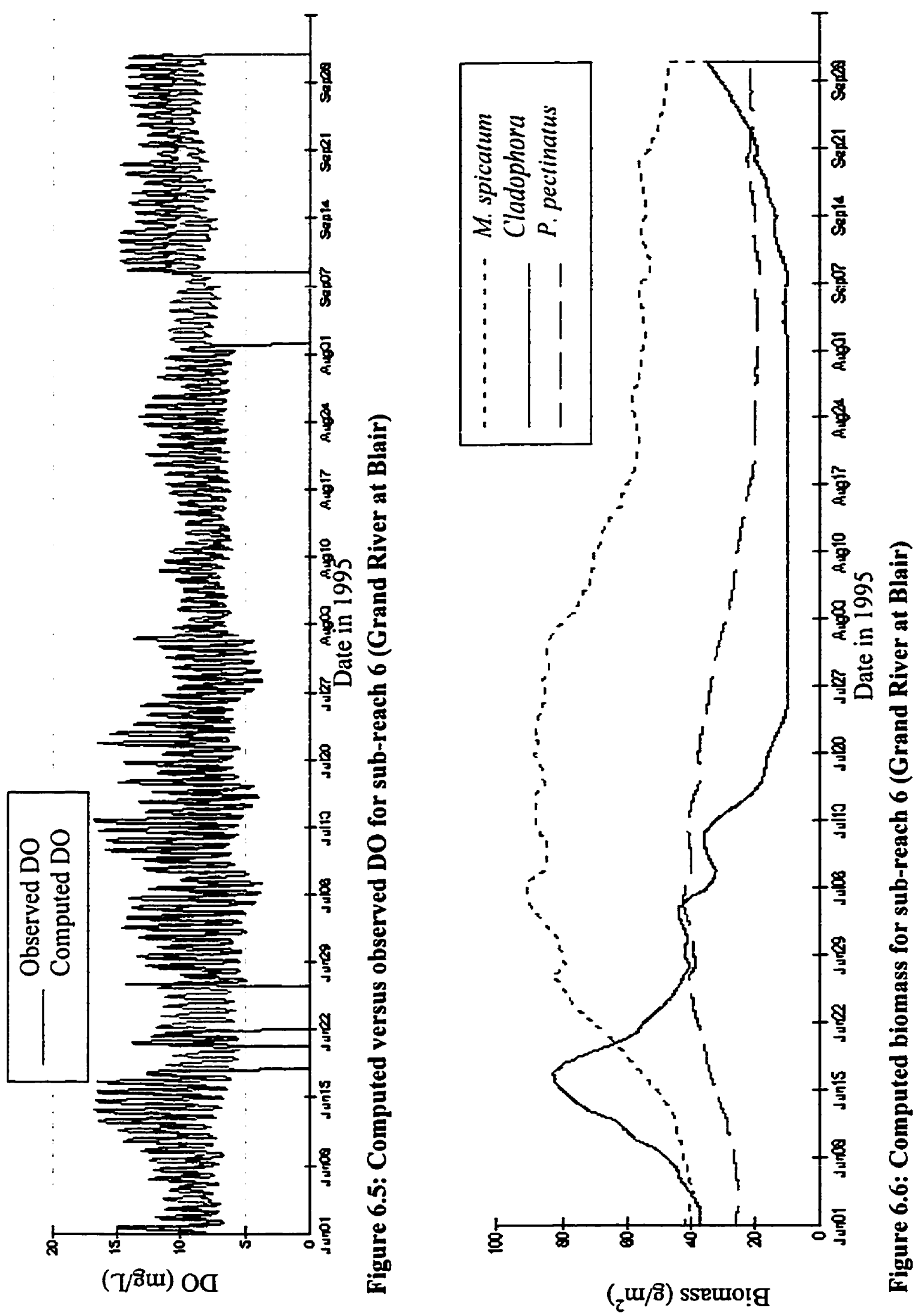
Tables 6.1 to 6.3 indicate the changes, to account for potential grazing effects, made to the plant inhibition factors by species and month.

Table 6.1: Plant inhibition factors for Cladophora

\begin{tabular}{|l|l|l|l|l|l|l|}
\hline Sub-reach & $\begin{array}{l}\text { Original/ } \\
\text { Grazing }\end{array}$ & June & July & August & September & Changed \\
\hline 2 & original & 1.0 & 1.0 & 1.0 & 1.0 & No \\
\hline 2 & grazing & 1.0 & 1.0 & 1.0 & 1.0 & \\
\hline 6 & original & 1.0 & 1.2 & 1.0 & 1.2 & \multirow{2}{*}{ Yes } \\
\hline 6 & grazing & 1.0 & 0.9 & 0.9 & 1.0 & \\
\hline 10 & original & 1.0 & 1.2 & 1.0 & 1.2 & No \\
\hline 10 & grazing & 1.0 & 1.2 & 1.0 & 1.2 & \\
\hline
\end{tabular}

Table 6.2: Plant inhibition factors for $P$. pectinatus

\begin{tabular}{|l|l|l|l|l|l|l|}
\hline Sub-reach & $\begin{array}{l}\text { Original/ } \\
\text { Grazing }\end{array}$ & June & July & August & September & Changed \\
\hline 2 & original & 0.7 & 1.0 & 1.4 & 1.0 & Yes \\
\hline 2 & grazing & 0.7 & 1.0 & 1.2 & 1.0 & \\
\hline 6 & original & 1.0 & 1.15 & 1.2 & 1.1 & Yes \\
\hline 6 & grazing & 0.95 & 0.9 & 0.95 & 1.0 & \\
\hline 10 & original & 0.9 & 1.1 & 1.0 & 1.0 & No \\
\hline 10 & grazing & 0.9 & 1.1 & 1.0 & 1.0 & \\
\hline
\end{tabular}

Table 6.3: Plant inhibition factors for $M$. spicatum

\begin{tabular}{|l|l|l|l|l|l|l|}
\hline Sub-reach & $\begin{array}{l}\text { Original/ } \\
\text { Grazing }\end{array}$ & June & July & August & September & Changed \\
\hline 2 & original & 1.2 & 1.17 & 1.06 & 0.9 & \multirow{2}{*}{ No } \\
\hline 2 & grazing & 1.2 & 1.17 & 1.06 & 0.9 & \\
\hline 6 & original & 1.15 & 1.1 & 1.0 & 0.9 & Yes \\
\hline 6 & grazing & 1.0 & 0.9 & 0.9 & 1.0 & \\
\hline 10 & original & 1.0 & 1.1 & 0.95 & 0.9 & \multirow{2}{*}{ No } \\
\hline 10 & grazing & 1.0 & 1.1 & 0.95 & 0.9 & \\
\hline
\end{tabular}

Table 6.4 presents the final input parameters values used in the calibration of GRSM98AH. 
Table 6.4: GRSM98AH input parameters used in final calibration run

\begin{tabular}{|l|l|c|l|}
\hline Parameter Name & \multicolumn{1}{|c|}{ Description } & Value & \multicolumn{1}{|c|}{ Units } \\
\hline CGMEW & Maximum photosynthesis & 0.024 & g biomass/ \\
PPMEW & rates & 0.020 & g biomass-hr \\
EPMEW & & 0.025 & \\
\hline CGR20 & Unit respiration rates & 0.003 & g biomass/ \\
PPR20 & & 0.003 & g biomass-hr \\
EPR20 & & 0.003 & \\
\hline KMLC & Half-saturation constant & 0.09 & Langleys/min \\
KMLP & for light & 0.09 & \\
KMLE & & 0.117 & \\
\hline TEMPMAXC & Maximum temperature & 28 & ${ }^{\circ} \mathrm{C}$ \\
TEMPMAXP & for growth & 37 & \\
TEMPMAXM & & 54 & \\
\hline TEMPMINC & Minimum temperature for & 7 & ${ }^{\circ} \mathrm{C}$ \\
TEMPMINP & growth & 10 & \\
TEMPMINM & & 10 & \\
\hline TEMPOPT2C & Lower optimum & 15 & ${ }^{\circ} \mathrm{C}$ \\
TEMPOPT2P & temperature for growth & 24 & \\
TEMPOPT2M & & 30 & \\
\hline TEMPOPT3C & Upper optimum & 20 & ${ }^{\circ} \mathrm{C}$ \\
TEMPOPT3P & temperature fore growth & 31 & \\
TEMPOPT3M & & 35 & \\
\hline K1C,K1P,K1M & Minimum and maximum & 0.1 & dimension- \\
K4C,K4P,K4M & temperature reaction rates & & less \\
\hline K2C,K2P,K2M & Optimum temperature & 0.98 & dimension- \\
K3C,K3P,K3M & reaction rates & less \\
\hline KWC & Light attentuation from & 0.0083 & m/g \\
KWP & weedbed coefficient & 0.024 & \\
KWM & & 0.0083 & \\
\hline KMPC & Half-saturation constant & 83 & $\mu \mathrm{g} / \mathrm{L}$ \\
KMPP & for external P & 8 & \\
KMPE & & 8 & \\
\hline KqC & falf-saturation constant & 0.07 & $\% \mathrm{P}$ \\
\hline Qo & Minimum internal P & 0.02 & $\% \mathrm{P}$ \\
\hline ROWPMAX & Maximum P uptake rate & 0.3 & $\% \mathrm{P} / \mathrm{hr}$ \\
\hline KE_CONSTANT & Light attenuation (SS) & 1.111 & $1 / \mathrm{m}$ \\
& constant & & \\
\hline KE_SLOPE & Light attenuation (SS) & 0.093 & Langleys/mg- \\
& slope & & $\mathrm{m}$ \\
\hline
\end{tabular}




\subsection{Sensitivity Analysis}

The sensitivity analysis for each parameter, except those relating to temperature, is summarized in Table 6.5. The value used in comparing the sensitivity of model results to change in the parameters in Table 6.5 was the ratio of the percent change in biomass to the percent change in the given parameter, called the sensitivity ratio. For non-speciesspecific parameters, the sensitivity ratios for the three species were averaged. For example:

$$
\begin{aligned}
& \text { O2ASSIM sensitivity ratio }_{P \text { pectunatus }}=\frac{\% \text { change in } P \text {. pectinatus biomass }}{\% \text { change in O2ASSIM }} \\
& \text { O2ASSIM sensitivity ratio }_{M-\text { spcatum }}=\frac{\% \text { change in } M \text {.spicatum biomass }}{\% \text { change in O2ASSIM }} \\
& \text { O2ASSIM sensitivity ratio }_{\text {Cludophoru }}=\frac{\% \text { change in } \text { Cladophora biomass }}{\% \text { change in O2ASSIM }}
\end{aligned}
$$

The sensitivity ratio for each species is the mean of the six sensitivity tests calculated for each of the three parameters:

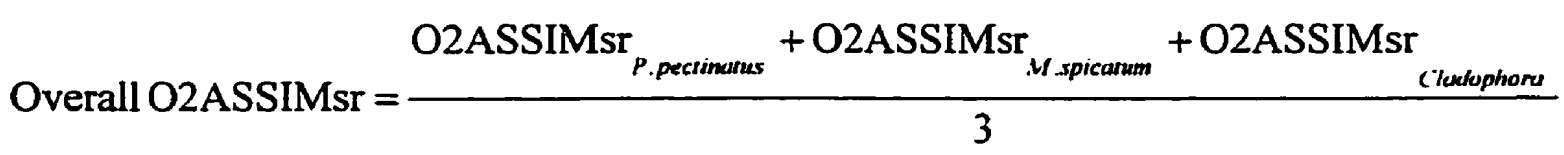

The sensitivity ratios for the species-specific parameters were averaged to give one result for comparison to non-species-specific parameters. For example: 


$$
\begin{aligned}
& \mathrm{K}_{\mathrm{m}} \text { Light sensitivity ratio } \text { P.pectmanus }=\frac{\% \text { change in P.pectinatus biomass }}{\% \text { change in } \mathrm{K}_{\mathrm{m}} \text { Light }_{P \text {.pectinenus }}} \\
& \mathrm{K}_{\mathrm{m}} \text { Light sensitivity ratio }{ }_{M \text {-spicarum }}=\frac{\% \text { change in } M \text {-spicatum biomass }}{\% \text { change in } \mathrm{K}_{\mathrm{m}} \text { Light }_{M \text { spicarum }}} \\
& \mathrm{K}_{\mathrm{m}} \text { Light sensitivity ratio }{ }_{\text {cludophora }}=\frac{\% \text { change in Cladophora biomass }}{\% \text { change in } \mathrm{K}_{\mathrm{m}} \text { Light }_{\text {Cladophora }}}
\end{aligned}
$$

The sensitivity ratios for each species and parameter are the mean of the six sensitivity results for each of the three parameters:

$\mathrm{K}_{\mathrm{m}}$ Light sensitivity ratio $=\frac{\mathrm{K}_{\mathrm{m}} \text { Lightsr }_{P \text {. pectinerus }}+\mathrm{K}_{\mathrm{m}} \text { Lightsr }_{\text {M.spicarum }}+\mathrm{K}_{\mathrm{m}} \text { Lightsr }_{\text {Clucophora }}}{3}$

The process in ECOL98AH associated with the given parameter and the species specificity is indicated in Table 6.5. All these parameters, and their respective equations, are described in more detail in Chapter 4. In addition, in Table 6.4, each parameter is ranked in 3 categories: most sensitive, less sensitive or insensitive.

Table 6.5: Sensitivity ranking of all ECOL98AH non-temperature parameters

\begin{tabular}{|l|l|l|l|l|}
\hline \multicolumn{1}{|c|}{ Parameter } & \multicolumn{1}{|c|}{$\begin{array}{c}\text { Associated } \\
\text { Process }\end{array}$} & $\begin{array}{c}\text { Overall } \\
\text { Sensitivity } \\
\text { Ratio }\end{array}$ & $\begin{array}{c}\text { Ranking } \\
\text { (More/Less/ } \\
\text { Insensitive) }\end{array}$ & $\begin{array}{l}\text { Species } \\
\text { Specific } \\
\text { (Yes/No) }\end{array}$ \\
\hline KE_SLOPE & $\begin{array}{l}\text {-light limitations } \\
\text { due to turbidity }\end{array}$ & 0.00 & Insensitive & No \\
\hline KqPClad & $\begin{array}{l}\text {-P limitations due } \\
\text { to internal plant P } \\
\text { conc }\end{array}$ & 0.00 & Insensitive & Yes \\
\hline KE_CONSTANT & $\begin{array}{l}\text {-light limitations } \\
\text { due to turbidity }\end{array}$ & 0.00 & Insensitive & No \\
\hline KW* $^{*}$ & $\begin{array}{l}\text {-light limitations } \\
\text { due to self-shading }\end{array}$ & 0.02 & Insensitive & Yes \\
\hline
\end{tabular}




\begin{tabular}{|c|c|c|c|c|}
\hline ROWPClad & $\begin{array}{l}\text {-P limitations due } \\
\text { to max } P \text { uptake } \\
\text { rate }\end{array}$ & 0.2 & $\begin{array}{l}\text { Less } \\
\text { Sensitive }\end{array}$ & Yes \\
\hline${ }^{*}$ FAC & $\begin{array}{l}-\mathrm{P} \text { limitations due } \\
\text { to plant } \mathrm{P} \\
\text { requirements }\end{array}$ & 0.2 & $\begin{array}{l}\text { Less } \\
\text { Sensitive }\end{array}$ & $\overline{\text { Yes }}$ \\
\hline PAS* & $\begin{array}{l}-\mathrm{P} \text { limitations due } \\
\text { to plant } \mathrm{P} \\
\text { assimilation }\end{array}$ & 0.3 & $\begin{array}{l}\text { Less } \\
\text { Sensitive }\end{array}$ & Yes \\
\hline O2ASSIM & $\begin{array}{l}\text { - limits to } \\
\text { respiration rate due } \\
\text { to } \mathrm{O} 2 \text { conc }\end{array}$ & 0.4 & $\begin{array}{l}\text { Less } \\
\text { Sensitive }\end{array}$ & No \\
\hline QoClad & $\begin{array}{l}\text {-P limitations due } \\
\text { to min internal } \\
\text { plant } \mathrm{P}\end{array}$ & 0.6 & $\begin{array}{l}\text { Less } \\
\text { Sensitive }\end{array}$ & Yes \\
\hline PLANT_DEPTH & $\begin{array}{l}\text {-light limitations } \\
\text { due to turbidity }\end{array}$ & 0.7 & $\begin{array}{l}\text { Less } \\
\text { Sensitive }\end{array}$ & No \\
\hline KMP* & $\begin{array}{l}\text {-P limitations due } \\
\text { to } \mathrm{P} \text { saturation }\end{array}$ & 0.7 & $\begin{array}{l}\text { Less } \\
\text { Sensitive }\end{array}$ & Yes \\
\hline NASSIM & $\begin{array}{l}-\mathrm{N} \text { limitations due } \\
\text { to plant } \mathrm{N} \\
\text { assimilation }\end{array}$ & 1.2 & $\begin{array}{l}\text { Less } \\
\text { Sensitive }\end{array}$ & No \\
\hline WAF* & $\begin{array}{l}\text {-limits to washout } \\
\text { rate for plant } \\
\text { biomass }\end{array}$ & 2.0 & $\begin{array}{l}\text { Most } \\
\text { Sensitive }\end{array}$ & Yes \\
\hline $\mathrm{KML}^{*}$ & $\begin{array}{l}\text {-light limitations } \\
\text { due to light } \\
\text { saturation }\end{array}$ & 4.3 & $\begin{array}{l}\text { Most } \\
\text { Sensitive }\end{array}$ & $\overline{\text { Yes }}$ \\
\hline${ }^{*} \mathrm{R} 20$ & $\begin{array}{l}\text {-limits to } \\
\text { respiration rates } \\
\text { due to base rate }\end{array}$ & 8.4 & $\begin{array}{l}\text { Most } \\
\text { Sensitive }\end{array}$ & Yes \\
\hline *MEW & $\begin{array}{l}\text {-limits to } \\
\text { photosynthesis rate } \\
\text { due to max rate }\end{array}$ & 10.5 & $\begin{array}{l}\text { Most } \\
\text { Sensitive }\end{array}$ & Yes \\
\hline
\end{tabular}

\subsubsection{Most Sensitive Parameters}

The parameters ranked as most sensitive were defined to have a sensitivity ratio of greater than 1.2. These included the washout fraction (WAF*), the half-saturation light 
constant $\left(\mathrm{KML}^{*}\right)$, the unit respiration rate $\left({ }^{*} \mathrm{R} 20\right)$ and the maximum photosynthesis rate ( $\left.{ }^{*} \mathrm{MEW}\right)$. All these parameters are species-specific and either directly related to the limitations to growth or to the net growth. ECOL98AH is most sensitive to the maximum photosynthesis rate, which averages 10.5 times the percent change in biomass over the percent change in the parameter. Figure 6.7 shows the average sensitivity ratios of the parameters ranked as most sensitive of each species, as well as an overall average of the three sensitivity ratios combined.

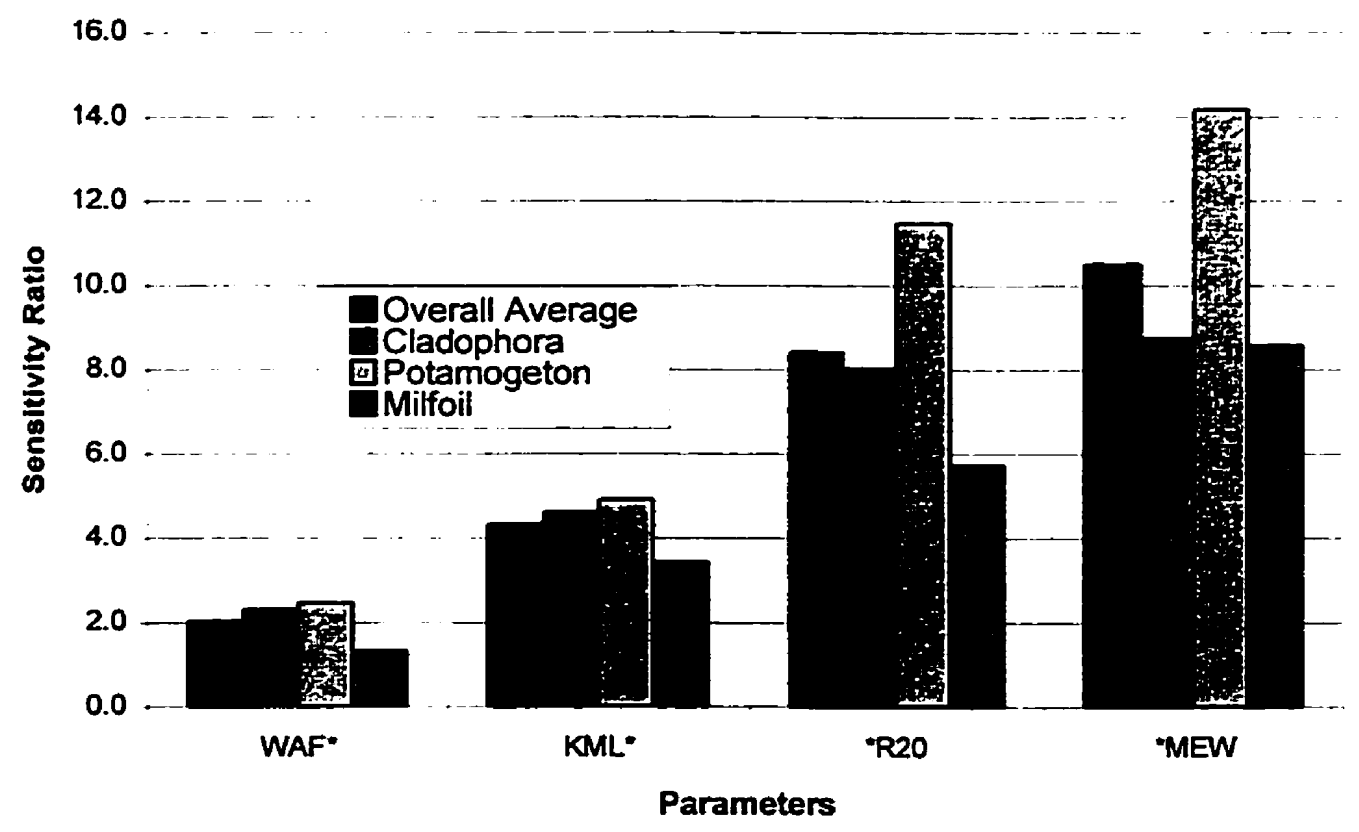

Figure 6.7: Sensitivity ratios of more sensitive species-specific parameters 


\subsubsection{Less Sensitive Parameters}

The parameters ranked as less sensitive were defined to a have a sensitivity ratio of less than or equal to 1.2 and greater than 0.1 . The weedbed attenuation constant $\left(\mathrm{KW}^{*}\right)$, nutrient utilization factor $\left({ }^{*} \mathrm{FAC}\right)$, phosphorus assimilation $\left(\mathrm{PAS}^{*}\right)$, and phosphorus halfsaturation constant (KMP*) were the species-specific parameters that were ranked in the less sensitive category. These parameters are presented in Figure 6.8.

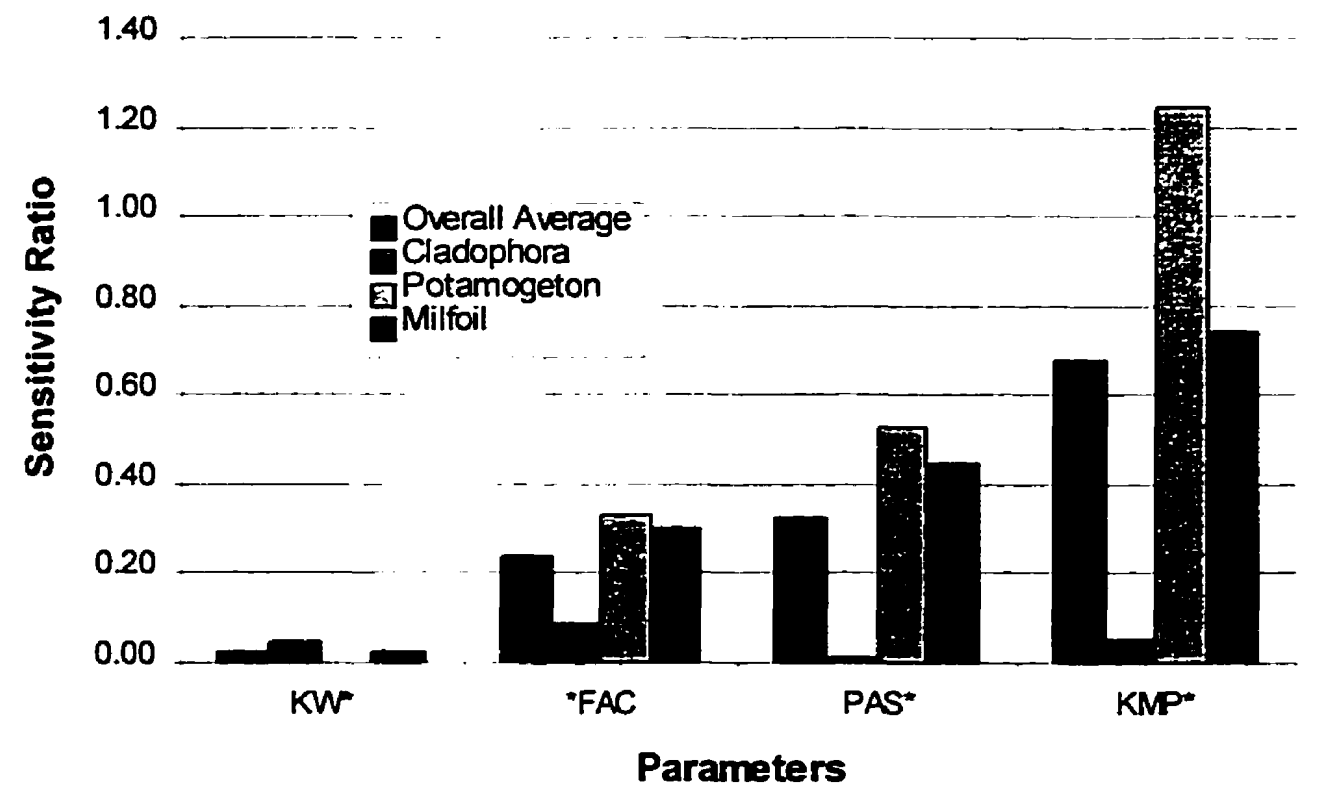

Figure 6.8: Sensitivity ratios of less sensitive species-specific parameters

The non-species-specific parameters of depth of the plant growth (PLANT_D), and oxygen (O2ASSIM) and nitrogen (NASSIM) assimilation rates were also in the less sensitive parameter class. Figure 6.9 presents the sensitivity ratios for these parameters. 


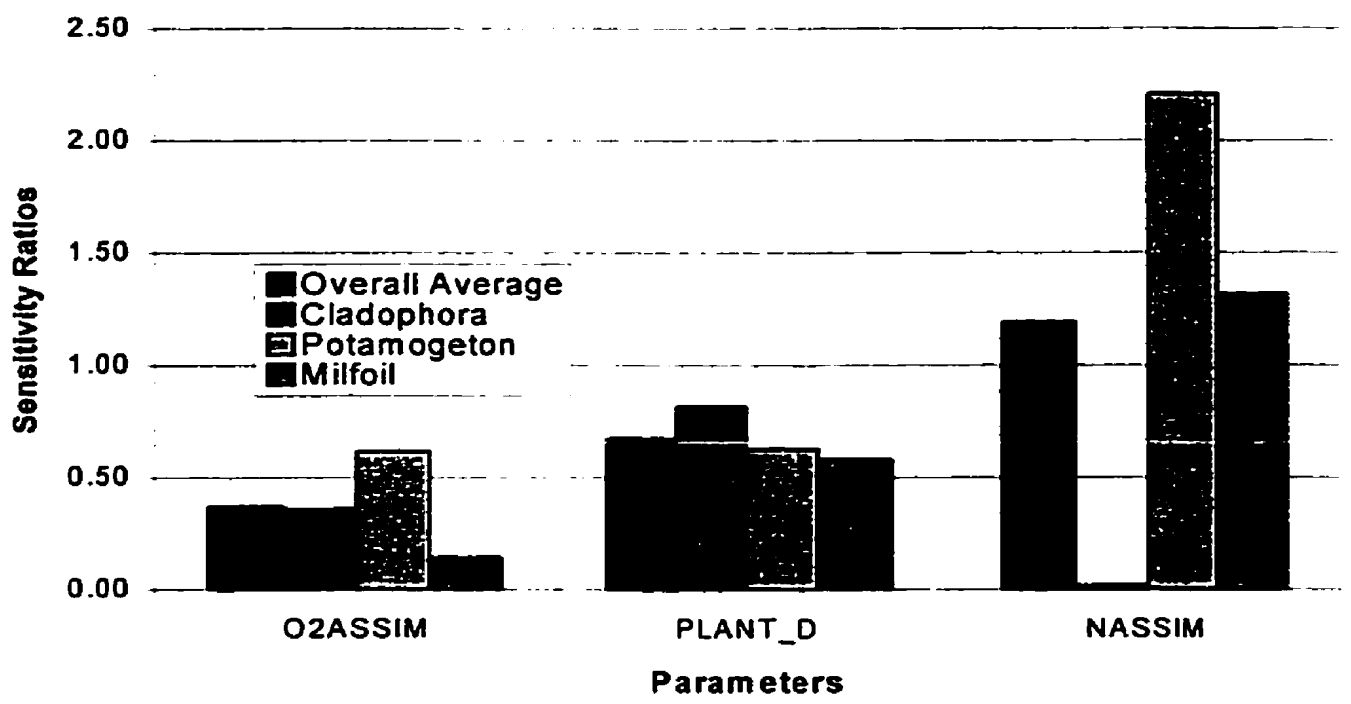

Figure 6.9: Sensitivity ratios for less sensitive non-species specific parameters

\subsubsection{Insensitive Parameters}

The insensitive parameters were defined by a sensitivity ratio less than or equal to 0.1 . The insensitive category consisted of three light-related parameters and one phosphorusrelated parameter. The light related parameters were the slope and constant for the calculating the light attenuation due to turbidity and the light attenuation from selfshading.

\subsubsection{General Comments}

The direction of change in the parameter also appears to affect the sensitivity. The direction of changing the parameter that caused an increase in biomass caused the 
greatest sensitivity in the parameter. This phenomenon is illustrated in Figure 6.10. For instance, the model had a greater sensitivity to increases in the maximum photosynthesis rate compared to decreases in this parameter. The maximum photosynthesis rate is positively related to biomass, that is, increases in the maximum photosynthesis rate cause an increase in biomass. Conversely, the half-saturation light constant is negatively related to biomass, since increases in this parameter cause a decrease in biomass. This is because the plant requires more light to become saturated as the half-saturation point increases.

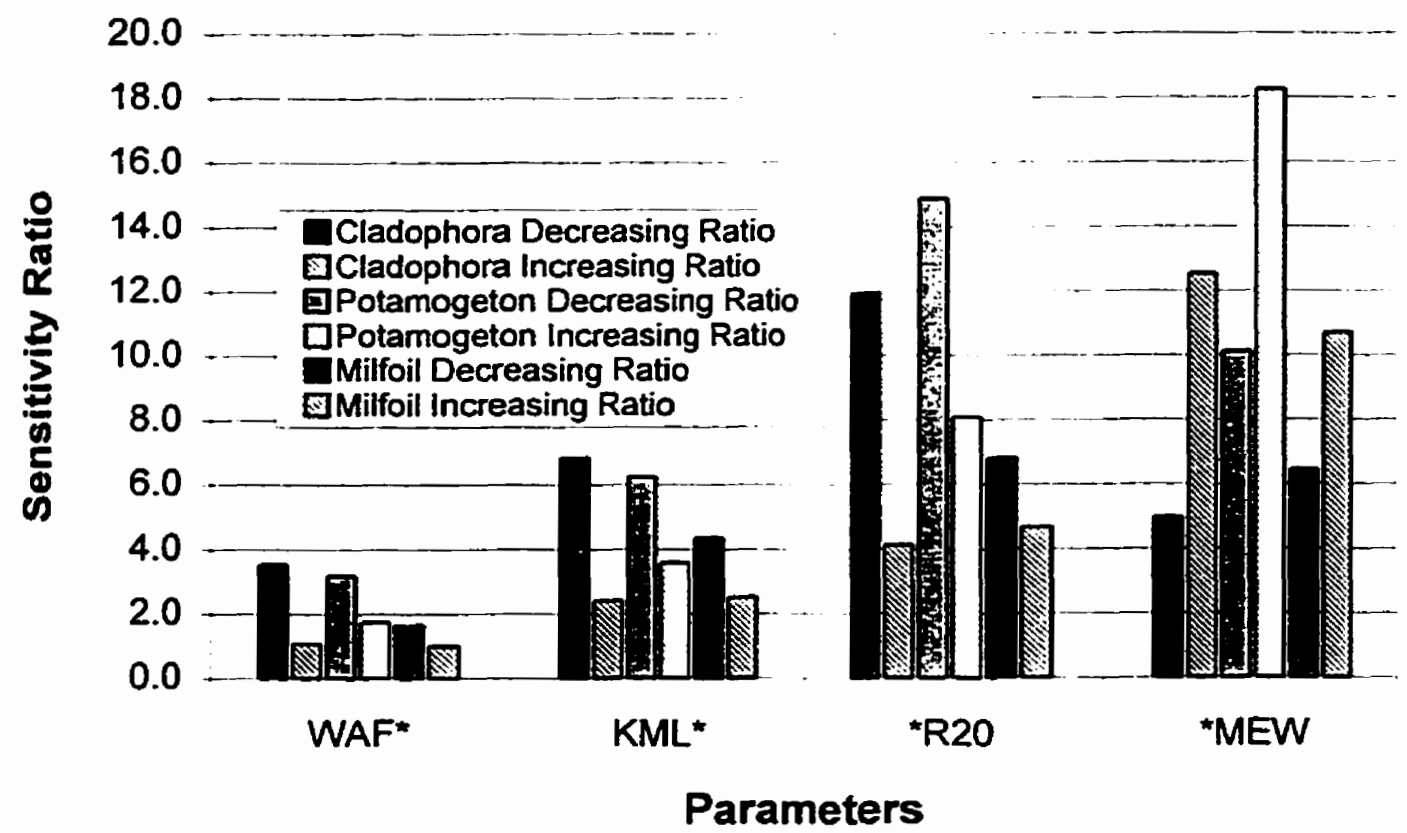

Figure 6.10: Increasing and decreasing sensitivity ratios of more sensitive parameters 


\subsubsection{Temperature-Related Parameters}

The parameters governed by temperature include the marker (maximum, minimum, lower optimum, and upper optimum) temperatures for plant growth for each species, the related $\mathrm{k}$ rates for each marker temperature, and the temperatures for biomass washout. Initially, these parameters were ranked with the parameters in Table 6.4 in the previous section. However, the temperature parameters were removed for two reasons:

1) The sensitivity ratios were not comparable since the sensitivity ratio for the temperature marker parameters were measured as the percent change in biomass over the change in degrees Celsius of the parameter. The sensitivity ratios for the temperature marker parameters were calculated in this manner because temperature is not an absolute measurement and a percent change in degrees Celsius does not hold significant meaning. The sensitivity ratios for the $\mathrm{k}$ rates were calculated as the non-temperature parameters but were still taken off the ranking list for reasons outlined below.

2) It became apparent that there was a separate distinct pattern in the degree of sensitivity of the temperature-related parameters. That is, the sensitivity of these parameters increased with the increase in frequency of the marker temperature as the stream temperature. For instance, the upper optimum growth temperature for Cladophora was $23^{\circ} \mathrm{C}$ and the frequency of a stream temperature of $23^{\circ} \mathrm{C}$ was found to be $13.8 \%$. By contrast, the minimum temperature for growth for Cladophora was $7^{\circ} \mathrm{C}$ and this 
temperature showed a $0 \%$ frequency during the growth season. Therefore, the upper optimum temperature was much more sensitive with a sensitivity ratio of 0.828 compared to the minimum temperature, with a sensitivity ratio of 0.001 . This pattern of the sensitivity ratio increasing with the frequency of occurrence of the temperature associated with the given parameter is illustrated in Figure 6.11. This trend was also found in the $\mathrm{k}$ rates for these marker temperatures, as shown in Figure 6.12.

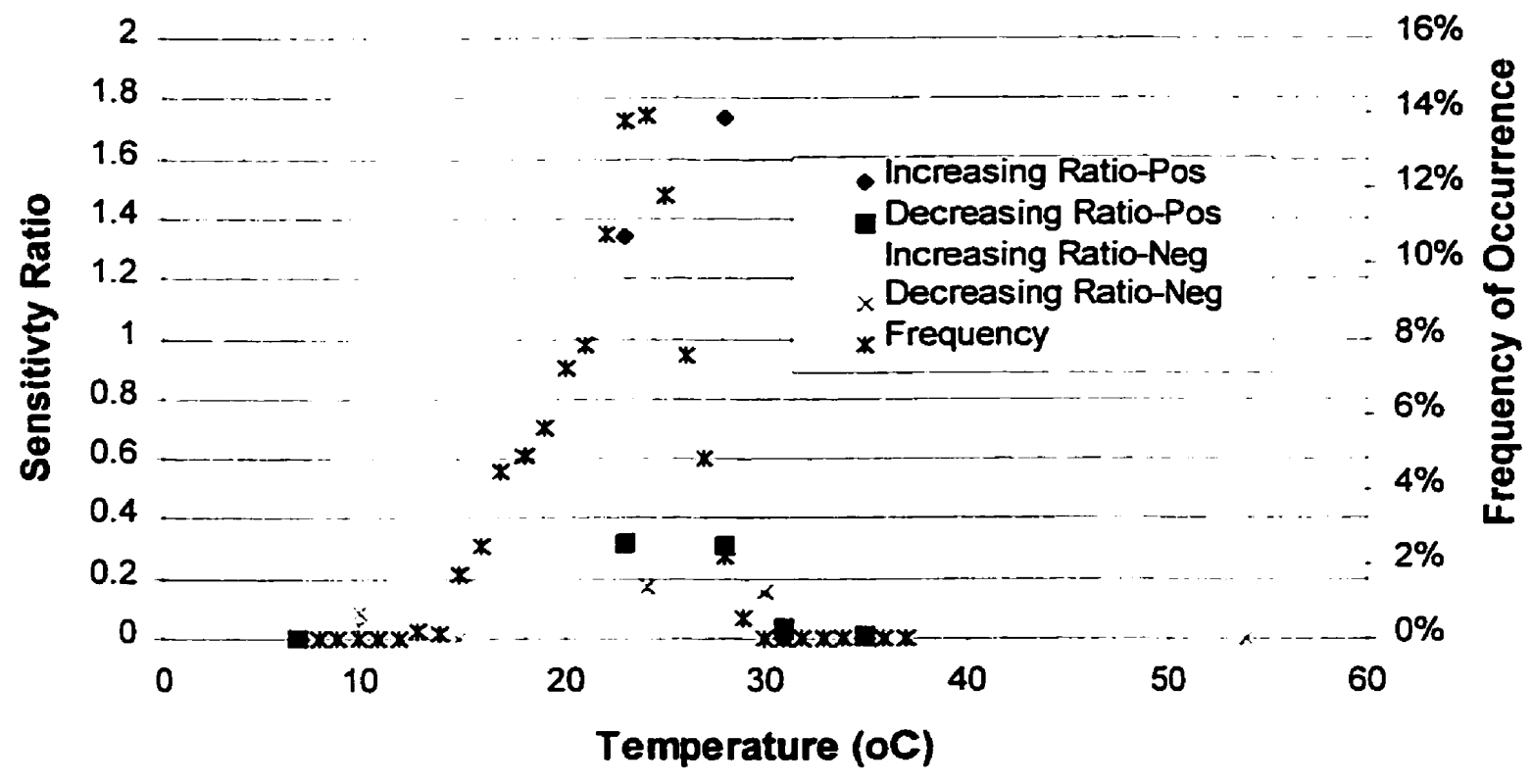

Figure 6.11: Sensitivity ratios of temperature parameters and frequency of observed stream temperatures occurrence 


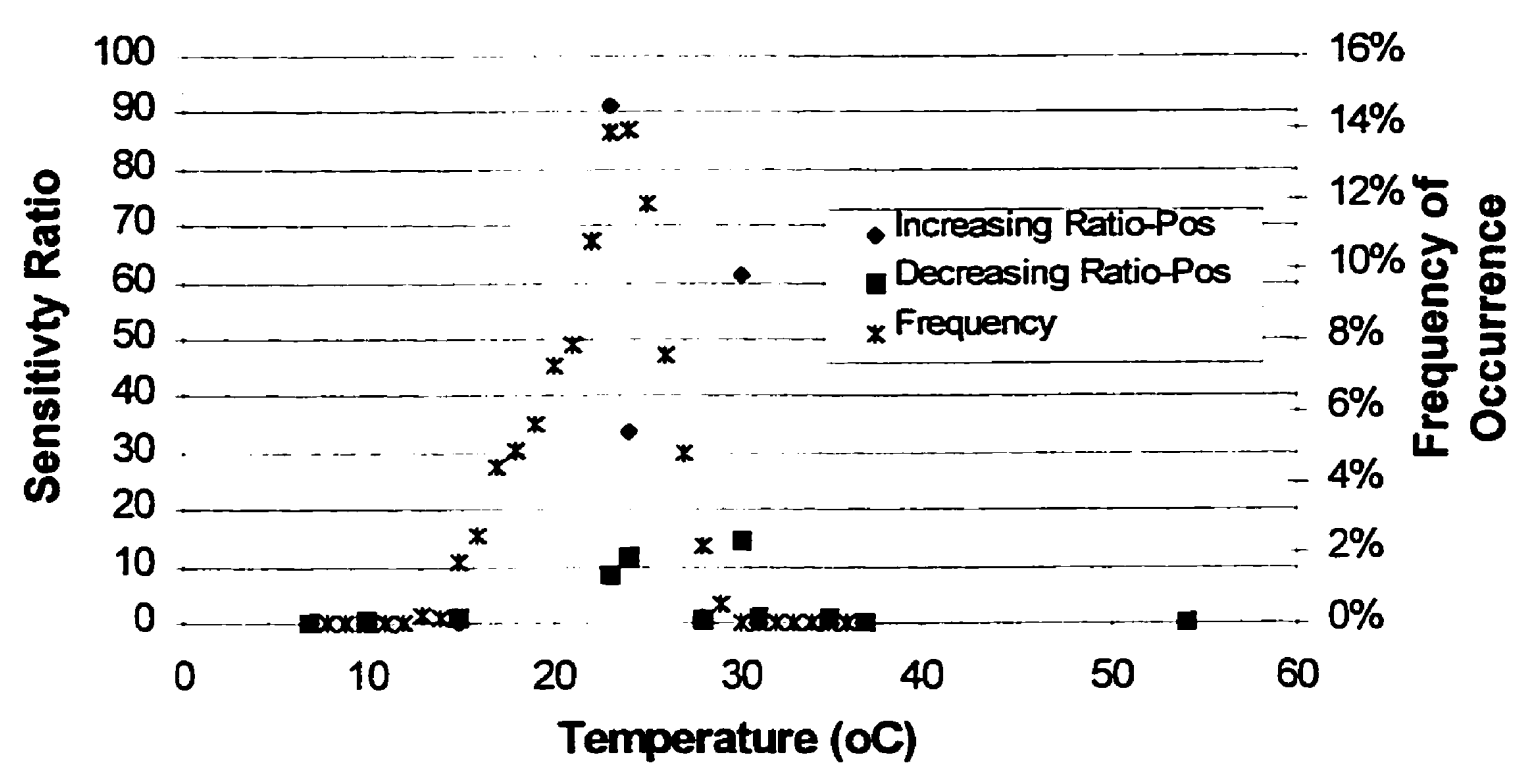

Figure 6.12: Sensitivity ratios of $k$ (temperature) parameters and frequency of observed stream temperature

\subsection{Comparing ECOLAH to GRSM98AH}

The computed maximum biomass of each species was recorded for ECOLAH and ECOL98AH in GRSM98AH and plotted on an XY scatter graph. For each run, the same changes in input data were applied to both models. These model runs are shown in Figure 6.13. It can be noted that the slope is very close to unity indicating that ECOLAH is behaving similarly to ECOL98AH in GRSM98AH. The highest point on the plot in Figure 6.13 was from the computation of a decrease of $2^{\circ} \mathrm{C}$ in the temperature series. This produced the highest peak biomass values from both models and the most variation between models. The decrease in the temperature series was then modified to only $1^{\circ} \mathrm{C}$, which produced the plot in Figure 6.14. 


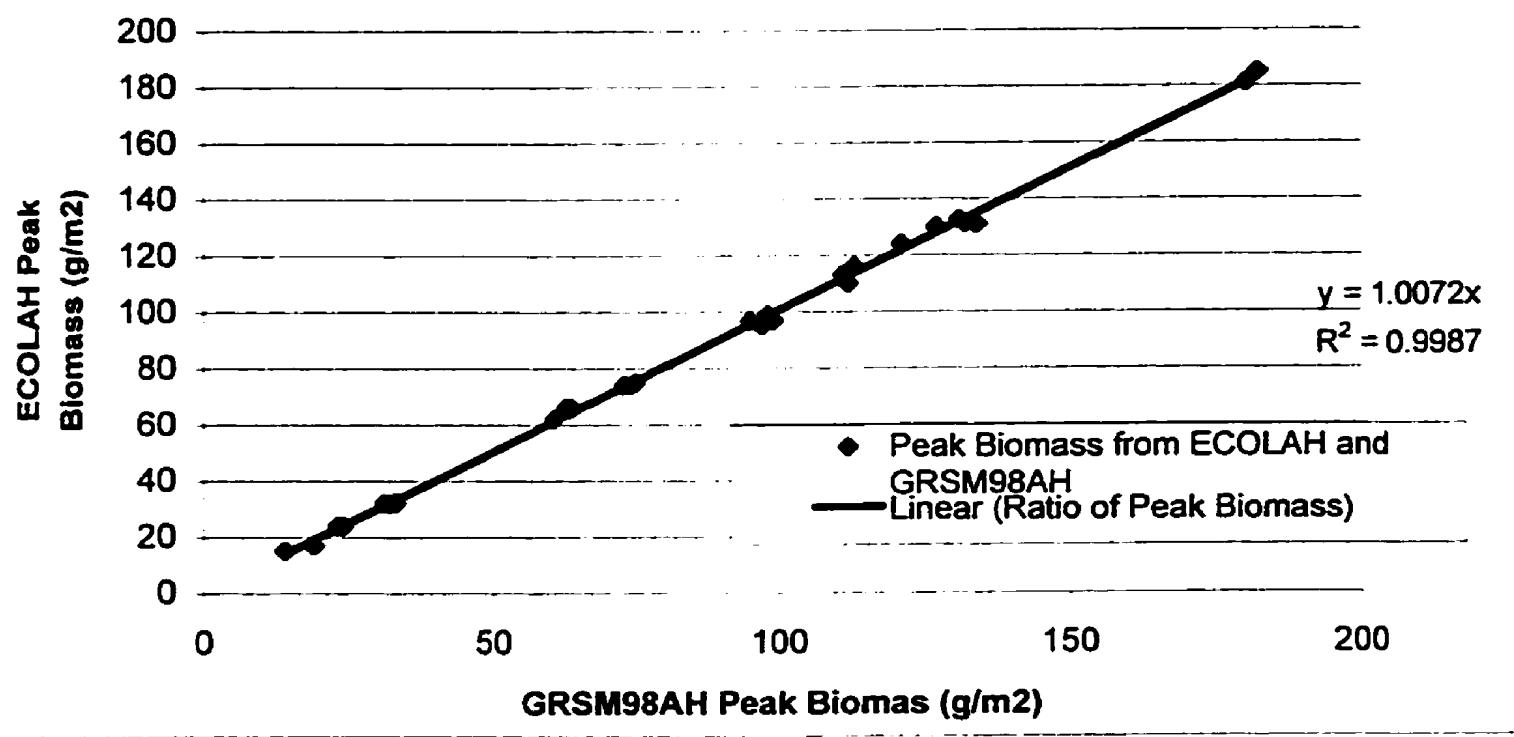

Figure 6.13: Comparison of ECOLAH and GRSM98AH peak biomass values

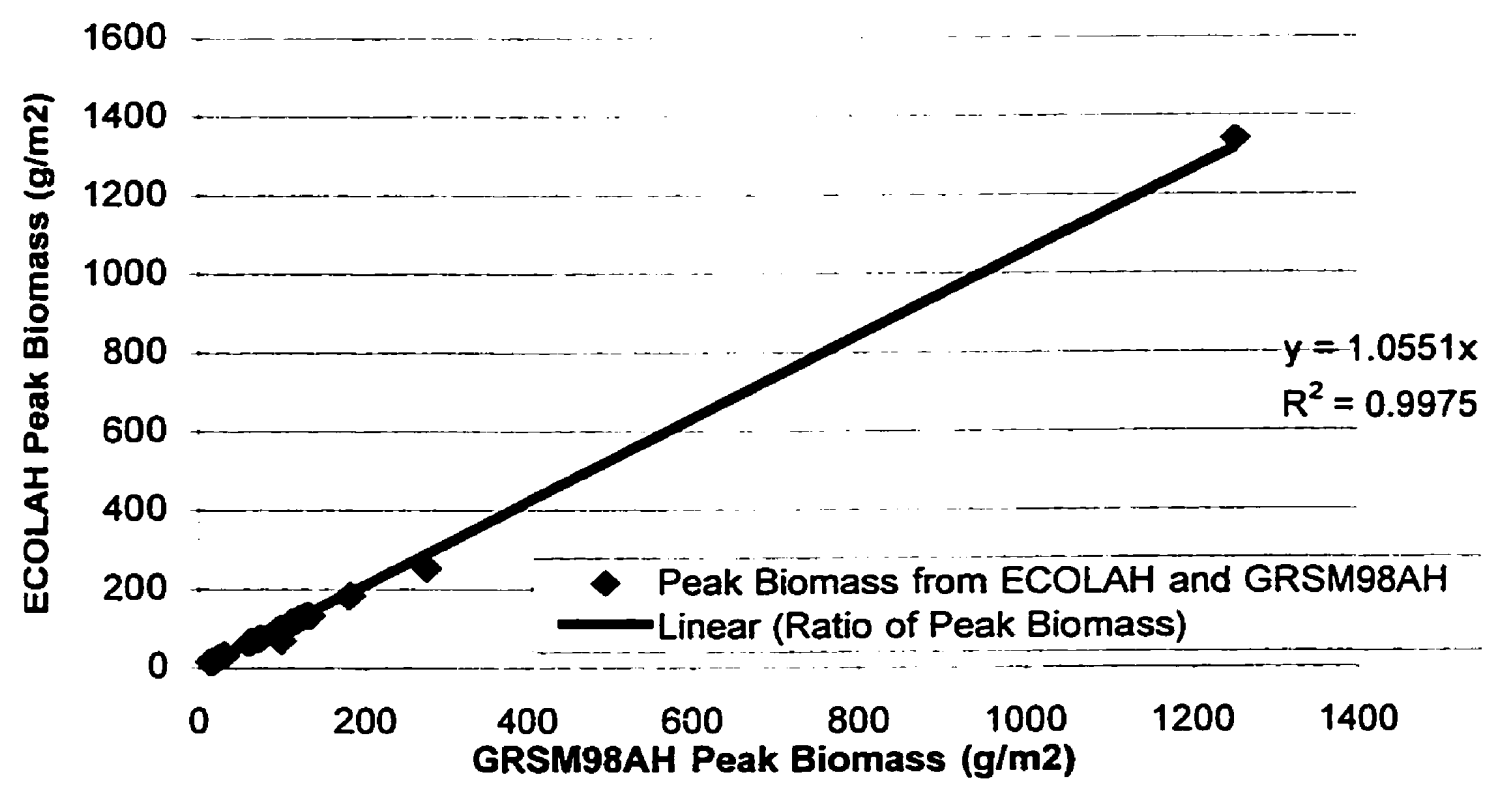

Figure 6.14: Modified comparison of ECOLAH and GRSM98AH peak biomass values 
Figure 6.14 showed a high degree of agreement between ECOLAH and GRSM98AH within the expected peak biomass values. Therefore, ECOLAH was accepted as a simple representation of ECOL98AH in GRSM98AH. The high peak biomass values simulated by a $2^{\circ} \mathrm{C}$ decrease in the temperature time series were further investigated in the model functionality tests simulated by the ECOLAH model.

\subsection{Model Functionality Testing}

The results obtained from the comparison of ECOLAH and GRSM98AH were used to identify areas of the model which required further detailed testing to determine if the model was computing reasonable and realistic results, given the change in the input data. Expected results for the changes in input data and computed results are presented in Table 6.6.

Table 6.6: Expected and computed results in model functionality for ECOLAH

\begin{tabular}{|l|l|l|}
\hline \multicolumn{1}{|c|}{$\begin{array}{c}\text { Change in Input } \\
\text { Data }\end{array}$} & $\begin{array}{c}\text { Expected Change } \\
\text { in Biomass Density }\end{array}$ & \multicolumn{1}{|c|}{$\begin{array}{c}\text { Computed Change by both } \\
\text { GRSM98AH and ECOLAH }\end{array}$} \\
\hline $\begin{array}{l}\text { Increase in water } \\
\text { column phosphorus }\end{array}$ & Increase & $\begin{array}{l}\text { Significant increase in } \text { P. pectinatus } \\
\text { and } M \text {. spicatum, insignificant increase } \\
\text { in Cladophora }\end{array}$ \\
\hline $\begin{array}{l}\text { Decrease in water } \\
\text { column phosphorus }\end{array}$ & Decrease & $\begin{array}{l}\text { Significant decrease in } \text { P. pectinatus } \\
\text { and } M \text {. spicatum, small decrease in } \\
\text { Cladophora }\end{array}$ \\
\hline $\begin{array}{l}\text { Increase in water } \\
\text { column total nitrates }\end{array}$ & Increase & Insignificant change in plant growth \\
\hline $\begin{array}{l}\text { Decrease in water } \\
\text { column total nitrates }\end{array}$ & Decrease & Significant decrease in plant growth \\
\hline Increase in flow & Decrease & Insignificant change in plant growth \\
\hline Decrease in flow & Increase & Insignificant change in plant growth \\
\hline
\end{tabular}




\begin{tabular}{|l|l|l|}
\hline $\begin{array}{l}\text { Increase in solar } \\
\text { radiation }\end{array}$ & Increase & $\begin{array}{l}\text { Significant increase in } P \text {. pectinatus } \\
\text { and } M . \text { spicatum, significant decrease } \\
\text { in Cladophora }\end{array}$ \\
\hline $\begin{array}{l}\text { Decrease in solar } \\
\text { radiation }\end{array}$ & Decrease & $\begin{array}{l}\text { Significant decrease in } \text { P. pectinatus } \\
\text { and } M \text {. spicatum, significant increase in } \\
\text { Cladophora }\end{array}$ \\
\hline $\begin{array}{l}\text { Increase in suspended } \\
\text { solids }\end{array}$ & Decrease & Insignificant decrease in plant growth \\
\hline $\begin{array}{l}\text { Decrease in } \\
\text { suspended soiids }\end{array}$ & Increase & Insignificant increase in plant growth \\
\hline $\begin{array}{l}\text { Increase in } \\
\text { temperature }\end{array}$ & $\begin{array}{l}\text { Increase in } M . \\
\text { spicatum, decrease in } \\
\text { Cladophora }\end{array}$ & $\begin{array}{l}\text { Significant increase in } M \text {. spicatum, } \\
\text { significant decrease in } \text { Cladophora }\end{array}$ \\
\hline $\begin{array}{l}\text { Decrease in } \\
\text { temperature }\end{array}$ & $\begin{array}{l}\text { Decrease in } M . \\
\text { spicatum, increase in } \\
\text { Cladophora }\end{array}$ & $\begin{array}{l}\text { Decrease in } M \text {. spicatum, unreasonably } \\
\text { large increase in Cladophora }\end{array}$ \\
\hline
\end{tabular}

The next chapter discusses the inconsistencies between some of the expected and computed results, and presents results from further detailed testing. 


\section{Discussion}

The results from the calibration process, sensitivity analysis, and model functionality tests are discussed in the following sections. The average of $80 \%$ agreement between observed data and computed results was deemed to be satisfactory. From the calibration results and field observations, it is hypothesized that macroinvertebrates play a significant role in the net plant biomass produced. In terms of non-temperature parameters, the sensitivity analysis revealed that biomass computed in ECOL98AH is most sensitive to changes in the maximum photosynthesis rates, unit respiration rates, wash-out fraction and the half-saturation light constants. Sensitivity of temperature parameters was demonstrated using a frequency distribution plot. Model functionality tests provided insight into model response under numerous realistic alternate scenarios. As a result of the model functionality tests, changes to temperature parameters were incorporated into the model.

\subsection{Calibration}

An average agreement of $80 \%$ between the available sets of computed DO and observed DO was achieved with revisions to phosphorus, temperature and light algorithms and plant inhibition factors. The standard error of estimate for computed DO versus observed DO was $1.86 \mathrm{mg} / \mathrm{L}$. For a severe case of depleted levels of DO under $3 \mathrm{mg} / \mathrm{L}$, the model 
would identify the waters as being under the MOE guideline of $5 \mathrm{mg} / \mathrm{L}$ (MOE, 1994), based on an error of $1.86 \mathrm{mg} / \mathrm{L}$.

The need to adjust the plant inhibition factors for sub-reaches 2 and 6 may indicate spatially-differing constraints to growth. Because the maximum photosynthetic rates were set for sub-reach 10 , these rates intrinsically included the plant inhibition factor that applied for the environmental conditions in sub-reach 10. As only one species, for one month, required an adjustment to the plant inhibition factor, sub-reach 2 appears to have the same degree of constraints to growth as sub-reach 10. Sub-reach 6 required more adjustment to the plant inhibition factors, indicating different constraints to growth from non-modelled environmental pressures.

The need for decreased inhibition factors (which leads to a decrease in biomass density) to maintain a good agreement between observed and computed DO may be linked to macroinvertebrate fauna observed at this site (Mangile, 1997, and from personal observations). This finding is consistent with other reports in the literature showing that macroinvertebrates have significantly decreased the densities of macrophyte and algal stands (Dudley and D'Antonio, 1991; Bergey, 1995; Feminella and Resh, 1991; Creed and Sheldon, 1993). 


\subsection{Sensitivity Analysis}

Few of the aquatic plant models found in the literature described a sensitivity analysis on the plant growth related parameters and therefore, few meaningful comparisons could be made between sensitivity in ECOL98AH and in other models. ECOL98H results were most sensitive to the following non-temperature parameters: the washout fraction, the half-saturation constant for light, the unit respiration rate at $20^{\circ} \mathrm{C}$ and the maximum photosynthesis rate, all of which were species-specific. MEGAPLANT results (Scheffer et al., 1993) were found to be the most sensitive to the maximum photosynthesis rate. Model results from ECOL96 were sensitive to the half-saturation constant for light and the unit respiration rate (CH2M Gore and Storrie, 1996, Walker et al., 1982). Therefore, the parameters with greatest influence on model results in ECOL98AH are consistent with sensitivity analyses on other aquatic plant models.

In comparison to the growth and respiration rates, ECOL98AH maximum biomass was either insensitive or less sensitive to all the phosphorus-related parameters, including the half-saturation constants for internal and external phosphorus, the assimilation rate and the uptake rate of phosphorus and the phosphorus efficiency utilization factor. Because of the high phosphorus concentrations in the water column, it is hypothesized that the modelled system is at saturation for phosphorus and therefore is not affected by changes in phosphorus-related parameters. The same conclusion was drawn from the $\mathrm{CH} 2 \mathrm{M}$ Gore and Storrie sensitivity analysis (1996) for the phosphorus parameters in ECOL96. 
ECOL98AH model results were found to be less sensitive to the light attenuation parameters, including the weedbed and suspended solids attenuation coefficients and plant depth. It is hypothesized that because the Grand and Speed Rivers are generally shallow rivers, they therefore do not have enough water column depth to effectively attenuate light from the surface to the plants.

Model results were found to be highly sensitive to the temperature-related parameters when the temperature parameters were near observed water temperature. Figure 6.12 shows that the frequency of a given water temperature and the sensitivity of a marker temperature (maximum, optimum, minimum) were correlated. This type of sensitivity is expected because the temperature curves flatten as they extend to the minimum and maximum marker temperatures. For example, if the maximum temperature for $M$. spicatum is altered between $30^{\circ} \mathrm{C}$ and $40^{\circ} \mathrm{C}$ (the original value being $35^{\circ} \mathrm{C}$ ), one would not expect a major change in the plant response if water temperatures never approached this range of temperatures. Titus et al. (1975) found $M$. spicatum to increase by only $10 \%$ with $10^{\circ} \mathrm{C}$ increase in water temperature, which may have been attributed to the average water temperatures being outside the range of the optimum growth temperatures for that species. Therefore, the sensitivity analysis for temperature-related parameters in this study are consistent with previous work on aquatic plant growth response to temperature. 


\subsection{Comparing ECOLAH to GRSM98AH}

The unrealistic increase, when the water temperature series was decreased by $2^{\circ} \mathrm{C}$, of computed Cladophora biomass density in both GRSM98AH and ECOLAH was problematic and prompted further investigation of the Cladophora growth pattern in the GRSM98AH model under 1995 conditions. The direction and degree of biomass change computed (i.e., significantly increasing) at the end of the growing season was suspect because there was a steeply increasing biomass density curve at the end of September for Cladophora. In addition, when the model was extended into December, the unreasonably high biomass density that remained confirmed that the computed growth pattern was unrealistic.

Two factors were hypothesized to have contributed to the computation of unrealistically high Cladophora biomass densities. In ECOL (96 and 98AH), computed water temperatures greater than the upper Cladophora washout temperature trigger the model to calculate higher Cladophora washout values. However, there is no lower washout temperature for Cladophora to trigger the computation of similarly high washout at the end of the growing season. Secondly, the optimum temperature ranges for Cladophora inputted into ECOL98AH may have been too wide. After temporarily incorporating a function to increase Cladophora biomass wash-off at lower temperatures and decreasing the optimum temperature range for Cladophora, more realistic biomass density values 
were computed by both ECOLAH and GRSM98AH. However, there was no significant change in the agreement between computed and observed DO.

In the field season of 1997, the author and Mangile (1997, and from personal observations), observed higher densities of macroinvertebrate larvae on the macrophytes at the Blair station, compared to the Speed River and Bridgeport stations, during the mid to late summer, the time period where model performance is weakest. Based on the literature on herbivory by macroinvertebrates, it is possible that these larva could suppress plant growth enough to cause the lower fluctuations in the observed DO data, compared to the computed DO results. The plant inhibition factor for this sub-reach was lowered, which caused a decrease in computed plant growth, for the months where lower minima of DO fluctuations were observed.

\subsection{Model Functionality Testing}

The model functionality tests confirmed the validity of the sensitivity analysis results and provided further insight into the behaviour of the model. Only one test, where temperature values were decreased, produced an unexplainable result, which subsequently led to recommendations to incorporate additional changes in the temperature-related algorithms for Cladophora. 
Increases and decreases in water column phosphorus led to expected model results for $P$. pectinatus and $M$. spicatum. The low sensitivity of Cladophora to changes in water column phosphorus in ECOL98AH was attributed to its (Cladophora's) higher halfsaturation constant, which produces a flatter limitation curve compared to $P$. pectinatus and $M$. spicatum, as shown in Figure 7.1.

Increases in total nitrates produced insignificant changes in biomass production. This supports the assumption that phosphorus is normally the limiting nutrient in eutrophic waterbodies. Furthermore, when the total nitrates are decreased, potentially below saturation, there is a noticeable decrease in computed plant growth, indicating that nitrogen, if low enough, can become the limiting nutrient.

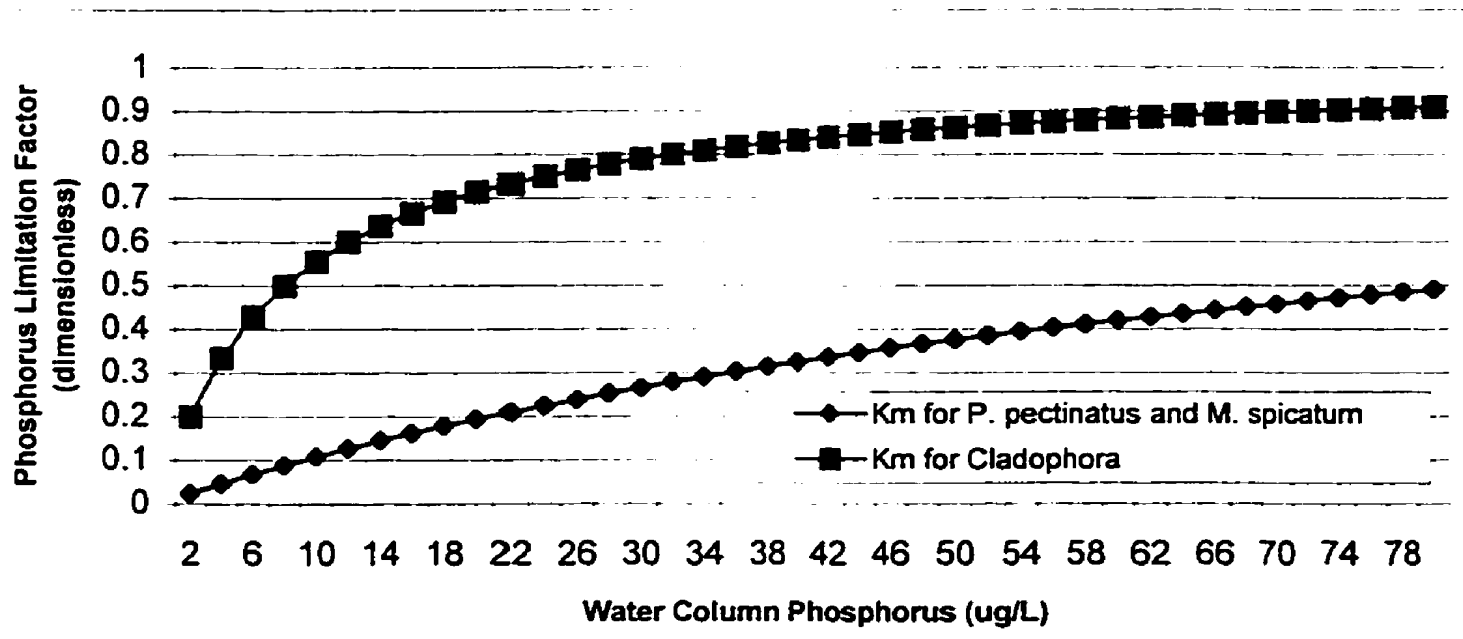

Figure 7.1: Phosphorus limitation curves for the three species modelled

Biomass densities for $P$. pectinatus and $M$. spicatum increased, as expected, with increased solar radiation. However, $C$. glomerata in both models decreased with 
increasing solar radiation. Initially, this was considered to be an indication of a faulty model but after more testing, a satisfactory reason for this inconsistency was discovered. GRSM98AH calculates water temperature based on air temperature and solar radiation. Figure 7.2, which shows the computed water temperatures from the original solar radiation time series and the decreased solar radiation time series, shows the resulting decrease in computed water temperature. Therefore, when the input solar radiation increases, the computed water temperature also increases. In GRSM98AH, the optimum temperatures inputted for Cladophora are low, and therefore increases in computed water temperature cause a decrease in computed Cladophora density. Likewise, decreases in input solar radiation, which result in lower computed water temperatures, calculates increased growth of Cladophora. As expected, decreases in computed $P$. pectinatus and M. spicatum densities coincide with decreases in solar radiation.

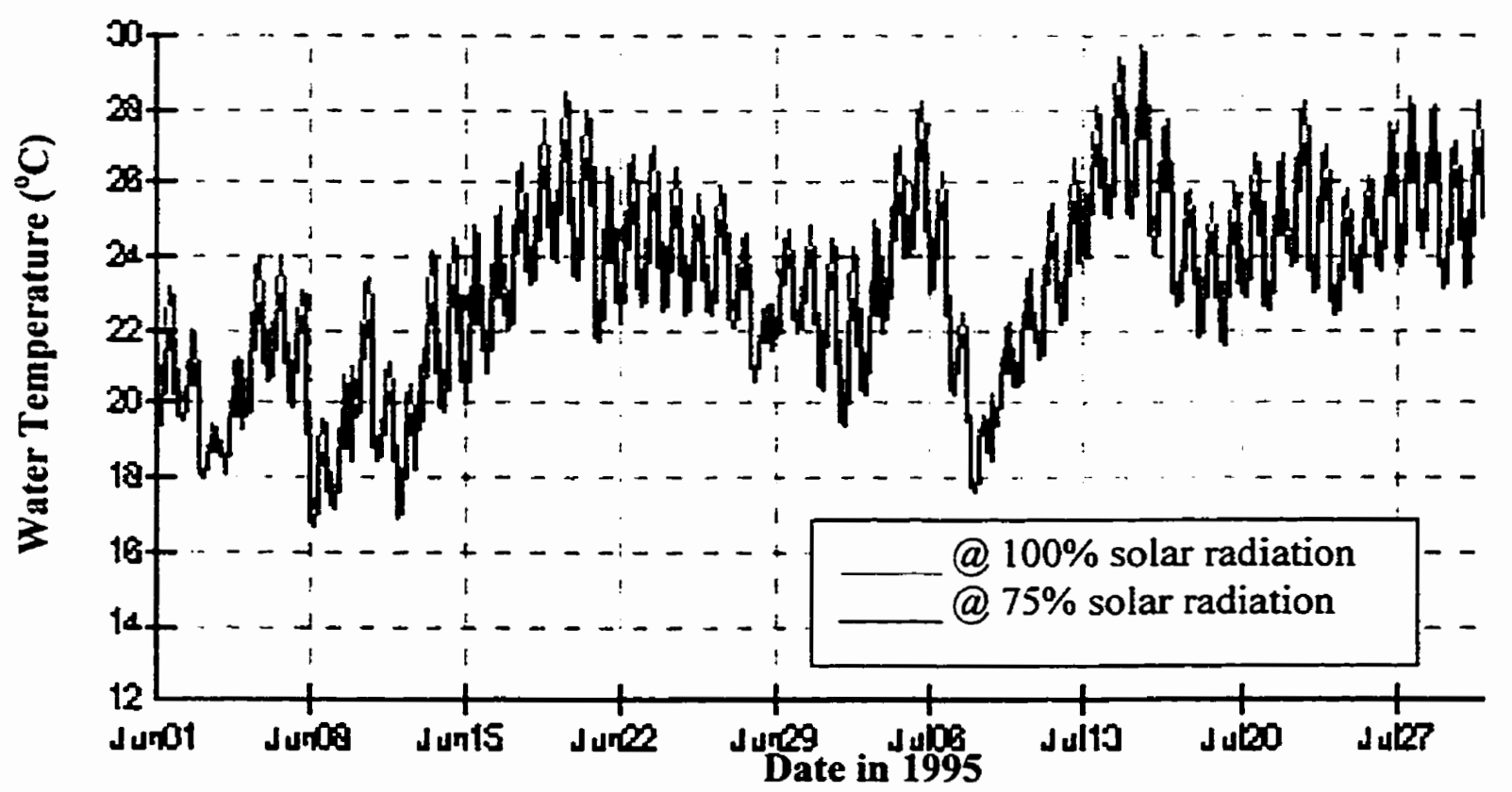

Figure 7.2: Computed water temperature from $100 \%$ and $75 \%$ solar radiation input 
Changes in input suspended solids concentrations did not have a significant impact on computed plant biomass. For the shallow depths in the Grand and Speed Rivers where the most prolific aquatic plant growth occurs (Mangile 1997, and from personal observations), suspended solids may not have enough depth to attenuate light effectively. ECOLAH was based on a shallow reach in the Grand River and therefore does not reflect the possibility of suspended solids attenuation in deeper reaches. Because the light attenuation algorithm is only activated when the computed water column is deeper than the inputted plant growth depth, after the computed water depth increases over the modelspecified plant depth, the model became sensitive to suspended solids concentrations, as shown in Table 7.1. The designated plant depth is $0.9 \mathrm{~m}$, which falls between the depths of 0.84 and 1.05; the latter depth being where sensitivity to suspended solids begins. High sensitivity to suspended solids and related parameters in GRSM96 reported by CH2M Gore and Storrie (1996) was probably determined under deeper water conditions.

Table 7.1: Maximum computed biomass densities (in $\mathrm{g} / \mathrm{m}^{2}$ ) under varying suspended solids concentrations and depths in ECOLAH

\begin{tabular}{|c|c|c|}
\hline & $\mathrm{SS}=4.57 \mathrm{mg} / \mathrm{L}$ & SS $=20 \mathrm{mg} / \mathrm{L}$ \\
\hline Depth $=0.42 \mathrm{~m}$ & $\begin{array}{l}\text { MaxClad }=132 \\
\text { MaxPot }=97 \\
\text { MaxMil }=32\end{array}$ & $\begin{array}{l}\text { MaxClad = 132 } \\
\text { MaxPot }=97 \\
\text { MaxMil = 32 }\end{array}$ \\
\hline Depth $=0.84 \mathrm{~m}$ & $\begin{array}{l}\text { MaxClad }=132 \\
\text { MaxPot }=97 \\
\text { MaxMil }=32\end{array}$ & $\begin{array}{l}\text { MaxClad }=132 \\
\text { MaxPot }=97 \\
\text { MaxMil }=32\end{array}$ \\
\hline Depth $=1.05 \mathrm{~m}$ & $\begin{array}{l}\text { MaxClad }=99 \\
\text { MaxPot }=62 \\
\text { MaxMil }=16\end{array}$ & $\begin{array}{l}\text { MaxClad }=82 \\
\text { MaxPot }=48 \\
\text { MaxMil }=11\end{array}$ \\
\hline Depth $=1.26 \mathrm{~m}$ & $\begin{array}{l}\text { MaxClad }=73 \\
\text { MaxPot }=44 \\
\text { MaxMil }=10\end{array}$ & $\begin{array}{l}\text { MaxClad }=46 \\
\text { MaxPot }=40 \\
\text { MaxMil }=10\end{array}$ \\
\hline
\end{tabular}


Results for input air temperature increases were as expected. Computed biomass densities of Cladophora, which has a lower input optimum temperature range, were lowered while computed biomass of $M$. spicatum, which has a higher input optimum temperature range, increased. Input air temperature decreases in the model produced expected results for $M$. spicatum. However, the computed biomass curve for Cladophora again reached unreasonably high densities. When a tighter range of input optimum temperatures and the addition of an input lower wash-off temperature were applied to ECOLAH, the computed Cladophora curve returned to a normal range.

Changes to flow inputs did not have any significant effect on computed aquatic plant growth. Because ECOLAH was setup to have constant concentrations of phosphorus and nitrogen, input flows did not change input nutrient concentrations. Since the computed plant response to phosphorus, the limiting nutrient, is based on the input concentration and not the loading, input flows would not have an effect of increasing the plants' exposure to phosphorus. The input flows would only have an effect on algorithms relating to respiration, because of their dependence on oxygen concentrations, which can be affected by the reaeration rates, computed from flow inputs. Therefore, it appears that computed plant growth is not sensitive to oxygen concentrations, as is also concluded in Carr's review of environmental factors regulating aquatic plant production (1997). 


\subsection{Summary}

The research described in this thesis has been directed at improving the functionality and predictive accuracy of GRSM98AH. The improved algorithms for phosphorus, light and temperature (Section 4.2, 4.4 and 4.6) and adjustment to plant inhibition factors have produced a model with an average error of $19.6 \%$ and a relative error of $7.7 \%$. The standard error of estimate for DO was $1.86 \mathrm{mg} / \mathrm{L}$. The model remains highly sensitive to the maximum photosynthesis, unit respiration and washout rates. In addition to these parameters, the half-saturation light constants and temperature-related parameters, are identified as the most critical parameters for calibration. Realistic responses to numerous alternate input scenarios, except for decreases in temperature, demonstrate good model flexibility and realism. The model functionality tests revealed unrealistic computed Cladophora growth response to input air temperature decreases; a problem which was corrected by adjusting Cladophora temperature input parameters and incorporating an algorithm to trigger washout at lower temperatures. 


\section{CONCLUSIONS AND RECOMMENDATIONS}

The following conclusions may be drawn from the present research:

1) ECOL98AH is a unique aquatic plant model based on its ability to compute the DO fluctuations cause by the net production of multiple plant species;

2) the average error of estimation of ECOL98AH in computed DO results is approximately $20 \%$;

3) the relative error for computed DO is $8 \%$;

4) the standard error of estimation for computed DO was $1.86 \mathrm{mg} / \mathrm{L}$;

5) the most sensitive non-temperature related parameters in ECOL98AH are the maximum photosynthesis rates, the unit respiration rates, the washout rates, and the half-saturation light constants;

6) the least sensitive parameters are the light attenuation coefficients, for both suspended solids and weedbed density, and the internal half-saturation constant for phosphorus;

7) marker temperatures (maximum, upper optimum, lower optimum, minimum) and their corresponding reaction rates become sensitive in ECOL98AH when they are within the normal frequency water temperatures;

8) replacement of older linear functions with Michalis-Menten algorithms brought ECOL98AH into line with current botanical practices for modelling aquatic plant response to phosphorus; 
9) the amended GRSM98AH, which included a tighter input optimum temperature range for Cladophora, responds reasonably, in term of computed biomass density and direction of response, within normal ranges of input data;

10) aquatic plant production in the Grand and Speed Rivers may be more sensitive to changes in temperature and light than to phosphorus because phosphorus levels are at saturation;

11) shallow depths do not allow water to significantly attenuate light from either suspended solid or plant biomass and thus incident radiation has little impact on computed plant production;

12) based on literature, field observations and observed DO results, macroinvertebrates are believed to suppress plant biomass production in the Grand River at Blair.

The following recommendations are made for future development of the ECOL model within GRSM:

Model Code

1) Code should be reorganized in a logical and rational manner which includes the following:

a) re-coding in an updated language such as Visual Basic ${ }^{\otimes} / \mathrm{C}+{ }^{\otimes}$;

b) full documentation of the new code;

c) taking out of all code which will never be used (i.e. historical code); 
2) Output files should be exportable to Excel ${ }^{\oplus}$, Lotus ${ }^{\circledast}$, and Quattro-Pro ${ }^{\circledast p}$ applications;

3) An instructional manual, fully documenting every input parameter and all of the algorithms, should be written.

Model Reliability and Utility

4) Statistical analysis of observed data versus simulated results should be incorporated into the application;

5) Estimated error from this statistical analysis should be incorporated in the results;

6) The air temperature time series should be replaced with the observed water temperature time series available from the four GRCA continuous monitoring stations;

7) The sub-reaches should be broken into shorter, homogenous sections;

8) The model should be recalibrated on biomass data collected from the summers of 1997 and 1998.

Model Theory (when available in the literature):

9) The model should be reconfigured to distinguish between attached and soluble phosphorus in input concentrations and in plant uptake and release;

10) Phosphorus equations for the other two plant species ( $P$. pectinatus and $M$. spicatum) should be changed to the form of the phosphorus equations used by Cladophora; 
11) An upper and a lower washout temperature for all the plant species should be incorporated in the model;

12) Old simplistic phosphorus equations in ECOL98AH should be removed and replaced with the algorithms developed in recommendation 10). 


\section{REFERENCES}

Adams, M.S. Guilizzoni, P., Adams, S. (1978) Relationship of dissolved inorganic carbon to macrophyte photosynthesis in some Italian lakes. Limnology and Oceanography 23:912-919.

Ambrose, R.B. Jr., Wool, T.A., Martin, J.L. (1993) The Water Quality Analysis Simulation Program, WASP5 Part B: The WASP5 Input Dataset. Environmental Research Laboratory, Athens, Georgia.

Auer, M.T. and Canale, R.P. (1982a) Ecological studies and mathematical modeling of Cladophora in Lake Huron: 2. Phosphorus uptake kinetics. Journal of Great Lakes Research 8:84-92.

Auer, M.T. and Canale, R.P. (1982b) Ecological studies and mathematical modeling of Cladophora in Lake Huron: 3. The dependence of growth rates on internal phosphorus pool size. Journal of Great Lakes Research 8:93-99.

Barko, J.W., Gunnison, D., Carpenter, S.R. (1991) Sediment interactions with submersed macrophyte growth and community dynamics. Aquatic Botany 41:41-65.

Barko, J.W., Hardin, D.G. and Matthews, M.S. (1982) Growth and morphology of submersed freshwater macrophytes in relation to light and temperature. Canadian Journal of Botany 60: 877-887.

Barko, J.W. and Smart, R.M. (1980) Mobilization of sediment phosphorus by submersed freshwater macrophytes. Freshwater Biology 10: 229-238.

Bergey, E. A. (1995) Local effects of a sedentary grazer on stream algae. Freshwater Biology 33:40 1-409.

Bruskin, A.B. (1984) Vaekst og biomasse af Cladophora i Susaen M.S. thesis, Freshwater Biological Laboratory, University of Copenhagen (cited in Sand-Jensen et al.. 1989)

Carignan, R. (1982) An empirical model to estimate the relative importance of roots in phosphorus uptake by aquatic macrophytes. Canadian Journal of Fisheries and Aquatic Sciences 39: 243-247.

Carignan, R. and Kalff, J. (1980) Phosphorus sources for aquatic weeds: Water or sediments. Science 207: 987-989. 
Carr, G. (1997) Environmental Factors Regulating Aquatic Plant Production in Freshwater Ecosystems: A Literature Review. University of Waterloo.

CH2M, Gore and Storrie Ltd. (1996) Water Quality Modelling on the Grand River: Final Report GRSM Upgrade.

Chambers, P.A. (1987) Light and nutrients in the control of aquatic plant community structure . In situ observations. Journal of Ecology 75: 621-628.

Chambers, P.A. and Kalff, J. (1987) Light and nutrients in the control of aquatic plant community structure. In situ experiments. Journal of Ecology 75: 61 1-619.

Chambers, P.A. and Kalff, J. (1985) The influence of sediment composition and irradiance on the growth and morphology of Myriophyllum spicatum L. Aquatic Botany 22: 253-263.

Collins, C.D. and Wlosinski, J.H. (1989) A macrophyte submodel for aquatic ecosystems. Aquatic Botany 33: 191-206.

Creed, R.P. Jr. (1994) Direct and indirect effects of crayfish grazing in a stream community. Ecology 75: 2091-2103.

Creed, R.P. Jr. and Sheldon. S.P. (1993) The effect of feeding by a North American weevil, Euhrychiopsis lecontei, on Eurasion waterfmilfoil (Myriophyllum spicatum) Aquatic Botany 45: 245-256.

Crivelli, A.J. (1983) The destruction of aquatic vegetation by carp. A comparison between southern France and the United States. Hydrobiologia 106: 37-41.

Dawson, F.H. (1978) Aquatic plant management in semi-natural streams: The role of marginal vegetation. Journal of Environmental Management 6: 213-221.

deWit, C.T. (1965) Photosynthesis of leaf canopy. Agricultural Resources Report 663. 57 p. (cited in Titus et al.. 1975)

Dodds, W.K. (1991a) Community interactions between the filamentous alga Cladophora glomerata (L.) Kutzing, its epiphytes and epiphyte grazers. Oecologia 85:572580 .

Dodds, W.K. (1991b) Factors associated with dominance of the filamentous green alga Cladophora glomerta. Water Research 25: 1325-1332.

Drolc, A. and Koncan, J.Z. (1996) Water quality modelling of the River Sava, Slovenia. Water Research 30: 2587-2592. 
Dudley, T.L. and D'Antonio, C.M. (1991) The effects of substrate texture, grazing and disturbance on macroalgal establishment in streams. Ecology 72: 297-309.

Duncan, W.G., Loomis, R.S., Williams, W.A., Hanau, R. (1967) A model for simulating photosynthesis in plant communities. Hilgardia 38: 181-205.

Everitt, D.T. and Burkholder, J.M. (1991) Seasonal dynamics of macrophyte communities from a stream flowing over granite flatrock in North Carolina, USA. Hydrobiologia 222:159-172.

Feminella, J.W. and Resh, V.H. (1991) Herbivorous caddisflies, macroalgae, and epilithic microalgae: dynamic interactions in a stream grazing system. Oecologia 87: 247256.

French, T.D. and Chambers, P.A. (1996) Habitat partitioning in riverine macrophyte communities. Freshwater Biology 36: 509-520.

Gordon, D.M. and McComb, A.J. (1989) Growth and production of the green alga Cladophora montagneana in a eutrophic Australian estuary and its interpretation using a computer program. Water Research 23: 633-645.

Graham, J.M, Auer, M.T., Canale, R.P., Hoffman, J.P. (1982) Ecological studies and mathematical modeling of Cladophora in Lake Huron: 4. Photosynthesis and respiration functions of light and temperature. Journal of Great Lakes Research 8:100-110.

Gregg, W.W. and Rose, F.L. (1982) The effects of aquatic macrophytes on the stream microenvironment. Aquatic Botany 14:309-324.

Gumbricht, T. (1993a) Nutrient removal capacity in submersed macrophyte pond systems in a temperate climate. Ecological Engineering 2: 49-61.

Gumbricht, T. (1993b) Nutrient removal processes in freshwater submersed macrophyte systems. Ecological Engineering 2: 1-30.

Hart, D.D. (1992) Community organization in streams: the importance of species interactions, physical factors, and chance. Oecologia 91: 220-228.

Hill, A.R. (1982) Phosphorus and major cation mass balances for two rivers during low summer flows. Freshwater Biology 12: 293-304.

Holford, I.C.R. and Patrick, W.H. Jr. (1979) Effects of reduction and pH changes on phosphate sorption and mobility in an acid soil. Soil Science Society of America Journal 43: 292-297. 
Howard-Williams, C. (1985) Cycling and retention of nitrogen and phosphorus in wetlands: a theoretical and applied perspective. Freshwater Biology. 15: 391-431.

James, W. (1994) Rules for Responsible Modelling. Computational Hydraulics International, Ontario.

Jupp, B.P. and Spence, D.H.N. (1977) Limitations on macrophytes in a eutrophic lake, Loch Leven. II. wave action, sediments and waterfowl grazing. Journal of Ecology 65:431-446.

Khalid, R.A., Patrick, W.H., DeLaune, R.D. (1977) Phosphorus sorption characteristics of flooded soils. Soil Science Society of America Journal 41:305-310.

Khedr, A.H.A, El-Demerdash, M.A. (1997) Distribution of aquatic plants in relation to environemtnal factors in the Nile Delta. Aquatic Botany 56:75-86.

Ku, W.C., DiGiano, F.A. and Feng, T.H. (1978) Factors affecting phosphate adsorption equilibria in lake sediments. Water Research 12: 1069-1074.

Lester, W.W., Adams, M.S. Farmer, A.M. (1988) Effects of light and temperature on photosynthesis of the nuisance alga Cladophora glomerata (L.) Kutz from Green Bay, Lake Michigan. The New Phytologist 109:53-58.

Lodge, D.M. (1991) Herbivory on freshwater macrophytes. Aquatic Botany 41: 195-224.

Lodge, D.M., Kershner, M.W., Aloi, J.E., Covich, A.P. (1994) Effects of an omnivorous crayfish (Orconectes rusticus) on a freshwater littoral food web. Ecology: 75: 1265-1281.

Lodge, D.M and Lorman, J.G. (1987) Reductions in submersed macrophyte biomass and species richness by the crayfish Orconectes rusticus. Canadian Journal of Fisheries and Aquatic Sciences 44:591-597.

Lohman, K. and Priscu, J.C. (1992) Physiological indicators of nutrient deficiency in Cladophora (Chlorophyta) in the Clark Fork of the Columbia River, Montana. Journal of Phycology 28: 443-448.

Lorman, J.G. and Magnusan, J.J. (1978) The role of crayfishes in aquatic ecosystems. Fisheries 3: 8-10.

Madsen, J.D. and Adams, M.S. (1989a) The distribution of submerged aquatic macrophyte biomass in a eutrophic stream, Badfish Creek: the effect of environment. Hydrobiologia 171:111-119. 
Madsen, J.D. and Adams, M.S. (1989b) The light and temperature dependence of photosynthesis and respiration in Potamogeton pectinatus L. Aquatic Botany 36:23-31.

Madsen, J.D., Hartleb, C.F., Boylen, C.W. (1991) Photosynthetic characteristics of Myriophyllum spicatum and six submersed aquatic macrophyte species native to Lake George, New York. Freshwater Biology 26: 233-240.

Madsen, T.V. and Warncke, E. (1983) Velocities of currents around and within submerged aquatic vegetation. Arch. Hydrobiologia 97:389-394.

Mangile, T. Personal Communication. Aug 28, 1997.

McCallister, D.L. and Logan, T.J. (1978) Phosphate adsorption-desorption characteristics of soils and bottom sediments in the Maumee River Basin of Ohio. Journal of Environmental Quality 7: 87-92.

MOEE (1994) Water Management-Policies, Guidelines, and Provincial Water Quality Objectives of the Ministry of Environment and Energy. MOEE.

Monteith, J.L. (1965) Light distribution and photosynthesis on field crops. Ann. Botany NS 19: 17-37. (cited in Titus et al., 1975)

Novotny, V. and Olem, H. (1994) Water Quality. Prevention, Identification, and Management of Diffuser Pollution. Van Nostrand Reinhold. New York. U.S.A. ISBN: 0-442-00559-8.

Nystrom, P. and Strand. J.A. (1996) Grazing by a native and an exotic crayfish on aquatic macrophytes. Freshwater Biology 36: 673-682.

Olila, O.G. and Reddy, K.R. (1995) Influence of $\mathrm{pH}$ on phosphorus retention in oxidized lake sediments. Soil Science Society of America Journal 59: 946-959.

Ondok, J.P. and Pokorny, J. (1987) Modelling photosynthesis of submerged macrophyte stands in habitats with limiting inorganic carbon I. Model description. Photosynthetica 21: 543-554.

Owens, M., Learner, M.A. and Maris, P.J. (1967) Determination of biomass of aquatic plants using an optical method. Journal of Ecology 55: 671-676.

Owttrim, G.W. and Colman, B. (1989) Measurement of the photorespiratory activity of the submerged aquatic plant Myriophyllum spicatum L. Plant, Cell and Environment 12:805-811. 
Painter, D.S. and Jackson, M.B. (1989) Cladophora internal phosphorus modeling: verification. Journal of Great Lakes Research 15: 700-708.

Park, S.S. and Lee, Y.S. (1996) A multiconstituent moving segment model for water quality predictions in steep and shallow streams. Ecological Modi!lling 89: 121131.

Planas, D., Maberly, S.C. and Parker, J. E. (1996) Phosphorus and nitrogen relationships of Cladophora glomerata in two lake basins of different trophic status. Freshuater Biology 35: 609-622.

Rabinowitch, E.I. (1951) Photosynthesis and related processes. Vol. II, Part 1. Interscience, New York, 1208 p.

Reddy, K.R., Flaig, E., Scinto. L.J., Diaz, O. DeBusk, T.A. (1996) Phosphorus assimilation in a stream system of the Lake Okeechobee Basin. Water Resources Bulletin 32: 901-915.

Robinson, A. R. and McKay, G. (1990) Regional scale dynamical modelling of biogeochemical processes. Harvard Univ., Cambridge, MA (USA). Div. of Applied Sciences, $31 \mathrm{p}$.

Robinson, J.S., Sharpley, A.N.. Smith, S.J. (1994) Development of a method to determine bioavailable phosphorus loss in agricultural runoff. Agriculture, Ecosystems and Environment 47: 287-297.

Rørslett, B. and Johansen, S.W. (1996) Remedial measures connected with aquatic macrophytes in Norwegian regulated river and reservoirs. Regulated Rivers: Research and Management 12: 509-522.

Rosemarin, A.S. (1982) Phosphorus nutrition of two potentially competing filamentous algae, Cladophora glomerata Kutz. and Stigeoclonium tenue (Agardh) Kutz. from Lake Ontario. Journal of Great Lakes Research 8: 66-72.

Sand-Jensen, K. (1983) Photosynthetic carbon sources of stream macrophytes. Journal of Experimental Biology 34:198-210.

Sand-Jensen, K. Jeppesen, E., Nielson, K., van der Bijl, L., Hjermind, L., Nielsen, L.W. Iversen, T.M. (1989) Growth of macrophytes and ecosystem consequences in a lowland Danish stream. Freshwater Biology 22:15-32.

Scheffer, M., Bakema, A. H., Wortelboer, F.G. (1993) MEGAPLANT: a simulation model of the dynamics of submerged plants. Aquatic Botany 45: 341-356. 
Schmitt, M.R. and Adams, M.S. (1981) Dependence of rates of apparent photosynthesis on tissue phosphorus concentrations in Myriophyllum spicatum L. Aquatic Botany 11: 379-387.

Schugart, R.A., Golstein, R.A., O'Neill, R.V., Mankin, J.B. (1974) TEEM: A terrestrial ecosystem energy model for forests. Oecologia Plantarum 9: 231-264.

Simpson, J.W. and Eaton, J.W. (1986) Comparative studeis of the photosynthesis of the submerged macrophyte Elodea canadensis and the filamentous algae Cladophora glomerata and Spirogyra sp. Aquatic Botany; 24:1-12

Smith, C.S. and Adams, M.S. (1986) Phosphorus transfer from sediments by Myriophyllum spicatum. Limnology and Oceanography 31: 1312-1321.

Spencer, D.F. (1986) Early growth of Potamogeton pectinatus (L.) in response to temperature and irradiance: morphology and pigment composition. Aquatic Botany 26:1-12.

Steele, J.H. (1962) Environmental control of photosynthesis in the sea. Limnology and Oceanography 7: 137-150.

Stevenson, J.C. (1988) Comparitive ecology of submersed grass beds in freshwater, estuarine, and marine environments. Limnology and Oceanography 33: 867-893.

Thorton, K.W. and Lessem, A.S. (1978) A temperature algorithm for modifying biological rates. Trans. American Fisheries Society 107: 284-287.

Tilman, D. and Kilham, S. S. (1976) Phosphate and silicate growth and uptake kinetics of the diatoms Asterionella formosa and Cyclotella meneghiniana in batch and semicontinuous culture. Journal of Phycology 12: 375-383.

Titus, J.E. and Adams, M.S. (1979) Coexistence and the comparative light relations of the submersed macrophytes Myriophyllum spicatum L. and Vallisneria americana Mich. Oecologia (Berlin) 40:273-276. (cited in Barko et al., 1982)

Titus, J.E., Goldstein, R.A., Adams, M.S., Mankin, J.B., O’Neill, R.V., Weiler, P.R., Jr., Shugart, H.H., Booth, R.S. (1975) A production model for Myriophyllum spicatum L. Ecology: 56: 1129-1138.

Toerien, D.F., Cary, P.R., Finlayson, C.M., Mitchell, D.S., Weerts, P.G.J. (1983) Growth models for Salvinia molesta. Aquatic Botany 16: 173-179. 
Van der Bijl, L., Sand-Jensen, K., Hjermind, A.L. (1989) Photosynthesis and canopy structure of a submerged plant, Potamogeton pectinatus, in a Danish lowland stream. Journal of Ecology 77: 947-962.

Van Donk, E. and Otte, A. (1996) Effects of grazing fish and waterfowl on the biomass and species composition of submerged macrophytes. Hydrobiologia 340: 285290.

Van Wijk, R.J. (1988) Ecological studies on Potamogeton pectinatus L. I. General characteristics, biomass production and life cycles under field conditions. Aquatic Botany 31: 211-258.

Van Wijck, C., Grillas, P., De Groot, C.J., Tan Ham, Laurine (1994) A comparison between the biomass production of Potamogeton pectinatus L. and Myriophyllum spicatum $\mathrm{L}$. in the Camargue (southern France) in relation to salinity and sediment characteristics. Vegetatio 113: 171-180.

Van, T.K., Haller, W.T., Bowes, G. (1976) Comparison of the photosynthetic characteristics of three submersed aquatic plants. Plant Physiology 58:761-768.

Walker, R., Weatherbe, D.G., Willson, K. (1982) Grand River Management Study, Technical Report Series: No.14.

Weisner, S.E.B., Strand, J.A., Sandsten, H. (1997) Mechanisms regulating abundance of submerged vegetation in shallow eutrophic lakes. Oecologia 109: 592-599.

Westlake, D.F. (1964) Light extinction, standing crop and photosynthesis within weed beds. Verh. Internat. Verein. Limnology. 15: 415-425. (cited in Sand-Jensen et al., 1989)

Westoby, M. (1984) The self-thinning rule. Advanced Ecology Research 14: 167-226.

Wong, S.L., Clark, B., Kirby, M., Kosciuw, R.F. (1978) Water temperature fluctuations and seasonal periodicity of Cladophora and Potamogeton in shallow rivers. Journal of the Fisheries Resources Board of Canada 35:866-870.

Wright, R. M. and McDonnell, A.J. (1986a) Macrophyte growth in shallow streams: field investigations. Journal of Environmental Engineering 112: 953-966.

Wright, R. M. and McDonnell, A.J. (1986b) Macrophyte growth in shallow streams: biomass model. Journal of Environmental Engineering 112: 967-982. 


\section{APPENDIX A: ECOL98AH CODE AS SEEN IN GRSM98AH CODE}

C PROGRAM UPDATE JANUARY 30, 1980

C CHANGES MADE IN 1995 BY GORE \& STORRIE - DR. RAY DEWEY

c0 **********************************4)

c0 CHANGES MADE IN 1998 BY U OF G

c0 LEGEND FOR U OF G 98 CHANGES:c0 INTRODUCTION/LEGEND

c0 cl U OF G 98 PHOSPHORUS KINETIC EQUATIONS AND RESULTING

cO NEW BIOMASS EQUATIONS

c0 cla DECLARING U OF G 98 PHOS VARIABLES/CONSTANTS

c0 c]b DEFINING U OF G 98 PHOS CONSTANTS

c0 clc PRE-U OF G BIOMASS PRODUCTION EQUATIONS

c0 c4 U OF G98 LIGHT CHANGES

c0 c4a DECLARING U OF G 98 LIGHT VARIABL.ES/CONSTANTS

c0 c4b DEFINING U OF G 98 LIGHT CONSTANTS

c0 c4c PRE-U OF G CALCULATIONS FOR THE LIGHT EFFECTS ON GROWTH RATES

c0 c7 U OF G 98 TEMP EQUATIONS

c0 c7a DECLARING U OF G 98 TEMP VARIABLES/CONSTANTS

c0 c7b DEFINING U OF G 98 TEMP CONSTANTS

c0 c7c PRE-U OF G CALCULATIONS OF TEMPERATURE CORRECTION

c0 FACTORS FOR CLAD,POT AND MIL

c0

SUBROU'TINE ECOL( JD, TS, TEMP, CLAD, POT, EPI, PINP, FPIN, NIN,

* SOLRAD, SS, HOUR, O2LAST, O2UP, O2P, NUP, NREL,

* PUP, PREL, DEPTH, SAREA, AINHC, AINHP, AINHE, irch,

* $\quad$ tres,tprod)

C

C ECOLOGICAL MODEL

C MODIFICATION FEBRUARY 20, 1980

C

INCLUDE 'PRMTR.FI' 
INCLUDE 'ECOLRATE.FI'

REAL DEPTH

REAL ITHER,KE,NSUPLY,NFAC,NIN,NUP,NREL

cla $U$ OF $G 98$ CONSTANTS AND VARIABLE FOR MICHAELIS MENTEN KINETICS

REAL Q,QNOT,ROWP,ROWPMAX,KMPCLAD,KQPCLAD,KMPPOT,KMPEPI,CLADP,POTP,

- EPIP

c4a U OF G 98 CONSTANTS AND VARIABLE FOR LIGHT CHANGES

REAL KW,KMLC,KMLP,KMLE

c7a U OF G 98 CONSTANTS AND VARIABLE FOR TEMPERATURE CHANGES (THORNTON AND LESSEM)

c7a CLADOPHORA

REAL GAMMAIC,TEMPOPT2C,TEMPMINC,K2C,KIC,GAMMA2C,TEMPMAXC,

* TEMPOPT3C,K3C,K4C,KAC,KBC,TEMPCI,C_WASHOFF_TEMPL.

c7a POTAMEGETON

REAL GAMMAIP,TEMPOPT2P,TEMPMINP,K2P,KIP,GAMMA2P,TEMPMAXP,

* TEMPOPT3P,K3P,K4P,KAP,KBP,TEMPPI

c7a MILFOIL

REAL GAMMAIM,TEMPOPT2M,TEMPMINM,K2M,KIM,GAMMA2M,TEMPMAXM,

* TEMPOPT3M,K3M,K4M,KAM,KBM,TEMPMI

clb SETTING VALUES TO CONSTANTS FOR MICHAELIS MENTEN KINETICS

PARAMETER (ROWPMAX $=0.3, \mathrm{KMPCLAD}=83, \mathrm{KQPCLAD}=0.07$ )

PARAMETER (QNOT $=0,02, \mathrm{KMPPOT}=8, \mathrm{KMPEPI}=8$ )

$c 4 b$ SETTING VALUES TO CONSTANTS FOR LIGHT CHANGES

PARAMETER (KMLC $=0.09, \mathrm{KMLP}=0.09, \mathrm{KMLE}=0.117$ )

c7b SETTING VALUES TO CONSTANTS FOR TEMPERATURE CHANGES (THORNTON AND LESSEM)

c7b CLADOPHORA

PARAME'TER $($ TEMPMINC $=7$, TEMPOPT2C $=15$, TEMPOPT3C $=20$, TEMPMAXC $=28$ )

PARAME'TER $(\mathrm{KIC}=0.1, \mathrm{~K} 2 \mathrm{C}=.98, \mathrm{~K} 3 \mathrm{C}=0.98, \mathrm{~K} 4 \mathrm{C}=0.1)$

PARAMETER (C WASHOFF TEMPL $=12$ )

c7b POTAMEGETON

PARAMETER (TEMPMINP $=10$, TEMPOPT2P $=24$, TEMPOPT3P $=31$, TEMPMAXP $=37$ )

PARAMETER $(K 1 \mathrm{P}=0.1, \mathrm{~K} 2 \mathrm{P}=0.98, \mathrm{~K} 3 \mathrm{P}=0.98, \mathrm{~K} 4 \mathrm{P}=0.1)$

c7b MILFOIL

PARAME'TER (TEMPMINM $=10$, TEMPOPT2M=30,TEMPOPT3M=35, TEMPMAXM $=54$ )

PARAME'TER (KIM=0.I,K2M $=0.98, K 3 \mathrm{M}=0.98, \mathrm{~K} 4 \mathrm{M}=0.1)$

DATA NLINES/0/

cc OPEN (UNIT=57,FILE='MICMEN.FI',STATUS='OLD')

cc READ $(57, *)$ ROWPMAX,KMPCLAD,KQPCLAD,KMPPOT,KMPEPI,QNOT 
cc CLOSE (UNIT $=57)$

$\mathrm{C}$

C CALCULATIONS OF TEMPERATURE CORRECTIONS

c7 U OF G 98 CALC OF TEMPERATURE FACTOR FOR CLAD BASED ON THORNTON AND LESSEM'S MODEL

GAMMAIC $=1 /\left(\right.$ TEMPOPT2C-TEMPMINC) $*$ LOG $\left(\left(K 2 C^{*}(1-K I C)\right) /\left(\mathrm{K} 1 C^{*}(1-K 2 C)\right)\right)$

GAMMA2C $=1 /(\text { TEMPMAXC-TEMPOPT3C })^{*} \operatorname{LOG}\left(\left(K 3 C^{*}(1-K 4 C)\right) /\left(K 4 C^{*}(1-K 3 C)\right)\right)$

$K A C=K I C^{*} \operatorname{EXP}($ GAMMAIC*$($ TEMP-TEMPMINC) $)$

* $\left(1+K I C^{*}(\operatorname{EXP}(\right.$ GAMMAIC*(TEMP-TEMPMINC))-1))

$K B C=K 4 C^{*} \operatorname{EXP}($ GAMMA2C*(TEMPMAXC-TEMP))

* $\left(1+K 4 C^{*}(\right.$ EXP(GAMMA2C*(TEMPMAXC-TEMP))-1 $\left.)\right)$

TEMPCI $=\mathrm{KAC} * \mathrm{KBC}$

CTFP=TEMPC 1

c7c PRE-U OF G CALCULATIONS OF TEMPERATURE CORRECTION FACTOR FOR CLAD

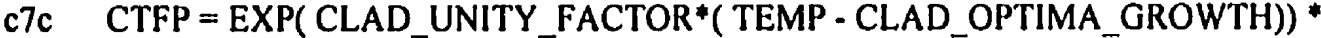

c7c * ((CLAD_UPPER_TEMP - TEMP )/

c7c * (CLAD_UPPER_TEMP - CLAD_OPTIMA_GROWTH)) ** CLAD_SHAPE_FACTOR

C? COMMENTED OUT PRE-U OF G TEMP CORRECTION FACTOR FOR CLAD

C? $\quad$ CTFP $=E X P\left(1.00^{*}(T E M P-20.0)\right)^{*}((35 .-T E M P) / 15 .)^{* *} 15.0$

c? IF (TEMP.GE.25.) CTFP $=\left(\text { CTFP }^{* *} 0.27\right)^{*}(-1.00)$

c7 U OF G 98 CALC OF TEMPERATURE FACTOR FOR POT BASED ON THORNTON AND LESSEM'S MODEL GAMMA IP $=1 /(\text { TEMPOPT2P-TEMPMINP })^{*} \operatorname{LOG}\left(\left(\mathrm{K} 2 \mathrm{P}^{*}(1-\mathrm{K} I \mathrm{P})\right) /(\mathrm{K} I \mathrm{P} *(1-\mathrm{K} 2 \mathrm{P}))\right)$

GAMMA2P $=1 /(\text { TEMPMAXP-TEMPOPT3P) })^{*} \mathrm{LOG}((\mathrm{K} 3 \mathrm{P} *(1-\mathrm{K} 4 \mathrm{P})) /(\mathrm{K} 4 \mathrm{P} *(1-\mathrm{K} 3 \mathrm{P})))$

$K A P=K 1 P * \operatorname{EXP}(G A M M A I P *(T E M P-T E M P M I N P)) /$

* $(1+K I P *(E X P(G A M M A I P *(T E M P-T E M P M I N P))-1))$

$K B P=K 4 P * E X P(G A M M A 2 P *(T E M P M A X P-T E M P)) /$

* $\left(1+K 4 P^{*}(\right.$ EXP(GAMMA2P*(TEMPMAXP-TEMP))-1))

TEMPP $1=K A P * K B P$

PTFP=TEMPPI 
c7c PRE-U OF G CALCULATIONS OF TEMPERATURE CORRECTION FACTOR FOR POT

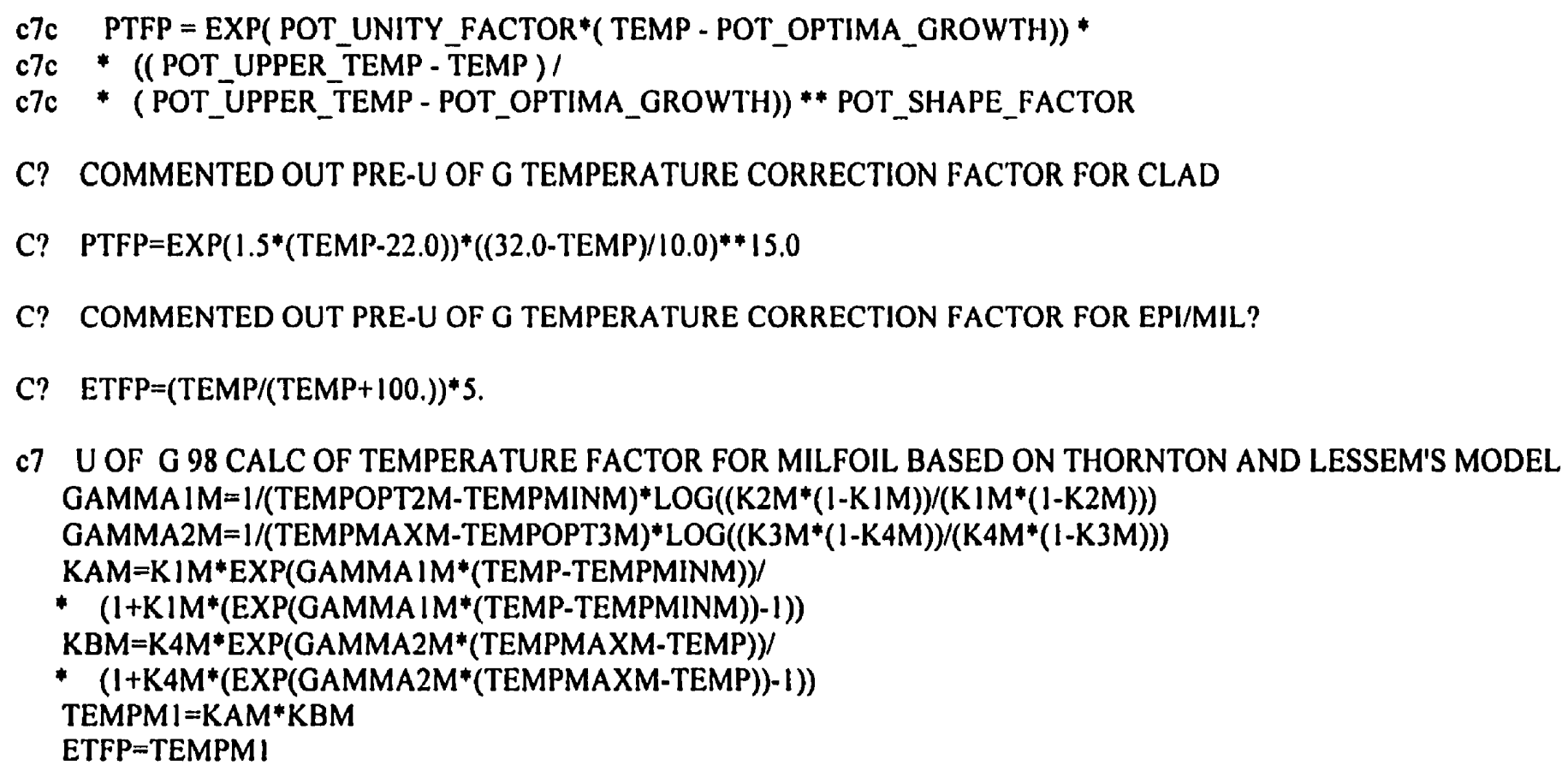

c7c PRE-U OF G CALCULATIONS OF TEMPERATURE CORRECTION FACTOR FOR MILFOIL

c7c ETFP $=$ EXP $(\text { MILF_UNITY_FACTOR* }(\text { TEMP - MILF_OPTIMA_GROWTH }))^{*}$

c7c * ((MILF_UPPER_TEMP-TEMP $) /$

c7c * (MILF_UPPER_TEMP-MILF_OPTIMA_GROWTH)) ** MILF_SHAPE_FACTOR

C? COMMENTED OUT PRE-U OF G TEMPERATURE FACTOR FOR EPI/MIL?

C? $\operatorname{ETFP}=\operatorname{EXP}\left(1.875^{*}(\mathrm{TEMP}-24.0)\right)^{*}((32.0-\mathrm{TEMP}) / 8.0)^{* *} 15.0$

$\mathrm{CTFR}=\mathrm{TC} *$ (TEMP-20.) 


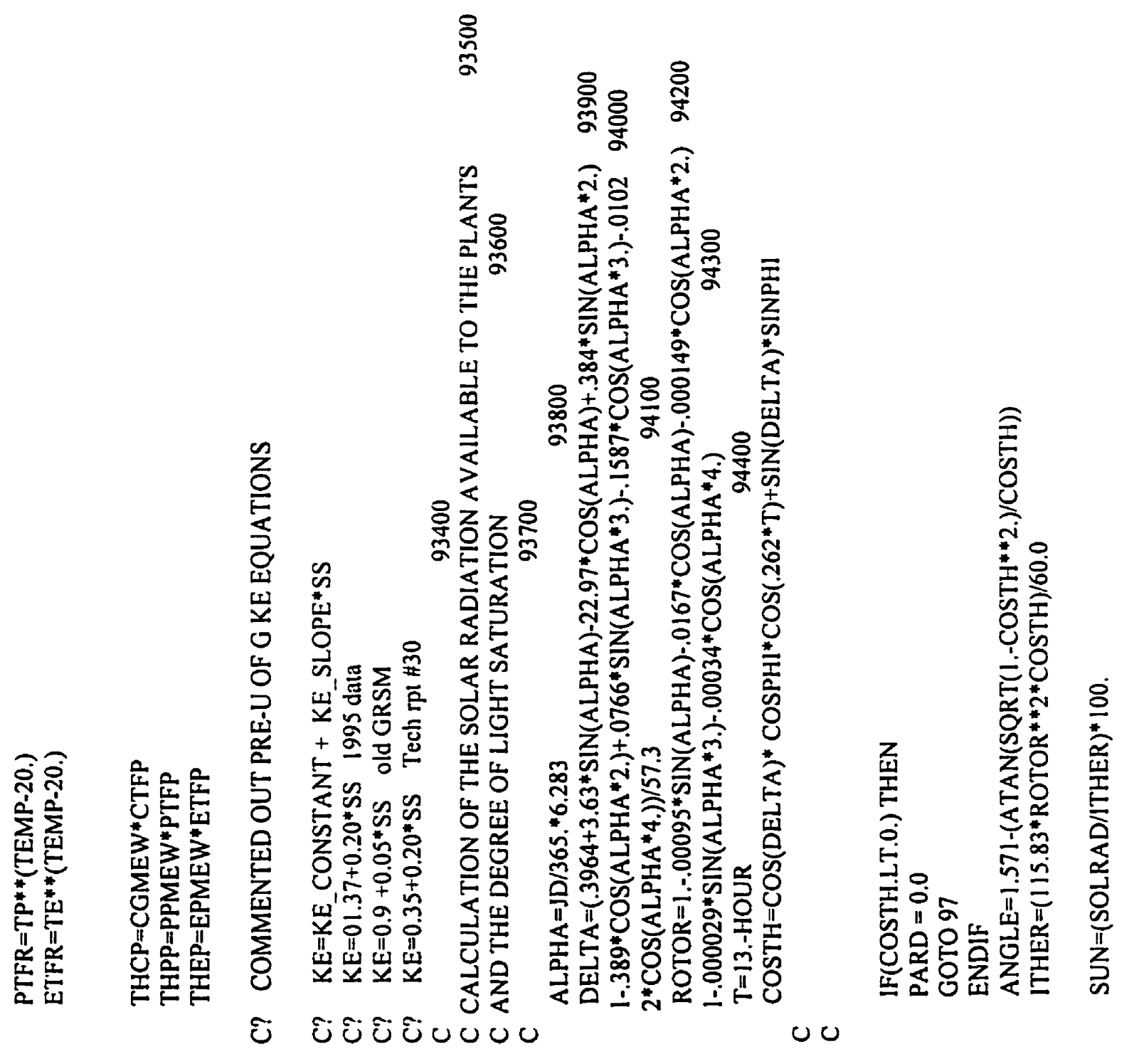



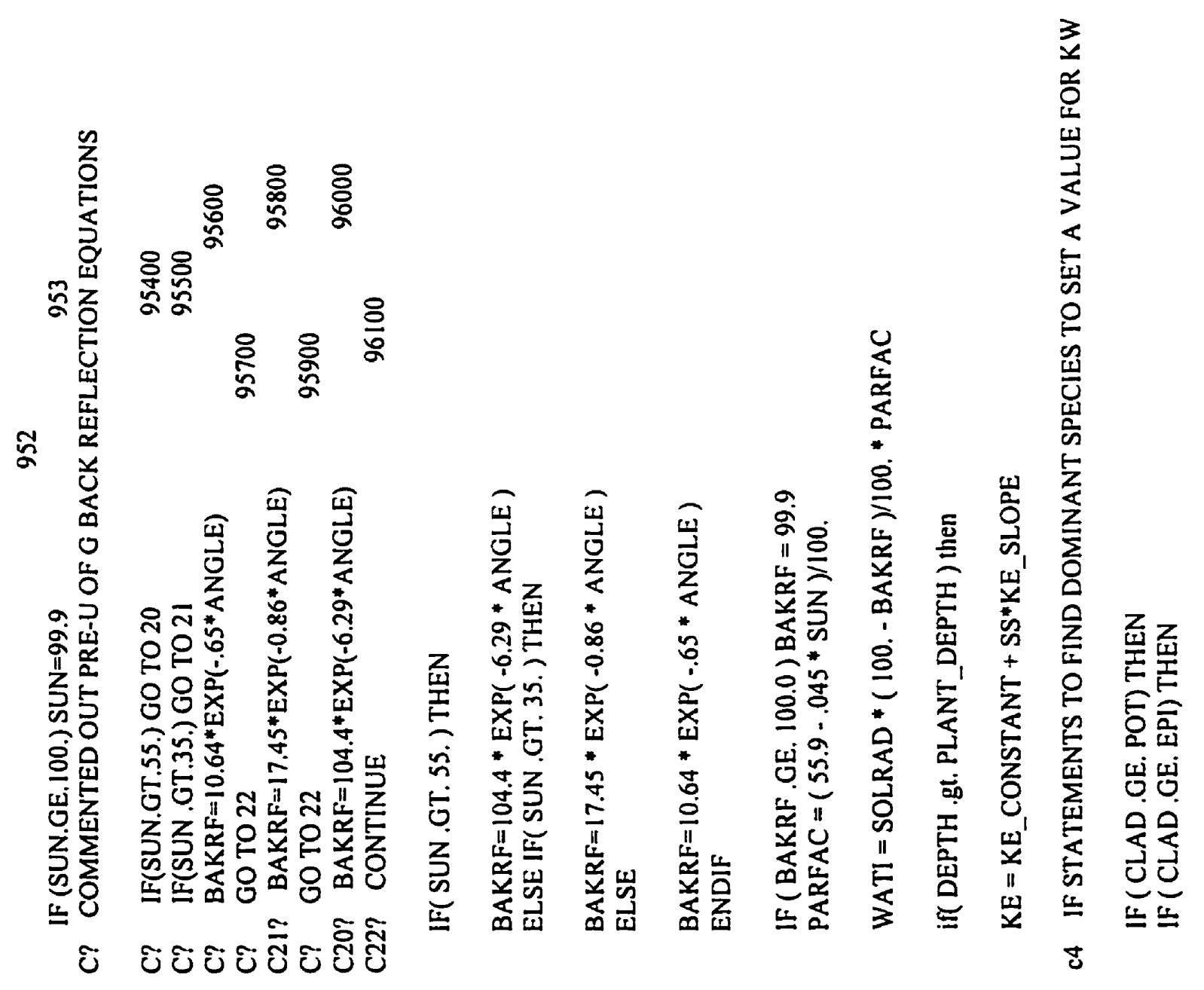
c .024

$\mathrm{KW}=.006$

ELSE

$\mathrm{KW}=0.0083$

ENDIF

ELSEIF (POT .GT. EPI) THEN

$\mathrm{KW}=0.024$

ELSE

$\mathrm{KW}=0.0083$

ENDIF

c4 U OF G 98 CALCULATIONS FOR THE LIGHT EFFECTS OF GROWTH RATES

PARD=WATI*EXP(-KE *(DEPTH - PLANT_DEPTH) $\left.-K W^{*}(C L A D+P O T+E P I)\right)$

C4C PRE-U OF G CALCULATIONS FOR THE LIGHT EFFECTS ON GROWTH RATES

c4c PARD $=$ WATI*EXP $($ KE* $*$ (PLANT_DEPTH - DEPTH $)$ )

C? COMMENTED OUT PRE-U OF G EQUATIONS FOR LIGHT AVAILABLE TO PLANTS FOR PHOTOSYNTHESIS

C? PARD $=$ WATI*EXP( $-K E *$ DEPTH $/ 2$.
else
pard=wati
endif

97 CONTINUE

96600

PFAC $=1.0$

96700

PDEN=CLAD+POT

C? COMMENTED OUT PRE-U OF G TOTAL PLANT DENSITY

C? PDEN2=PDEN+EPI

96800 
PDEN2 $=$ EPI

SHADEI $=$ COS $($ PDEN/SHADE_FACT_I $)$

IF ( SHADEI LT. 0.5) SHADEI $=0.5$

IF ( SHADEI LT. 0.0) SHADE $1=0.0$

SHADE2 $=$ COS(PDEN/SHADE_FACT_2)

IF (SHADE2.LT.0.5) SHADE2 $=0.5$

IF (SHADE2,LT,0,0) SHADE2 $=0.0$

SHADE $3=\operatorname{COS}($ PDEN /SHADE_FACT_3)

C COMMENTED OUT PRE-U OF G STATEMENT TO EXPLAIN NEW SHADE3 VALUE DUE TO MOVE TO MILFOIL SPECIES C SHADE3 WAS 0.1 FOR REAL EPI CHANGED TO 0.5 TO SIMULATE MILFOIL

C

IF (SHADE3.LT.0.5) SHADE3 $=0.5$

IF (SHADE3.LT.0.0) SHADE3 $=0.0$

C? COMMENTED OUT PRE-U OF G IF STATEMENT TO DETERMINE SHADE FACTOR FOR MILFOIL

C? IF (PDEN.GT.200.0) SHADE $3=0.5$

C

c7 U OF G 98 RAD CALCULATIONS

RADC $=$ PARD $/(P A R D+K M L C)$

RADP $=$ PARD/(PARD+KMLP)

RADE $=$ PARD $/(P A R D+K M L E)$

c7c PRE U OF G LIGHT LIMITATION CALCULATIONS

c7c $\mathrm{RADC}=\mathrm{PARD} /(\mathrm{PARD}+\mathrm{AIC}) * \mathrm{SHADEI}$

c7c $\mathrm{RADP}=\mathrm{PARD} /(\mathrm{PARD}+\mathrm{AIP}) * \mathrm{SHADE} 2$

97800

c7c RADE $=$ PARD/(PARD+AIE) $)^{*}$ SHADE3

97900

C

IF(SOLRAD .EQ. 0. .OR. PARD .EQ. 0.) GOTO 30

98000 
芯

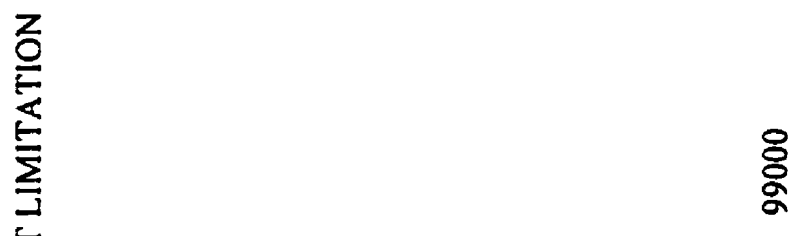

용융요

ஓి

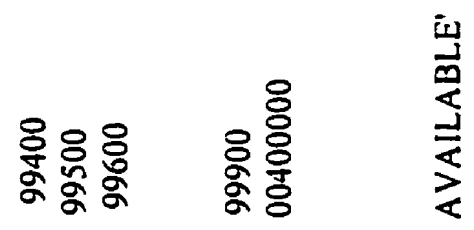

峁

오

究

岸

w $\quad \sum_{0}^{\infty}$

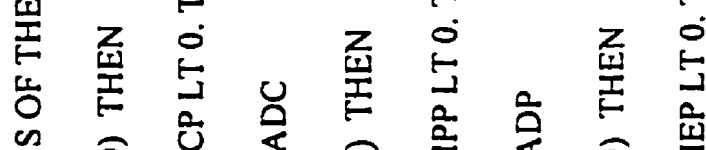

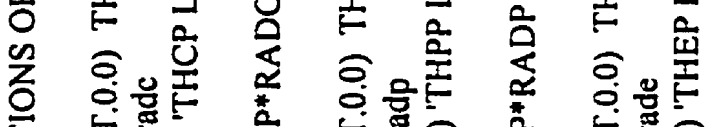

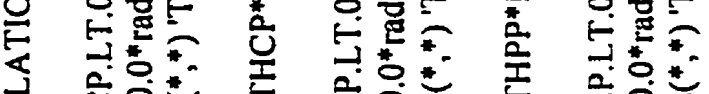

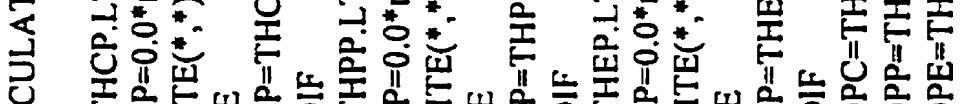

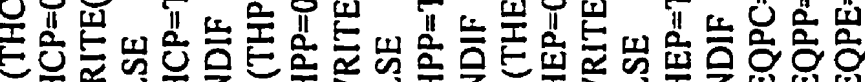

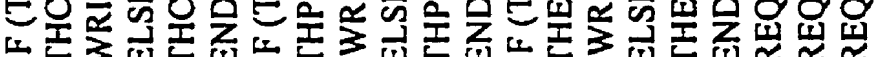

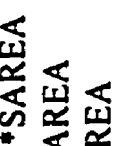

융용

瓷

(U)

क

要苍

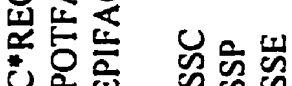

औ正舟

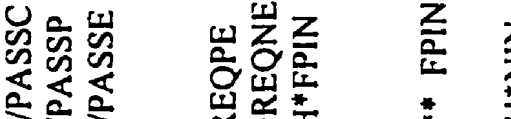

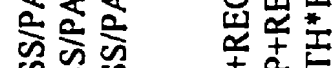

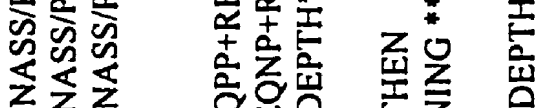

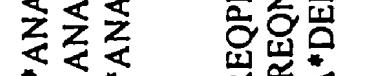

구운

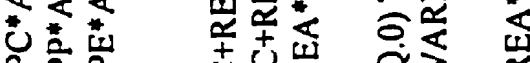

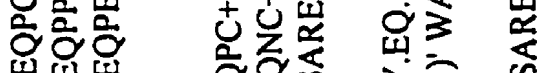

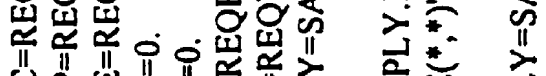

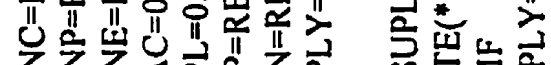

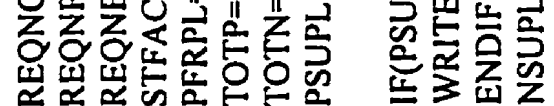
U 


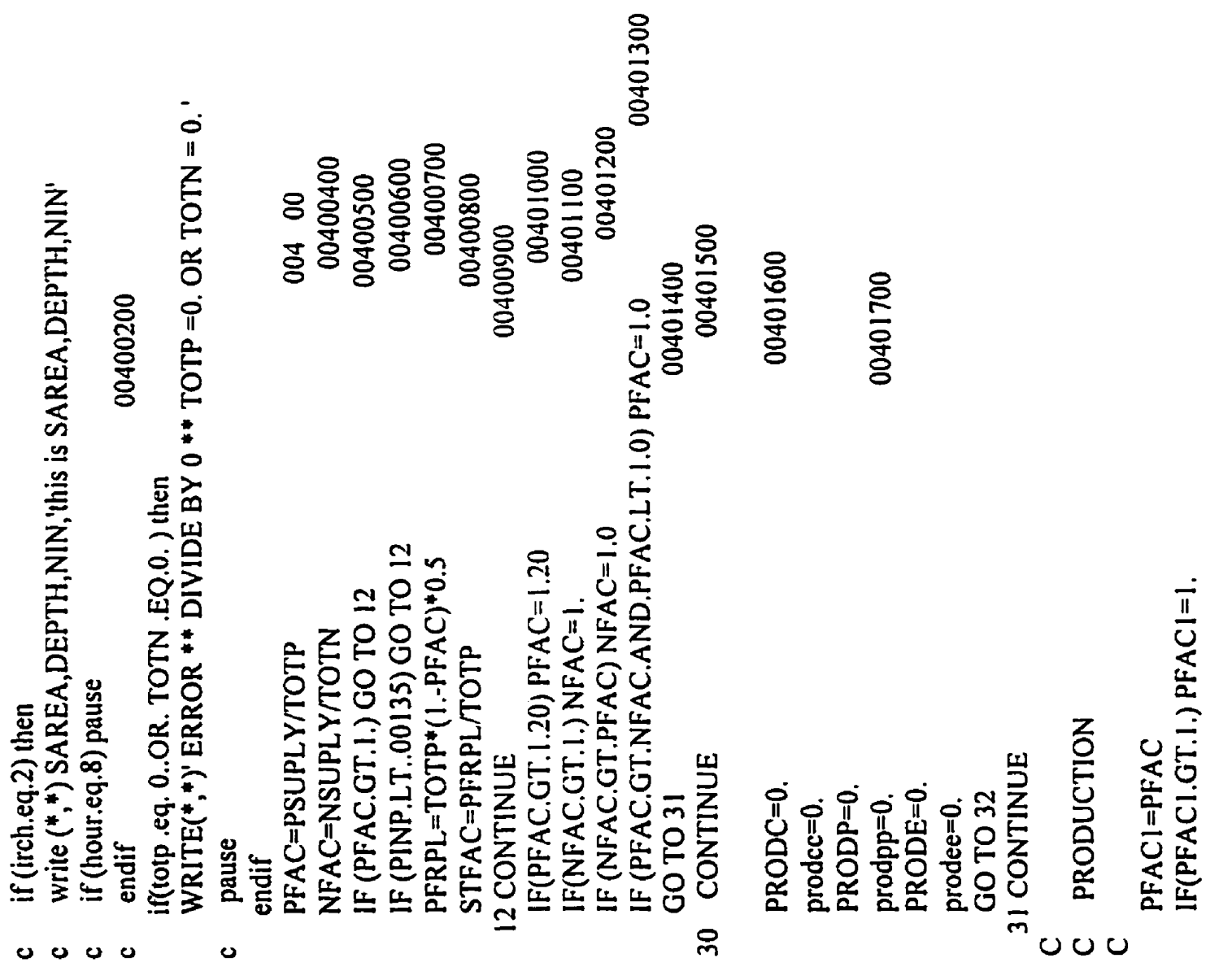



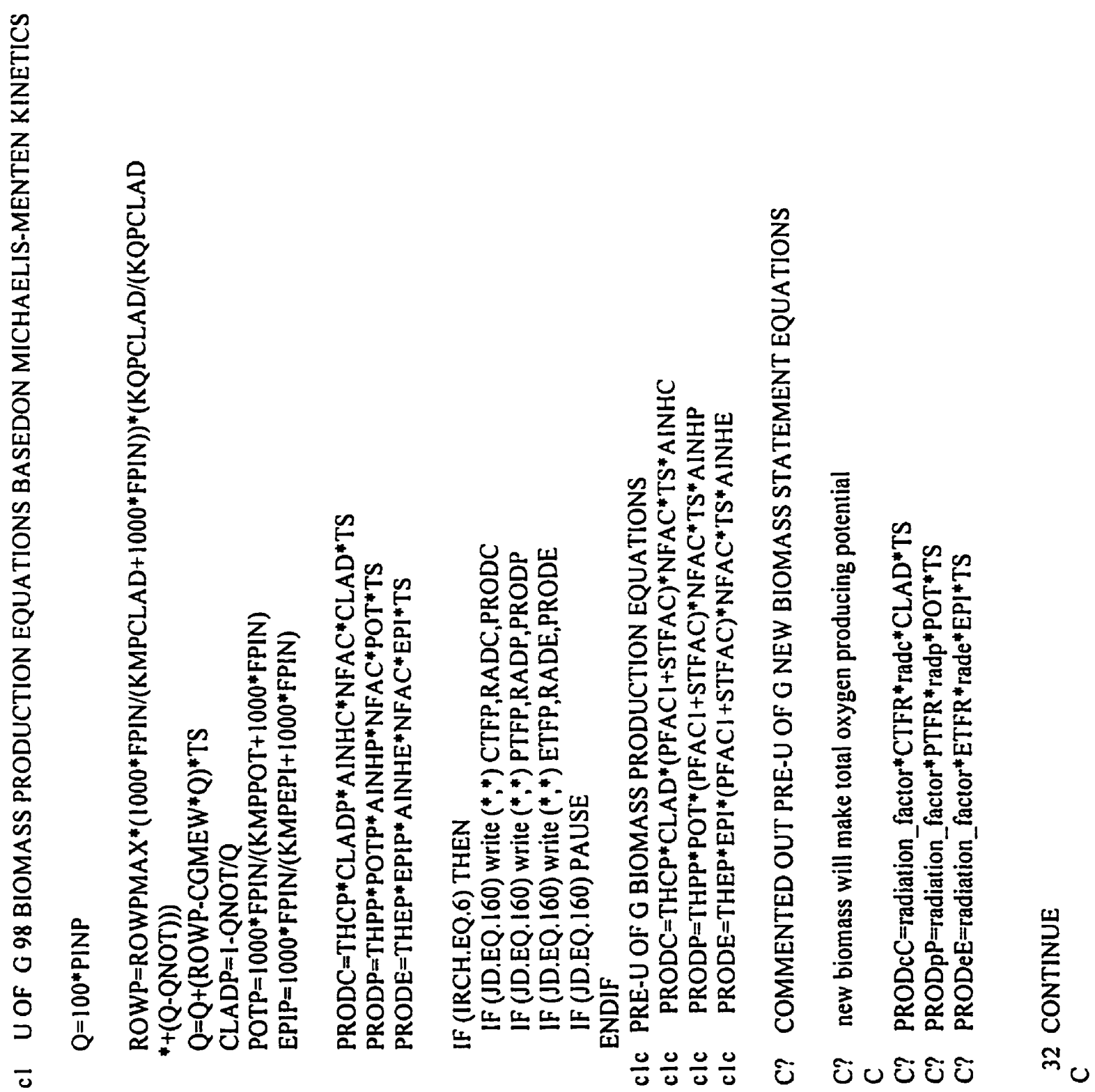


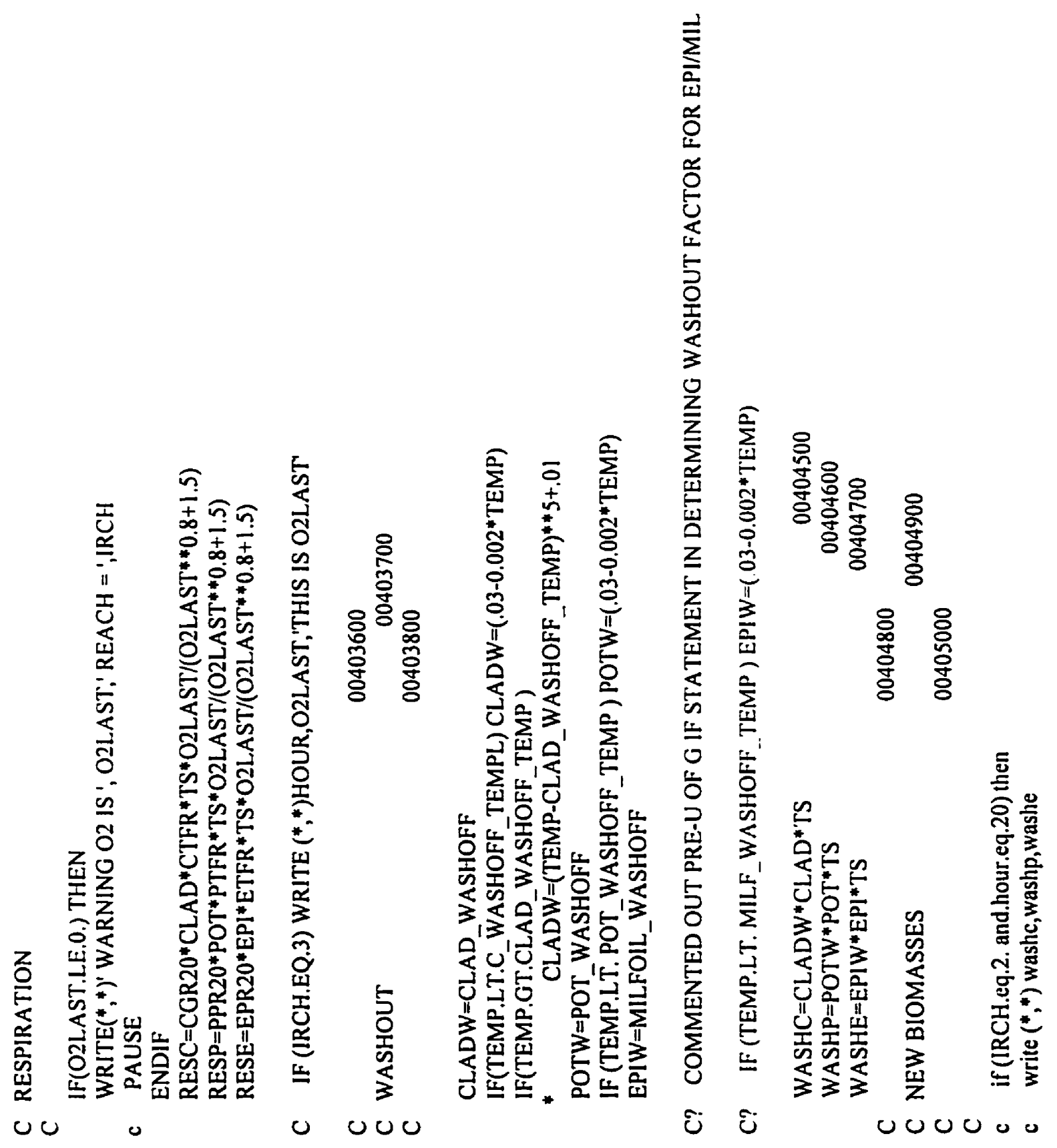




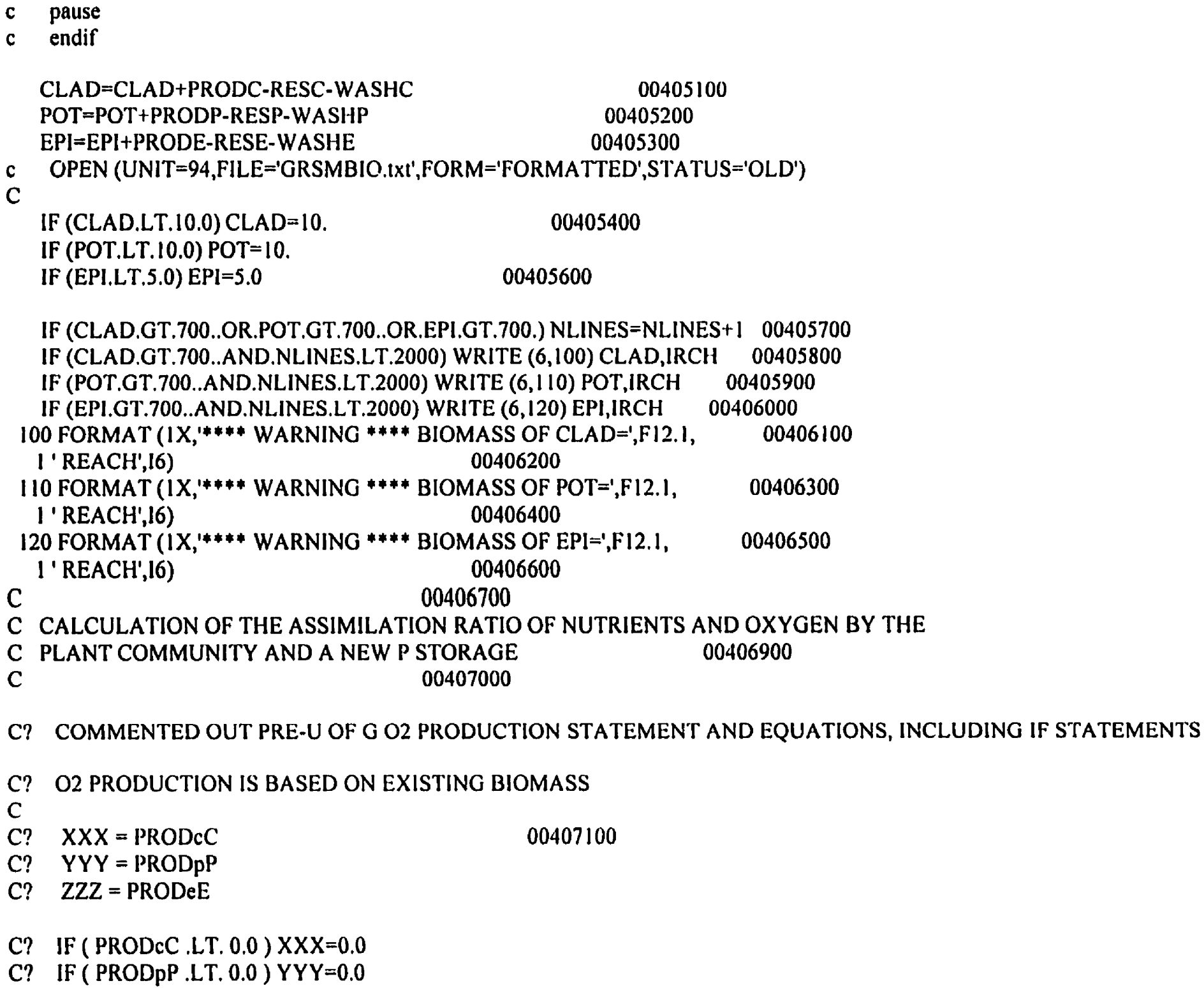



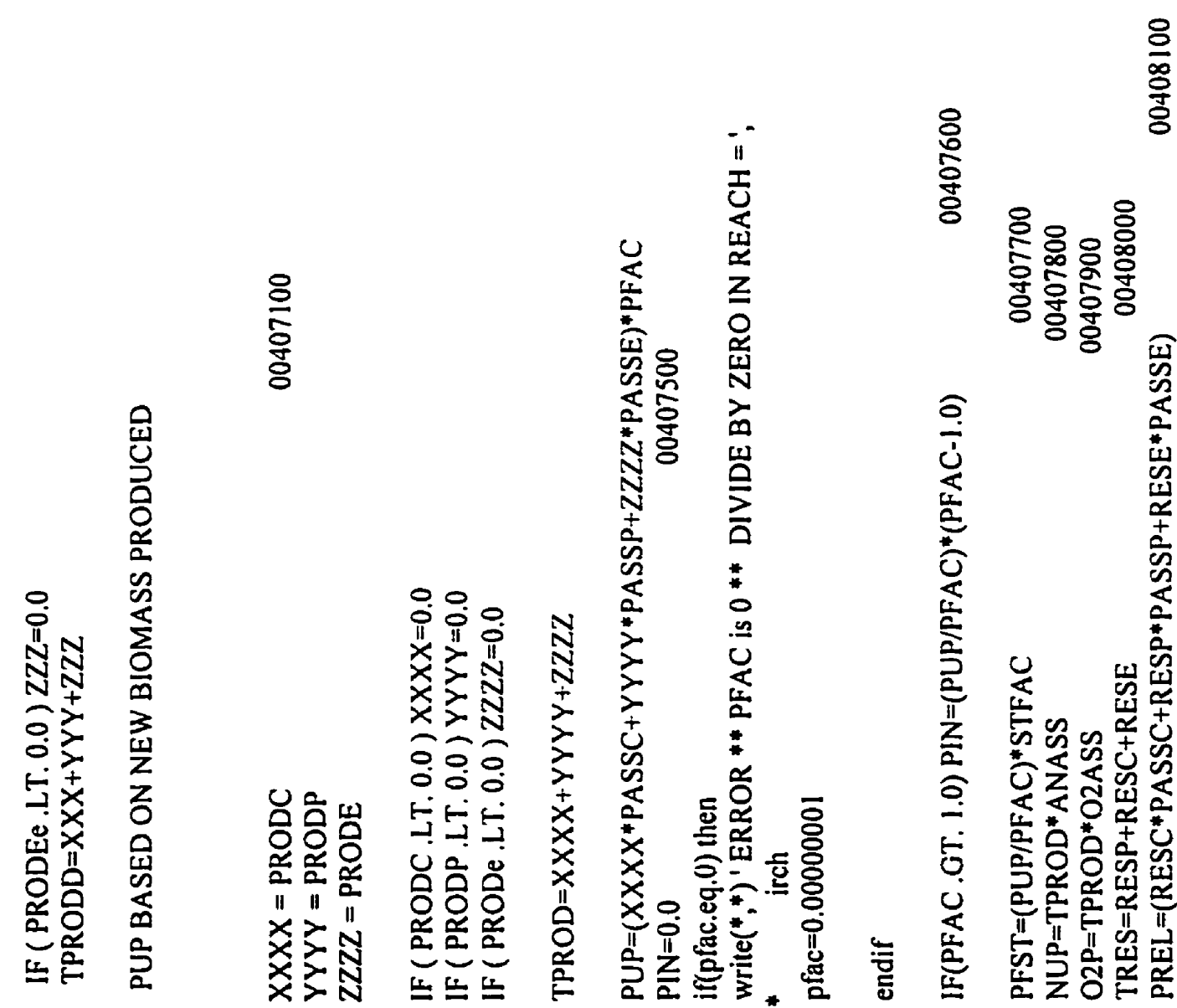
ฮษง ט 


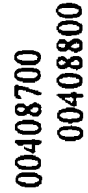

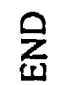




\section{APPENDIX B: STAND ALONE ECOLAH CODE}

\section{PROGRAM CHECKINGRSM98AH}

C This program is designed to grow aquatic plants based on light, temperature and

C phosphorus limitations as in the ECOL subroutine of the GRSM.

CALL NITIALIZE

C This subroutine gives initial values to the instream DO, NOD, BOD and phosphorus

C concentration, the average plant phosphorus concentration, and biomass of the 3

C aquatic plants. It also calculates the surface area covered for each timestep and

C the depth and velocity based on the flow and Leopold Maddock coefficients.

CALL MONTHLYCALC

C This subroutine calculates the sunlight factor per timestep for each month.

CALL STARTLOOP

C This subroutine reads the meteorlogical file (temperature and total radiation for

C each day) and starts the loop that runs through each timestep for every day of the

C simulation.

CALL OUTPUT

C This subroutine writes the main outputs, biomass density of each species and the

C total biomas density, as well as the DO. Each of these outputs are given for each

C timestep of each day of the simulation.

END

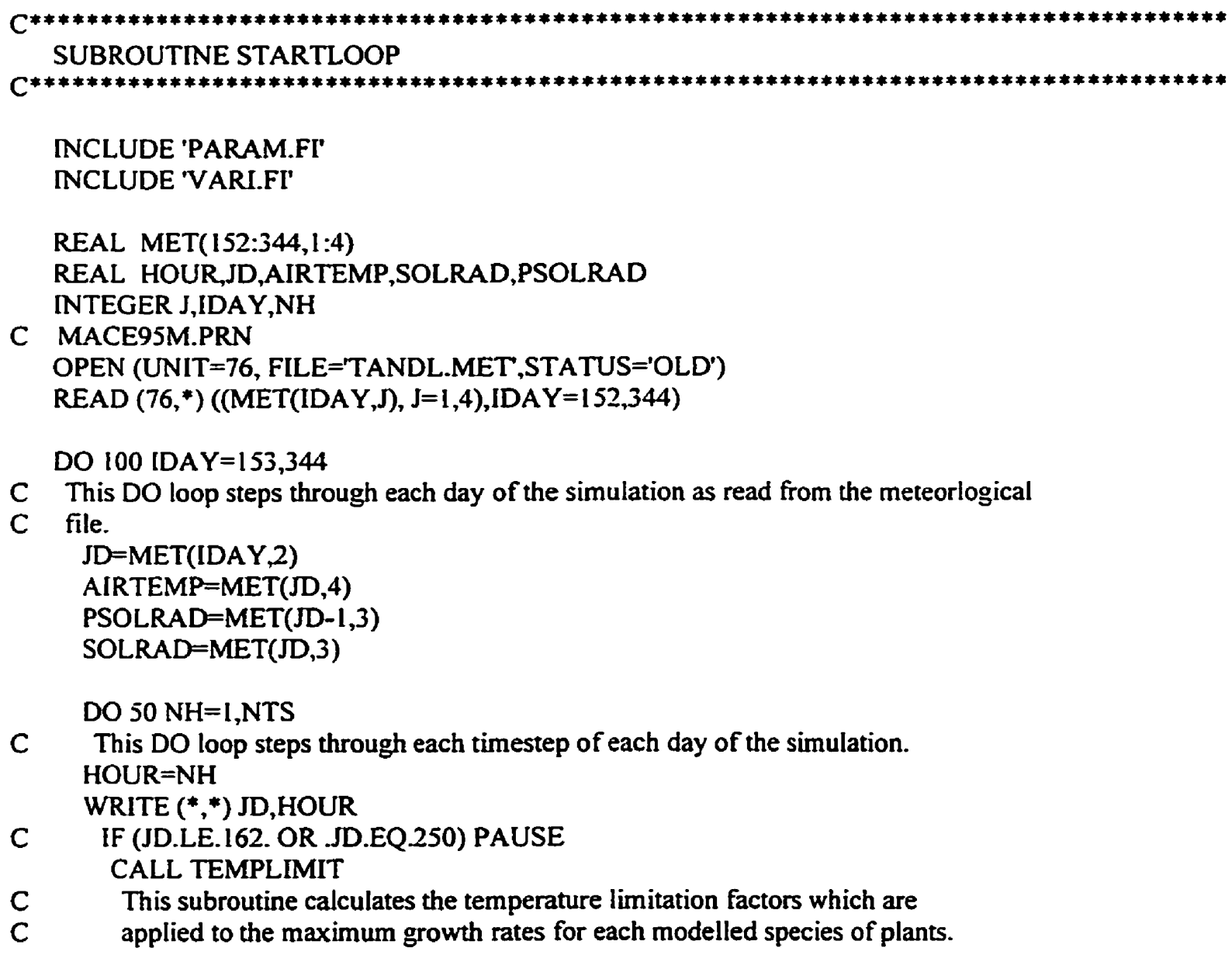

REAL MET(152:344,1:4)

REAL HOUR,JD,AIRTEMP,SOLRAD,PSOLRAD

INTEGER J,IDAY,NH

C MACE95M.PRN

OPEN (UNIT=76, FILE='TANDL.MET,STATUS='OLD')

$\operatorname{READ}(76, *)(($ MET(IDAY,J), J=1,4),IDAY $=152,344)$

DO 100 IDAY $=153,344$

C This DO loop steps through each day of the simulation as read from the meteorlogical

C file.

$$
\text { JD=MET(IDAY,2) }
$$

AIRTEMP=MET(JD,4)

PSOLRAD $=$ MET(JD-1,3)

SOLRAD $=$ MET $(J D, 3)$

DO $50 \mathrm{NH}=\mathrm{I}, \mathrm{NTS}$

C This DO loop steps through each timestep of each day of the simulation.

HOUR=NH

WRITE (*,*) JD,HOUR

C IF (JD.LE.162. OR .JD.EQ.250) PAUSE

\section{CALL TEMPLIMIT}

C This subroutine calculates the temperature limitation factors which are

C applied to the maximum growth rates for each modelled species of plants. 
CALL LIGHTLIMIT

C This subroutine calculates the light limitation factors which are

C applied to the maximum growth rates for each modelled species of plants.

\section{CALL PHOSLIMIT}

C This subroutine calculates the phosphorus limitation factors which are

C applied to the maximum growth rates for each modelled species of plants.

CALL PRODUCTION

C This subroutine calculates the production rate for biomass for each of

C the plant species modelled.

\section{CALL RESPIRATION}

C This subroutine calculates the respiration rate for biomass for each of

C the plant species modelled.

CALL WASHOFF

C This subroutine calculates the amount of biomass that washes off each

C timestep and day based on stream temperature.

\section{CALL GROW}

C This subroutine calculates the net biomass for each timestep for each day

C of the simulation based on the production and respiration rates.

CALL CALCO2

C This subroutine calculates the DO concentration for each timestep for each

C day based on CBOD, NOD, BOD, rearation and SOD rates and biomass production

$\mathrm{C}$ and respiration rates.

\section{CALL CALCPHOS}

C This subroutine calculates the instream TP based on the uptake and release

C of phosphorus from aquatic plants for each timestep for each day.

50 CONTINUE

C This is the end of the timestep DO loop.

100 CONTINUE

C This is the end of the timestep DO loop. END

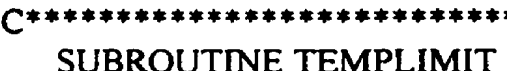

C

REAL TEMP,TEMPC1,TEMPPI,TEMPM1

REAL GAMMAIC,KAC,KBC,GAMMA2C

REAL GAMMAIP,KAP,KBP,GAMMA2P

REAL GAMMAIM,KAM,KBM

NNCLUDE 'VARI.FI'

INCLUDE 'TEMPARAM.FI'

CALL WATERTEMPCALC

C This subroutine calculates the water temperature from the air temperature read from

C the meteorlogical file.

GAMMAIC $=1 /\left(\right.$ TEMPOPT2C-TEMPMINC) $*$ LOG $\left(\left(K 2 C^{*}(1-K I C)\right) /\left(K I C^{*}(1-K 2 C)\right)\right)$

GAMMA2C $=1 /(\text { TEMPMAXC-TEMPOPT3C })^{*} \operatorname{LOG}\left(\left(\mathrm{K}^{2} \mathrm{C}^{*}(1-\mathrm{K} 4 \mathrm{C})\right) /\left(\mathrm{K} 4 \mathrm{C}^{*}(1-\mathrm{K} 3 \mathrm{C})\right)\right)$

$K A C=K I C * E X P(G A M M A I C *(T E M P-T E M P M I N C)) /$

* $\left(1+K I C^{*}(\operatorname{EXP}(\right.$ GAMMAIC*(TEMP-TEMPMINC))-1 $))$

$\mathrm{KBC}=\mathrm{K} 4 \mathrm{C}^{*} \mathrm{EXP}\left(\mathrm{GAMMA} 2 \mathrm{C}^{*}(\right.$ TEMPMAXC-TEMP $\left.)\right) /$

* $\left(1+\mathrm{K} 4 C^{*}(\right.$ EXP(GAMMA2C*(TEMPMAXC-TEMP) $\left.\left.)-1\right)\right)$

TEMPCl $=K A C^{*} \mathrm{KBC}$

C TEMPCl is the temperature limitation factor for Cladophora (no units). 
GAMMA IP=I/(TEMPOPT2P-TEMPMINP)*LOG $\left(\left(K 2 P^{*}(1-K I P)\right) /\left(K 1 P^{*}(1-K 2 P)\right)\right)$

GAMMA2P $=1 /(T E M P M A X P-T E M P O P T 3 P) * L O G\left(\left(K 3 P^{*}(1-K 4 P)\right) /\left(K 4 P^{*}(1-K 3 P)\right)\right)$

KAP $=K I P * E X P(G A M M A 1 P *(T E M P-T E M P M I N P)) /$

* $(1+K I P *(E X P(G A M M A I P *(T E M P-T E M P M I N P))-1))$

$K B P=K 4 P * E X P(G A M M A 2 P *(T E M P M A X P-T E M P)) /$

* $\left(1+K 4 P^{*}(\right.$ EXP(GAMMA2P*(TEMPMAXP-TEMP) $\left.\left.)-1\right)\right)$

TEMPPI $=K A P * K B P$

C TEMPPI is the temperature limitation factor for Potamogeton (no units).

GAMMA IM=1/(TEMPOPT2M-TEMPMINM)*LOG $\left(\left(K_{2} 2 M^{*}(1-K 1 M)\right) /\left(K 1 M^{*}(1-K 2 M)\right)\right)$

GAMMA2M=1/(TEMPMAXM-TEMPOPT3M)*LOG $\left(\left(\mathrm{K}_{3} \mathrm{M}^{*}(1-\mathrm{K} 4 \mathrm{M})\right) /\left(\mathrm{K} 4 \mathrm{M}^{*}(1-\mathrm{K} 3 \mathrm{M})\right)\right)$

KAM $=K I M^{*}$ EXP(GAMMA $1 M^{*}($ TEMP-TEMPMINM))

* $\left(1+K I M^{*}(\right.$ EXP(GAMMAIM*(TEMP-TEMPMINM))-1))

$\mathrm{KBM}=\mathrm{K} 4 \mathrm{M}^{*} \mathrm{EXP}($ GAMMA2M*(TEMPMAXM-TEMP))/

* $\left(1+K 4 M^{*}\left(E X P\left(G A M M A 2 M^{*}(T E M P M A X M-T E M P)\right)-1\right)\right)$

TEMPMI $=\mathrm{KAM}^{*} \mathrm{KBM}$

C TEMPMI is the temperature limitation factor for Milfoil (no units).

END

C

SUBROUTINE WATERTEMPCALC

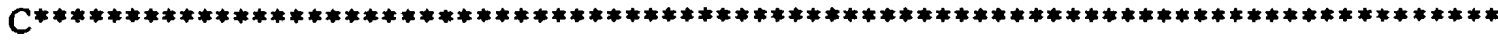

INCLUDE 'VARI.FI'

INCLUDE 'TEMPARAM.FI'

REAL TEMP,HOUR,JD,PSOLRAD,SOLRAD,AIRTEMP

REAL AVDAYTEMP

REAL DELTA

REAL TFACT(12)

DATA TFACT/ $-0.5,-0.866,-1.0,-0.866,-0.5,0.0,0.5,0.866,1.0,0.866$,

$10.5,0.0 /$

AVDAYTEMP=F1+F2*AIRTEMP+F3*PSOLRAD+F4*(JD**2)+

- F5*JD+F6*SOLRAD

C AVDAYTEMP is the average day temperature of the water (deg Celsius).

DELTA $=$ CDELT $1+C D E L T 2 * J D+C D E L T 3 * S O L R A D+$

- CDELT4*JD**2+CDELT5*PSOLRAD

TEMP=AVDAYTEMP+DELTA $2.0 *$ TFACT(HOUR)

C TEMP is the water temperature for the timestep and day (deg Celsius). END

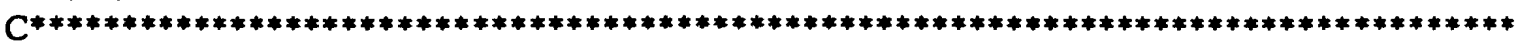

SUBROUTINE LIGHTLIMIT

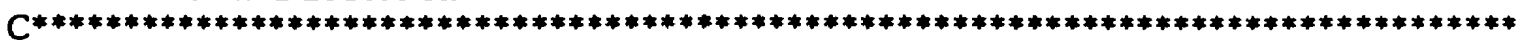

INCLUDE 'VARI.FI'

INCLUDE 'PARAM.FI'

INCLUDE 'LIGHTPAR.FI'

REAL ITHER,ANGLE

REAL JD,HOUR,PARD,RADC,RADP,RADM

REAL ALPHA,DELT,ROTOR,T 
REAL COSPHI,SINPHI

ALPHA $=\mathrm{JD} / 365^{*} 6.283$

DELT $=(.3964+3.63 * \operatorname{SIN}($ ALPHA $)-22.97 * \operatorname{COS}($ ALPHA $)+.384 * \operatorname{SIN}(A L P H A * 2)$.

$1-.389 * \operatorname{COS}(\mathrm{ALPHA} * 2)+..0766 * \operatorname{SIN}(\mathrm{ALPHA} * 3)-..1587^{*} \operatorname{COS}(\mathrm{ALPHA} * 3)-$.

$2 * \operatorname{COS}(\mathrm{ALPHA} * 4).) / 57.3$

ROTOR $=1 .-.00095 *$ SIN(ALPHA)-.0167* COS(ALPHA) $-.000149 * \operatorname{COS}(A L P H A * 2$.

I-.000029*SIN(ALPHA*3.)-.00034*COS(ALPHA*4.)

C ROTOR is the relative distance between the earth and the sun (no units)

IF (HOUR.EQ.I) THEN

$T=13-24$

ELSE

$T=13 .-($ HOUR -1$) * 2$

ENDIF

SINPHI $=$ SIN $($ LATITUDE $/ 180 * 3.1415926)$

COSPHI $=\operatorname{COS}($ LATITUDE/180*3.1415926)

$\operatorname{COSTH}=\operatorname{COS}(D E L T) * \operatorname{cosPHI} * \operatorname{COS}\left(.262^{*} T\right)+\operatorname{SIN}(D E L T) * \operatorname{SINPHI}$

ANGLE $=1.571-\left(\operatorname{ATAN}\left(\mathrm{SQRT}\left(1 .-\operatorname{COSTH} \mathrm{H}^{* * 2 .}\right) / \mathrm{COSTH}\right)\right)$

ITHER $=(115.83 *$ ROTOR $* 2 *$ COSTH $) / 60.0$

C ITHER is the theoretical radiation (langleys $/ \mathrm{min}$ )

CALL DAYTOMONTH

C This subroutine returns the month number based on the julian date.

CALL HOURLYSOLRAD

C This subroutine calculates the solar radiation for each time step for each day

C from the total daily solar radiation from the meteorlogical file.

\section{CALL CALCPARD}

C This subroutine calculates the photosynthetically available sunlight at plant depth

C for each timestep for each day.

RADC $=$ PARD $/($ PARD $+K M L C)$

RADP $=$ PARD/(PARD+KMLP)

RADM $=$ PARD/(PARD+KMLM)

C RAD_ is the the light limitation factor based on the photosynthetically available

C light at plant depth and the half-saturation coefficient (no units).

\section{IF (COSTH.LE.0) THEN}

C This IF statements says that if there's not enough light, then there is no

C production (ie. RAD limitation factors cannot be negative)
RADC $=0$
RADP $=0$
RADM $=0$
ENDIF

END

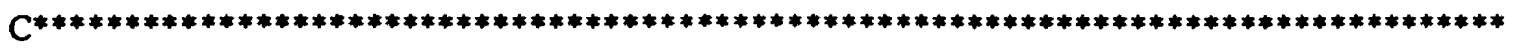




\section{SUBROUTINE DAYTOMONTH}

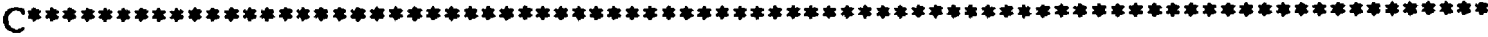

INCLUDE 'VARI.FI'

REAL MONTH,JD

MONTH=1

IF (JD.GE.32) MONTH=2

IF (JD.GE.61) MONTH=3

IF (JD.GE.92) MONTH=4

IF (JD.GE.122) MONTH=5

IF (JD.GE.153) MONTH=6

IF (JD.GE. 183) MONTH=7

IF (JD.GE.214) MONTH=8

IF (JD.GE.245) MONTH=9

IF (JD.GE.275) MONTH=10

[F (JD.GE.306) MONTH $=11$

IF (JD.GE.336) MONTH=12

END

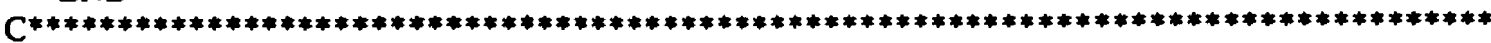

SUBROUTINE HOURLYSOLRAD

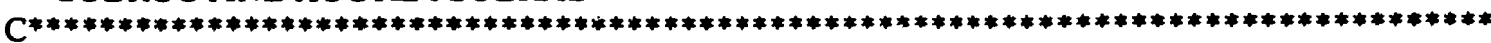

INCLUDE 'VARI.FI'

REAL SOLRAD,MONTH,SOLRADH,HOUR,ALPHF

REAL ALINT,ALPSL(12)

DATA ALPSL $.5, .5, .5, .5, .61, .64, .628, .581, .522, .5, .5, .51$

ALINT=SOLRAD*3.1415927/(2.0*ALPSL(MONTH))

SOLRADH=ALINT*ALPHF(MONTH,HOUR)/1440

C The solar radiation for each timestep for each day.

END

C

SUBROUTINE CALCPARD

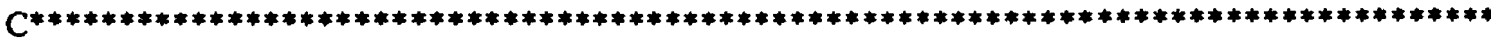

INCLUDE 'VARI.FI'

INCLUDE 'LIGHTPAR.FI'

REAL SOLRADH,ITHER,ANGLE,CLADAR,POTAR,MILAR,TBIOAR

REAL JD,HOUR,PARD,DEPTH

REAL BAKRF,KE,KW,PARFAC,WATI,SUN,CLAD,POT,MIL,TBIO

SUN $=($ SOLRADH/ITHER $) * 100$.

C SUN is the percentage of radiation (sunniness) for the period (\%)

IF (SUN.GE.100.) SUN=99.9 
BAKRF $=10.64 * \operatorname{EXP}(-.65 *$ ANGLE $)$

IF( SUN .GT. 35.) BAKRF $=17.45 * \operatorname{EXP}(-0.86 *$ ANGLE $)$

IF( SUN .GT. 55. ) BAKRF $=104.4 * \operatorname{EXP}(-6.29 *$ ANGLE )

IF ( BAKRF .GE. 100.0) BAKRF $=99.9$

C BAKRF is the percentage of solar radiation is reflected back at the water surface(\%).

PARFAC $=(55.9-.045 *$ SUN $) / 100$.

C PARFAC is the percentage of the photosynthetically useful portion of light (\%)

WATI $=$ SOLRADH *(100. - BAKRF $) / 100 . *$ PARFAC

C WATI is the amount of light just below the water surface (langleys/min)

IF( DEPTH .GT. PLANT_DEPTH) THEN

C This IF statement says that if there is a depth of water between the aquatic plants

C and the water surface, it is necessary to decrease the light reaching the plants

C by both the plants themselves and the SS in the water.

$\mathrm{KE}=\mathrm{KE}$ CONSTANT $+\mathrm{SS}{ }^{*} \mathrm{KE}$ SLOPE

C KE is the light attenuation coefficient from the $\mathrm{SS}(1 / \mathrm{m})$

C IF statement to calculate total biomass ( $\mathrm{g} / \mathrm{m} 2)$

IF (HOUR.EQ.1) THEN

CLAD=CLADAR(JD-1,12)

POT=POTAR(JD-1,12)

MIL=MILAR(JD- 1,12$)$

TBIO=CLADAR(JD-1,12)+POTAR(JD-1,12)+MILAR(JD-1,12)

ELSE

CLAD $=$ CLADAR(JD,HOUR -1$)$

POT=POTAR(JD, HOUR-1)

MIL $=$ MILAR(JD, HOUR-1)

TBIO=CLADAR(JD,HOUR-1)+POTAR(JD,HOUR-1)+MILAR(JD,HOUR-1)

ENDIF

C IF statements to find dominant species to set value for $\mathrm{KW}(1 / \mathrm{m})$

IF ( CLAD.GE. POT) THEN

IF ( CLAD.GE. MIL) THEN

$\mathrm{KW}=0$

ELSE

$\mathrm{KW}=.0083$

ENDIF

ELSEIF (POT.GT. MIL) THEN

$\mathrm{KW}=.024$

ELSE

$\mathrm{KW}=.0083$

ENDIF

PARD $=$ WATI*EXP(-KE *(DEPTH-PLANT_DEPTH) - KW*TBIO)

C PARD is based on the radiation just under the water surface, which is attenuated by

C the SS in the water and by plant shading (langleys/min).

ELSE

C If the plants are right at the water surface, the amount of light reaching them

C will not be significantly decreased by the SS or plant shading.

PARD $=$ WATI

C PARD is the amount of radiation just under the water surface(langleys/min). ENDIF

END

C 
SUBROUTINE PHOSLIMIT

C

INCLUDE 'PARAM.FI'

INCLUDE 'PHOSPAR.FI'

INCLUDE 'VARI.FI'

REAL ROWP,Q

REAL CLADP,POTP,MILP,JD,HOUR,PINP

$\mathrm{Q}=100 * \mathrm{PINP}$

ROWP=ROWPMAX*(1000*FPIN/(KMPCLAD+1000*FPIN) $)^{*}(\mathrm{KQPCLAD} /(\mathrm{KQPCLAD}+$ *(Q-QNOT)))

C ROWP is the uptake rate of phosphorus by Cladophora (ug/hr)

$\mathrm{Q}=\mathrm{Q}+(\mathrm{ROWP}-\mathrm{CGMEW}$ *Q)*TS

C $Q$ is the internal phosphorus (\%P) used to calculate Cladophora's phosphorus

C limitation factor

CLADP $=1-Q N O T / Q$

POTP $=1000^{*} \mathrm{FPIN} /(\mathrm{KMPPOT}+1000 * \mathrm{FPIN})$

MILP $=1000 *$ FPIN $/($ KMPMIL $+1000 *$ FPIN)

C $P$ is the limitation factor due to phosphorus (no units) $\overline{\mathrm{END}}$

C

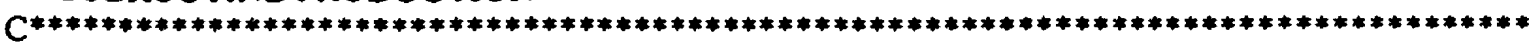

INCLUDE 'PARAM.FI'

INCLUDE 'VARI.FI'

REAL RADC,RADP,RADM,TEMPCI,TEMPPI,TEMPMI,CLADAR,POTAR,MILAR

REAL JD,HOUR,PRODC,PRODP,PRODM,TPROD,CLADP,POTP,MILP,NFAC

REAL DEPTH,HDAYS,O2P

IF (HOUR.EQ.1) THEN

PRODC $=$ CGMEW*CLADAR(JD-1,12)*RADC*TEMPCI*CLADP*NFAC*TS

PRODP=PPMEW*POTAR(JD-1,12)*RADP*TEMPPI $*$ POTP*NFAC*TS

PRODM $=$ MSMEW*MILAR(JD-1,12)*RADM*TEMPMI*MILP*NFAC*TS

ELSE

PRODC $=$ CGMEW ${ }^{*}$ CLADAR $(J D, H O U R-1) *$ RADC $*$ TEMPCI ${ }^{*}$ CLADP*NFAC*TS

PRODP $=$ PPMEW*POTAR(JD,HOUR-1)*RADP*TEMPPI*POTP*NFAC*TS

PRODM= MSMEW*MILAR(JD,HOUR-1)*RADM*TEMPMI*MILP*NFAC*TS

ENDIF

C PROD_ is the actual biomass production based on the maximum growth rate (MEW).

C the existing biomass (_AR) and the limitation factors due to solar

C radiation(RAD_, temperature(TEMP_1), and phosphorus ( $P$ ). $P R O D_{-}$is in $g m / m 2$. TPROD $=$ PRODC+PRODP+PRODM

C TPROD is the total plant biomass production calculated O2P=TPROD*O2ASSIM/(DEPTH*HDAYS) 
C $\mathrm{O} 2 \mathrm{P}$ is the oxygen released into the water by the production of the plants $(\mathrm{gm} 02 / \mathrm{m} 3$ ) END

C SUBROUTINE RESPIRATION

C

INCLUDE 'PARAM.FI'

INCLUDE 'VARI.FI'

REAL JD,HOUR,TEMP,RESC,RESP,RESM,TRES,CLADAR,POTAR,MILAR,O2AR

REAL O2UP,DEPTH,HDAYS,O2P

REAL CTFR,PTFR,MTFR

CTFR $=$ TC** (TEMP-20.)

PTFR $=$ TP**(TEMP-20.)

MTFR $=$ TM $^{* *}($ TEMP-20.)

C - TFR is the temperuature correction factor for respiration (no units).

IF (HOUR.EQ.1) THEN

RESC $=$ CGR20*CLADAR(JD-1,12)*CTFR*TS*O2AR(JD-1,12)/

1 (O2AR(JD-1,12)**0.8+1.5)

RESP=PPR20*POTAR(JD-1,12)*PTFR*TS*O2AR(JD-1,12)/

1 (O2AR(JD-1,12)**0.8+1.5)

RESM=MSR20*MILAR(JD-1,12)*MTFR*TS*O2AR(JD-1,12)/

1 (O2AR(ID- 1,12$\left.)^{* *} 0.8+1.5\right)$

ELSE

RESC $=$ CGR20*CLADAR(JD,HOUR-1)*CTFR*TS*O2AR(JD,HOUR-1)/

1 (O2AR(JD,HOUR-1)**0.8+1.5)

RESP=PPR20*POTAR(JD,HOUR-1)*PTFR*TS*O2AR(JD,HOUR-1)/

1 (O2AR(JD,HOUR-1)**0.8+1.5)

RESM=MSR20*MILAR(JD,HOUR-1)*MTFR*TS*O2AR(JD,HOUR-1)/

1 (O2AR(JD,HOUR-1)**0.8+1.5)

ENDIF

C RES_is the repiration by each species based on the unit respiraton rate @ $20 \mathrm{C}$

C $(R \overline{2} 0$ ), the existing biomass ( $A R$ ), the temperature correction factor (TFR), and

C the DO concentration (O2AR). RES_ is in $\mathrm{gm} / \mathrm{m} 2$.

TRES=RESC+RESP+RESM

C TRES is the total respiration of plant biomass calculated

O2UP $=$ TRES*O2ASSIM/(DEPTH*HDAYS)

C O2P is the oxygen taken from the water by the respiration of the plants(gm $02 / \mathrm{m} 3$ )

END

C

SUBROUTINE GROW

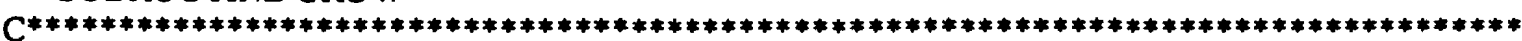

INCLUDE 'VARJ.FI'

REAL JD,HOUR,CLADAR,POTAR,MILAR,TBIOAR 
REAL PRODC,PRODP,PRODM,RESC,RESP,RESM,WASHC,WASHP,WASHM

IF (HOUR.EQ.1) THEN

CLADAR(JD,HOUR)=CLADAR(JD-1,12)+ PRODC - RESC - WASHC

POTAR(JD,HOUR) $=$ POTAR(JD-1,12)+ PRODP - RESP - WASHP

MILAR(JD,HOUR)=MILAR(JD-1,12)+PRODM -RESM - WASHM

ELSE

CLADAR(JD,HOUR)=CLADAR(JD,HOUR-1)+ PRODC - RESC - WASHC

POTAR(JD,HOUR)=POTAR(JD,HOUR-1)+ PRODP - RESP - WASHP

MILAR(JD,HOUR)=MILAR(JD,HOUR-1)+PRODM - RESM - WASHM ENDIF

IF (CLADAR(JD,HOUR).LE. I0) CLADAR(JD,HOUR) $=10$

IF (POTAR(JD,HOUR).LE.10) POTAR(JD,HOUR) $=10$

IF (MILAR(JD,HOUR).LE.5) MILAR(JD,HOUR) $=5$

C _ AR is the biomass density of each plant species based on the density from the

C last timestep, the new biomass made (PROD), the biomass respired (RES) and the

C biomass washed out (WASH). CLADAR, POTAR and MILAR are in $\mathrm{gm} / \mathrm{m} 2$.

TBIOAR(JD,HOUR) =CLADAR(JD,HOUR)+POTAR(JD,HOUR) + MILAR(JD,HOUR)

END

$C * * * * * * * * * * * * * * * * * * * * * * * * * * * * * * * * * * * * * * * * * * * * * * * * * * * * * * * * * * * * * * * * * * * * * * * * * * * * * * * * *)$

SUBROUTINE CALCO2

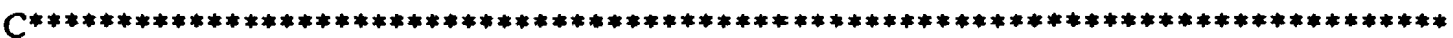

INCLUDE 'VARI.FI'

INCLUDE 'PARAM.FI'

REAL JD,HOUR,MONTH,O2AR,BUBBLE_LEVEL,K2,O2SAT

REAL TERM1,TERM2,TERM3,TERM4,TERM5

INTEGER ICOUNT

ICOUNT $=1$

210 CONTINUE

CALL CALCO2TERMS

C This subroutine calculates the terms for each source and sink for DO.

IF (HOUR.EQ.1) THEN

O2AR(JD,HOUR)=02AR(JD-1,12)*TERM1+BOD*TERM2+NOD*TERM3+TERM4+

I TERMS

ELSE

O2AR(JD,HOUR $)=02 A R(J D, H O U R-1) *$ TERMI+BOD*TERM2+NOD*TERM3+

1 TERM4+TERM5

ENDIF

IF (O2AR(JD,HOUR).LT.0) O2AR(JD,HOUR) $=0$

BUBBLE_LEVEL $=02 \mathrm{SAT}^{*} 1.5$

IF (O2AR(JD,HOUR).LT.BUBBLE_LEVEL.OR.ICOUNT.EQ.2) GO TO 2100

C O2AR is the oxygen concentration for a given timestep and calculated from the SOD,

C NOD, BOD, CBOD, 02 saturation level, rearation rate and previous $\mathrm{DO}$ level (mg/L)

$\mathrm{K} 2=\mathrm{K} 2 *(\mathrm{O} 2 \mathrm{AR}(\mathrm{JD}, \mathrm{HOUR}) / \mathrm{BUBBLE}$ LEVEL $) * 2.5$ 
ICOUNT $=$ ICOUNT +1

GOTO 210

2100 END

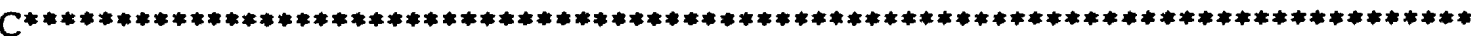

SUBROUTINE CALCO2TERMS

C

INCLUDE 'PARAM.FI'

INCLUDE 'VARI.FI'

INTEGER ICOUNT

REAL DELTAT,EXPON,DIVZ,O2SAT

REAL CBODR,NODR,BODR,SODR,K2,VEL,TFAC,O2P,O2UP

REAL TERM1,TERM2,TERM3,TERM4,TERM5

IF (ICOUNT.EQ.2) GOTO 310

CALL CALCRATES

C This subroutine caculates the rates for each source and sink of DO (except

C photosynthesis and respiration).

310 CONTINUE

DELTAT $=.3048^{*}($ LENGTH $) / V E L$

C DELTAT is the time it takes to flow from the start to the end of the reach (sec)

TFAC $=$ DELTAT $/ 86400$

C TFAC is the time it takes to flow from the start to the end of the reach (days)

DIVZ $=35.0+$ TEMP

$\mathrm{EXPON}=.028 * \mathrm{TEMP}+.672$

O2SAT $=0.678^{*}\left(760 .-10 .^{* *}(\right.$ EXPON $\left.)\right) /$ DIVZ

C O2SAT is the saturation oxygen concentration at the specified water temperature (mg/L)

EXD $=$ EXP( $(-C B O D R * T F A C)$

$E X N=E X P\left(-N O D R^{*} T F A C\right)$

TERMl=EXP(-K2*TFAC)

TERM2=BODR/(K2-CBODR)*(TERM1-EXD)

TERM3 $=$ NODR/(K2-NODR) $*($ TERM $1-E X N)$

TERM4=O2P/K2*(1-TERM1)

TERM5 $=(\text { O2SAT }-((\mathrm{O} 2 \mathrm{UP}+\mathrm{SODR}) / \mathrm{K} 2))^{*}(\mathrm{I}-\mathrm{TERM})$

c IF (O2UP.EQ.0) THEN

c WRITE $\left({ }^{*}, *\right)$ term 1 ,term2,term3,term4,term5

C pause

c ENDIF

C TERMI to TERM5 are used to calculate the oxygen concentrations above END

C SUBROUTINE CALCRATES

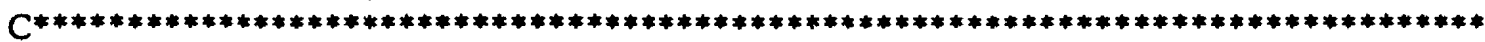

INCLUDE 'VARI.FI'

INCLUDE 'PARAM.FI'

REAL TEMP,DEPTH,MONTH 
REAL EXPON2,FACT2

REAL A(1:12),B(1:12),C(1:12),ALCTM(3)

REAL BCBODR(1:12),BNODR(1:12),BBODR(1:12),BSODR(1:12)

REAL CBODR,NODR,BODR,SODR,K2

DATA ALCTM/1.106,1.065,1.065/

DATA AVI $1,1,1,14,40,40,40,40,14,1,11$

DATA $B / 1,1,1,1, .5, .5, .5, .5, .5, .5,1,1 /$

DATA C/I, 1,1, I, 1.5,1.5,1.5,1.5,1.5,1.5,1,1/

DATA BCBODR/.1,.1,.1,.1,26,.26,.26,.26,.26,.46,.1,.1/

DATA BNODR/ $1 . .1 .1,1.1,25,25,25,25, .25 .1, .1, .1 /$

DATA BBODR $/ .1,1, .1, .1, .46, .28, .28, .46, .46, .46, .1, .1 /$

DATA BSODR/ $0,0,0,0,1,1,1,1,1,15,0,0 /$

C ALCTM corresponds to the temperature coefficients for the decay rates for CBOD,

C NOD and BOD (no units)

C A,C,B are empirical constants that are required for the calculation of the

C rearation rate

C BCBODR,BNODR,BBODR,BSODR are the base carbonaceous biochemical oxygen demand, the

$C$ base nitrogenous oxygen demand, the base ultimate biochemical oxygen demand and

C the base sediment oxygen demand rate for each of the 12 months. $(\mathrm{gm} / \mathrm{m} 2 / \mathrm{hr})$

C CALCULATE VOLUMETRIC RATE CONSTANTS

EXPON2 $=$ TFC $* *(T E M P-20$.

FACT2 $=$ EXPON2* $(B D E P T H /(D E P T H / .3048))$

SODR $=$ BSODR $(M O N T H) *$ FACT2

C CALCULATE REAERATION RATE

$\mathrm{K} 2=\left(\left(\mathrm{A}(\mathrm{MONTH}) *(\mathrm{VEL} / .3048)^{* *} \mathrm{~B}(\mathrm{MONTH})\right) /\left((\mathrm{DEPTH} / .3048)^{* *} \mathrm{C}(\mathrm{MONTH})\right)\right)^{*}$

$*\left(1.028^{* *}(\right.$ TEMP-20.0))

C ADJUST STREAM PARAMETERS FOR TEMPERATURE EFFECT

NODR $=$ BNODR(MONTH ${ }^{*}$ ALCTM(1)**(TEMP-20.0)

CBODR $=$ BCBODR(MONTH)*ALCTM $(2)^{* *}($ TEMP-20.0)

$B O D R=B B O D R(M O N T H) * A L C T M(3)^{* *}($ TEMP-20.0)

END

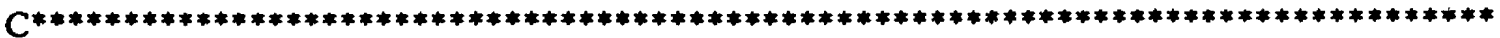

SUBROUTINE MONTHLYCALC

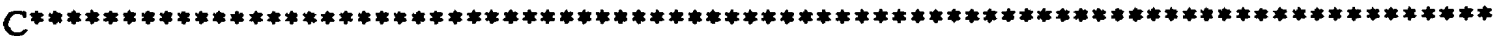

INCLUDE 'PARAM.FI'

INCLUDE 'VARI.FI'

REAL ALPHF,H

REAL SM3,SM2,SM1,ALPSL(1:12),ALSR(1:12)

INTEGER I,J,IHEUR,IMTH

DATA ALPSL/.5,.5,.5,.5, .61,.64,.628,.581,.522,.5,.5,.5/

DATA ALSR $.3, .3, .3, .3, .251,239,249,272, .294, .3, .3, .31$ 
C ALPSL is the sunlight period as a fraction of a day for the month

C ALSR is the time of sunrise for the month

$\mathrm{H}=\mathrm{TS} / 24$

C H-the fraction of day the timestep represents (no units)

DO 1610 IMTH=6,12

C INITIALIZE PHOTOSYNTHESIS VARIATION FACTORS TO ZERO

DO 1020 IHEUR $=1,12$

ALPHF(IMTH,IHEUR) $=0.0$

1020 CONTINUE

SM3 =ALSR(IMTH)+ALPSL(IMTH)

C SM3-is the time of sunset for the given month, as a fraction of the day (no units)

$\mathrm{I}=99$

$\mathrm{J}=99$

C LOOP DETERMINING TIMESTEPS WHICH THE SUNLIGHT FACTORS WILL APPLY,

c (IE. THE TIMESTEPS THAT FALL BETWEEN SUNRISE AND SUNSET)

DO 1110 IHEUR $=1$,NTS

SMl $=(\text { IHEUR }-1)^{*} \mathrm{H}$

SM2=IHEUR*H

C The IF statement below is determining the furst timestep of the day that has

C sunglight, which becomes I

IF (ALSR(IMTH).GE.SM1 .AND. ALSR(IMTH).LT.SM2) I=IHEUR

C The IF statement below loops back 1110 (therefore increasing the timestep) until the

C timestep, as a fraction of a the day, is greater than the sunset time. At this

C point it stops looping and goes to the next line. This sunset timestep is called J.

IF (SM3.LE.SM1 .OR. SM3.GT.SM2) GO TO 1110

$\mathrm{J}=$ IHEUR

C The GO statement below is to jump out of the loop after $\mathrm{J}$ has been assigned a value. GO TO 1130

C The CONTINUE statement below is part of the loop of increasing the timestep until a

C sunset timestep can be found.

1110 CONTINUE

1130 CONTINUE

C This DO loop is using going through the timesteps between sunrise and sunset to

C calculate how much of the sunlight factor, which are used to proportion the total

C daily solar radiation for each timestep that has sunlight.

DO 1140 IHEUR $=$ I, J

SMl $=(3.14159 /$ ALPSL $($ IMTH $)) *(($ IHEUR-1 $) *$ H-ALSR $($ IMTH $))$

SM2 $=(3.14159 / \mathrm{ALPSL}(\mathrm{IMTH}))^{*}(($ IHEUR $) * \mathrm{H}-\mathrm{ALSR}(\mathrm{IMTH}))$

IF(IHEUR.EQ.I) $\mathrm{SMl}=0.0$

IF(IHEUR.EQ.J) SM2=3.14159

ALPHF(IMTH,IHEUR) $=($ ALPSL(IMTH) $/(3.14159 * \mathrm{H})) *(\mathrm{COS}(\mathrm{SM} 1)-\mathrm{COS}(\mathrm{SM} 2))$

C ALPHF is the sunlight factor for a given timestep in a given month. Values during

C ths sunlight period are calculated above, while values during darkness remain zero. 
C (All values were initialized to 0 at the beginning of the routine.)

1140 CONTINUE

C The CONTINUE statement below is to loop back to the next month.

1610 CONTINUE

END

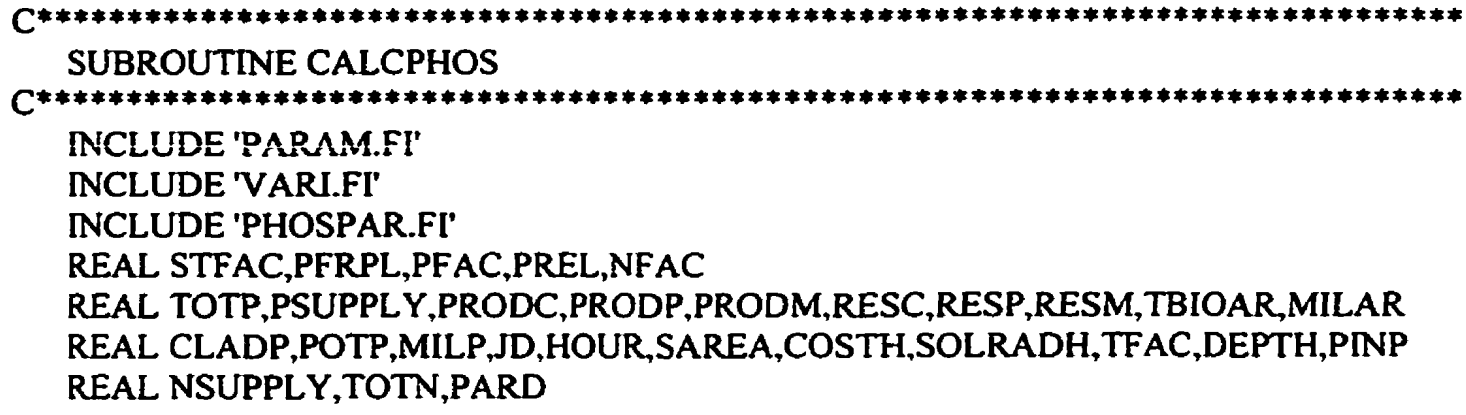

CALL CALCPREQ

C This subroutine calculates the phosphorus required by the plants and the

C phosphorus supplied by the water.

CALL CALCNREQ

C This subroutine calculates the nitrogen required by the plants and the

C nitrogen supplied by the water.

STFAC $=0$.

PFRPL $=0$.

C STFAC (the storage of phosphorus is set to 0 )

C PFRPL (the remaining $P$ that must be supplied if PFAC $<1$ )

IF (COSTH.LE.0. OR. SOLRADH.LE.0) THEN

PFAC $=1$

NFAC $=1$

GOTO 30

ENDIF

C The IF statement above is to set PFAC to 1 during darkness since TOTP will be zer0

C resulting in an error in the PFAC eqn below.

PFAC $=$ PSUPPLY/TOTP

C PFAC is the phosphorus availability; if PFAC $>1$ then the there is excess $P$ and if

$C$ PFAC $<1$ then more phosphorus is required from plant storage or no plant growth

C (no units)

c WRITE $\left(*,{ }^{*}\right)$ JD,TOTP,TOTN

NFAC $=$ NSUPPLY/TOTN

11 CONTINUE

IF (PFAC.GT.1.) GO TO 12

IF (PINP.LT..00135) GO TO 12

C PINP is the phosphorus in the plants (gm P/gm biomass)

PFRPL $=$ TOTP* $(1 .-P F A C) * 0.5$

STFAC $=$ PFRPL/TOTP 
12 CONTINUE

IF(PFAC.GT.1.20) PFAC $=1.20$

IF(NFAC.GT.1.) NFAC $=1$.

IF (NFAC.GT.PFAC) NFAC $=1.0$

IF (PFAC.GT.NFAC.AND.PFAC.LT.1.0) PFAC $=1.0$

$P U P=(P R O D C * P A S S C+P R O D P * P A S S P+P R O D M * P A S S M) * P F A C$

C PUP is the uptake of phosphorus by plants based on the biomass production (PROD_),

C the assimilation of phosphorus (PASS) and the phosphorus availability(PFAC).

C (gm P/m2)

$P I N=0.0$

IF(PFAC.EQ.0) PFAC $=0.00000001$

C

IF(PFAC .GT. 1.0) PIN=(PUP/PFAC)*(PFAC-1.0)

30 PFST $=($ PUP/PFAC $) * S T F A C$

$P R E L=($ RESC $*$ PASSC+RESP*PASSP+RESM*PASSM)

C PREL is the amount of phosphorus released by the plants through respiration (gm P/m2)

IF (PIN.EQ.0) GOTO 40

PINP=PINP+(PIN-PFST)/(TBIOAR(JD,HOUR))

C PINP is the phosphorus concentration within the plants (gm P/gm biomass)

40 PREL $=$ PREL/DEPTH

C PREL is now the concentration of phosphorus released (gm $\mathrm{P} / \mathrm{m} 3$ or $\mathrm{mg} P / \mathrm{L}$ ) PUP $=$ PUP/DEPTH

C PUP is now the concentration of phosphorus released (gn $\mathrm{P} / \mathrm{m} 3$ or $\mathrm{mg} \mathrm{P} / \mathrm{L}$ )

END

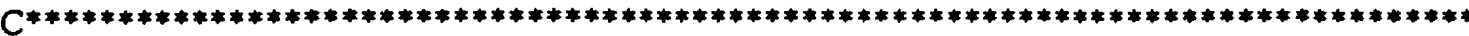

SUBROUTINE NITIALIZE

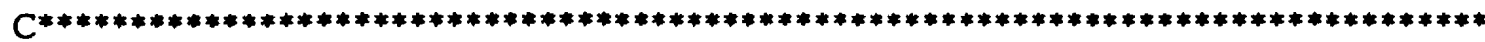

INCLUDE 'VARI.FI'

INCLUDE 'PARAM.FI'

INCLUDE 'PHOSPAR.FI'

REAL DEPTH,VEL

REAL CLADAR,POTAR,MILAR, TBIOAR,O2AR,SAREA,PINP

REAL HDAYS,HHRS,TSLENGTH

DEPTH $=.3048 * A A^{*}$ QFLOW**BB

C DEPTH is calculated from the flow using Leopold Maddox coefficients

$C$ and is converted from $\mathrm{ft}$ to $\mathrm{m}(\mathrm{m})$

$\mathrm{VEL}=.3048^{*} \mathrm{CC}^{*} \mathrm{QFLOW}{ }^{* *} \mathrm{DD}$

C VEL is the velocity, calculated from the flow using Leopold Maddox coefficients.

C It is also is converted from $\mathrm{ft} / \mathrm{s}$ to $\mathrm{m} / \mathrm{s}(\mathrm{m} / \mathrm{s})$

CLADAR $(152,12)=$ CLADI

$\operatorname{POTAR}(152,12)=$ POTI

MILAR(152,12)=MILI

C $\operatorname{AR}(152,12)$ is the biomass density for the first timestep of the first day $(\mathrm{g} / \mathrm{m} 2)$ O2AR $(152,12)=O 21$

C O2AR(152,12) is the dissolved oxygen for the first timestep of the first day (mg/l)

PINP=PINPI 
HDAYS $=1.0 / N T S$

C HDAYS is the fraction of a day for each timestep

HHRS $=$ HDAYS*24.0

C HHRS is the fraction of an hour for each timestep (ie. $2 / 1 \mathrm{hr}$ )

TSLENGTH=VEL $* 3600 *$ HHRS

C TSLENGTH is the distance the river flows in one timestep (m)

WIDTH $=$ QFLOW*.028316847/(DEPTH*VEL)

SAREA $=$ WIDTH*TSLENGTH

C SAREA is the surface area (distance times width) the river flows over in one

C timestep (m2)

END

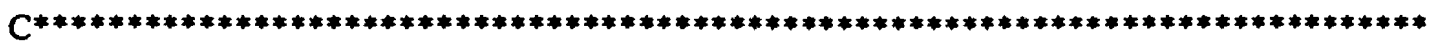

SUBROUTINE CALCPREQ

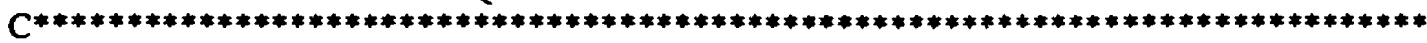

INCLUDE 'PHOSPAR.FI'

INCLUDE 'VARI.FI'

INCLUDE 'PARAM.FI'

REAL THCP,THPP,THMP, REQPC, REQPP, REQPM

REAL CLADAR,POTAR,MILAR,TOTP,PSUPPLY,DEPTH

REAL RADC,RADP,RADM,TEMPC1,TEMPPI,TEMPMI,JD,HOUR,SAREA

THCP $=$ CGMEW*TEMPCI*RADC

THPP=PPMEW*TEMPPI*RADP

THMP=MSMEW*TEMPMI*RADM

C TH_P is the growth rate with only limits of temperature and radiation

IF (HOUR.EQ.I) THEN

REQPC $=$ THCP*CLADAR(JD-1,12)*PASSC*CLADFAC ${ }^{*}$ SAREA

REQPP $=$ THPP $*$ POTAR(JD-1,12)*PASSP*POTFAC*SAREA

REQPM $=$ THMP*MILAR(JD-1,12)*PASSM*MILFAC*SAREA

ELSE

REQPC $=$ THCP*CLADAR(JD,HOUR-1)*PASSC*CLADFAC*SAREA

REQPP $=$ THPP*POTAR(JD,HOUR-1)*PASSP*POTFAC*SAREA

REQPM $=$ THMP*MILAR(JD,HOUR-1)*PASSM*MILFAC*SAREA

ENDIF

C REQP_ is the phosphonus requirement for this timestep based on the growth

C rate, existing biomass, the assimilation capacity of phosphorus and the surface

C area (gmP)

TOTP=REQPC+REQPP+REQPM

PSUPPLY $=$ SAREA*DEPTH*FPIN

END

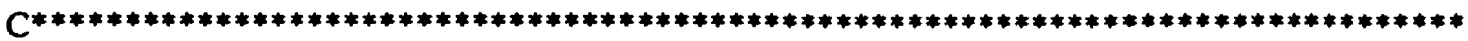

SUBROUTINE CALCNREQ

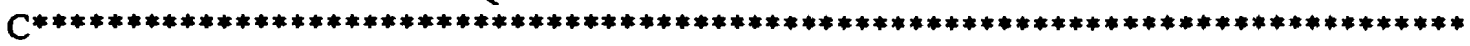

NCLUDE 'PHOSPAR.FI'

INCLUDE 'VARI.FI'

INCLUDE 'PARAM.FI' 
REAL REQNC,REQNP,REQNM,REQPC,REQPP,REQPM,FNIN

REAL TOTN,NSUPPLY,DEPTH,SAREA

REQNC $=$ REQPC $*$ NASSC/PASSC

REQNP $=$ REQPP $*$ NASSP/PASSP

REQNM $=$ REQPM*NASSM/PASSM

TOTN=REQNC+REQNP+REQNM

FNIN $=$ NOD/4.57+NOX-ORGN

NSUPPLY $=$ SAREA ${ }^{*}$ DEPTH ${ }^{*}$ FNIN

END

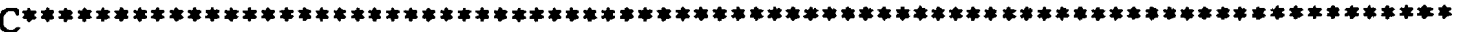

SUBROUTINE WASHOFF

C

INCLUDE 'VARI.FI'

INCLUDE 'PARAM.FI'

REAL TEMP,WASHC,WASHP,WASHM,JD,HOUR,CLADAR,POTAR,MILAR

REAL CLADW,POTW

CLADW $=.001$

IF(TEMP.GT.C_WASHOFF_TEMP) CLADW $=($ TEMP-C_WASHOFF_TEMP) $* * 5+.01$

C The following line was added Sept 14 to check temperature problemos

c IF(TEMP.LT.C_WASHOFF_TEMPL) CLADW=(.03-0.002*TEMP)

C CLADW is the fraction of Cladophora that washes out; if the water temp is above the

C Cladophora wash-off temperature the eqn above is used, other wise CLADW $=.001$ (no units)

POTW $=.001$

IF (TEMP.LT. P_WASHOFF_TEMP)POTW=(.03-0.002*TEMP)

C POTW is the fraction of Potamogeton that washes out; if the water temp is less than the

C Potamogeton wash-off temperature the eqn above is used, other wise POTW $=.001$ (no units)

IF (HOUR.EQ.1) THEN

WASHC $=$ CLADW*CLADAR(JD-1,12)*TS

WASHP $=$ POTW*POTAR(JD-1,12)*TS

WASHM $=$ MILW*MILAR(JD-1,12)*TS

ELSE

WASHC $=$ CLADW*CLADAR(JD,HOUR-1)*TS

WASHP=POTW*POTAR(JD,HOUR-1)*TS

WASHM $=$ MILW*MILAR(JD,HOUR-1)*TS

ENDIF

C WASH_is the amount of plant biomass washed off during the timestep due to die-off

C from upper or lower temperature limitatoin $(\mathrm{gm} / \mathrm{m} 2)$

C if (hour.eq.11) then

C write $(* ;)$ WASHC.WASHP.WASHM

C pause

$C$ end if

END 


\section{INCLUDE 'VARI.FI'}

REAL CLADAR,POTAR,MILAR, TBIOAR,O2AR

INTEGER I,J

C The Cladophora, Potamogeton, and Milfoil biomass and the dissolved oxgyen concentration

C for each timestep for each day of the simulation are written to file output2.txt

OPEN (UNIT $=69$, FILE='output2.Exi',STATUS='OLD')

DO $33 \mathrm{I}=153,344$

DO $22 \mathrm{~J}=1,12$

WRITE (69,1 111 l) I,J,CLADAR(I,J),POTAR(I,J),MILAR(I,J),O2AR(I,J)

1111 FORMAT (',214,4F20.2)

22 CONTINUE

33 CONTINUE

CLOSE (UNIT $=69$,STATUS='KEEP')

write $(*, *)$ 'wrote to output2.txt'

END 


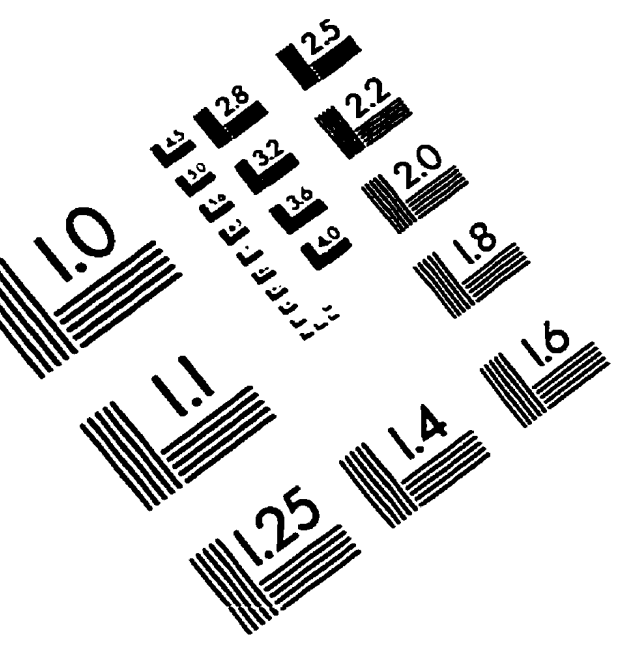

\section{IMAGE EVALUATION \\ TEST TARGET (QA-3)}
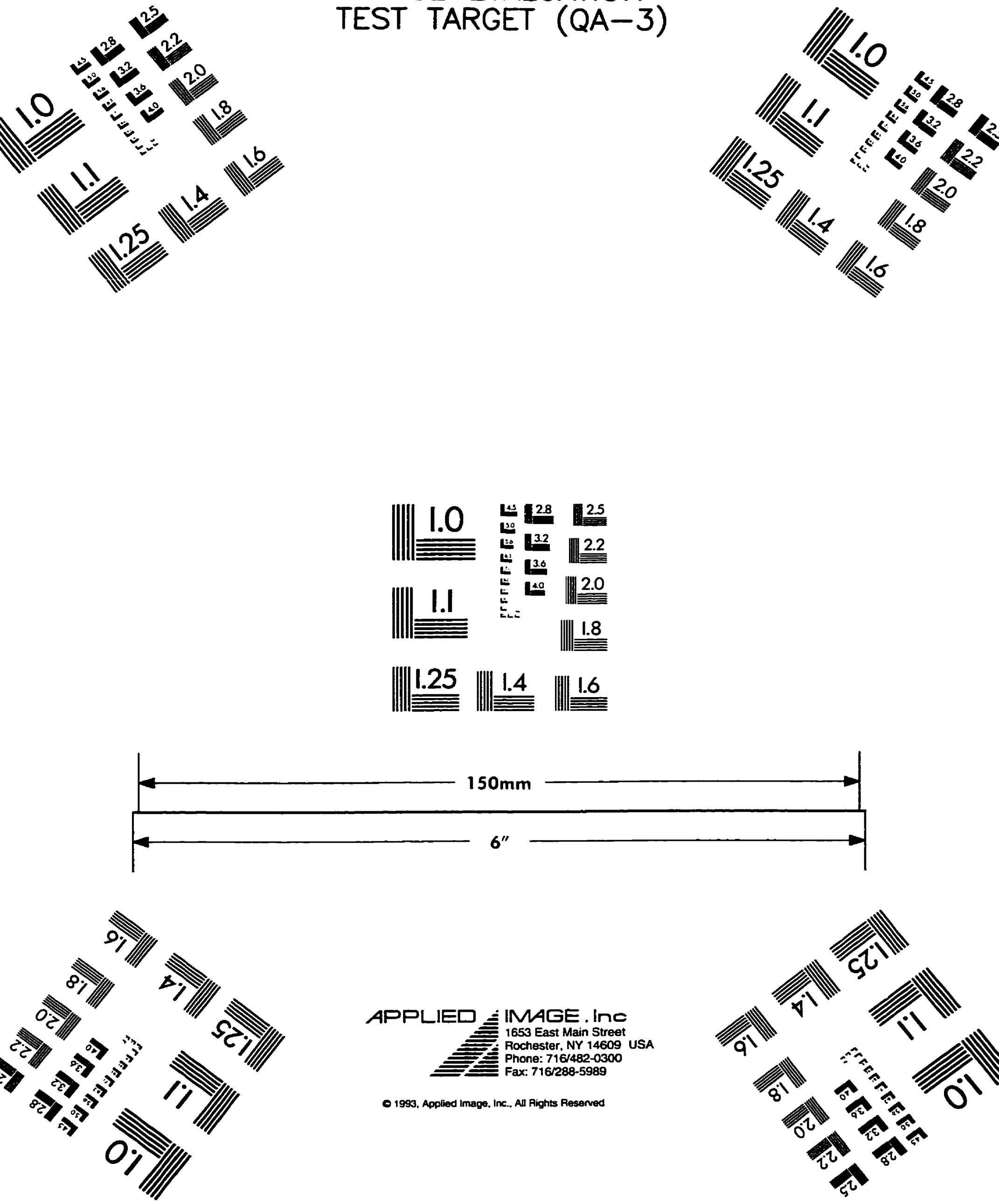